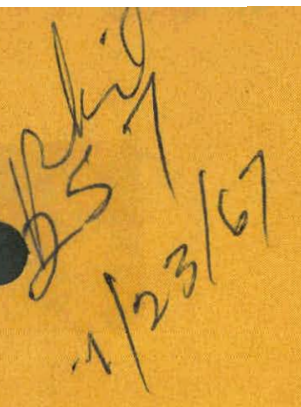

D. E. Black and B. R. Dickey

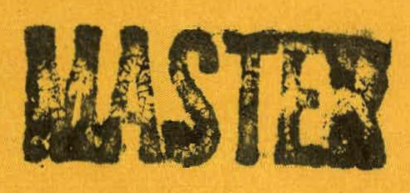

\title{
MATHEMATICAL AND EXPERIMENTAL ANALYSIS OF HEAT DISSIPATION FROM CYLINDRICAL SOURCES BURIED IN SOIL
}

D. E. Black and B. R. Dickey
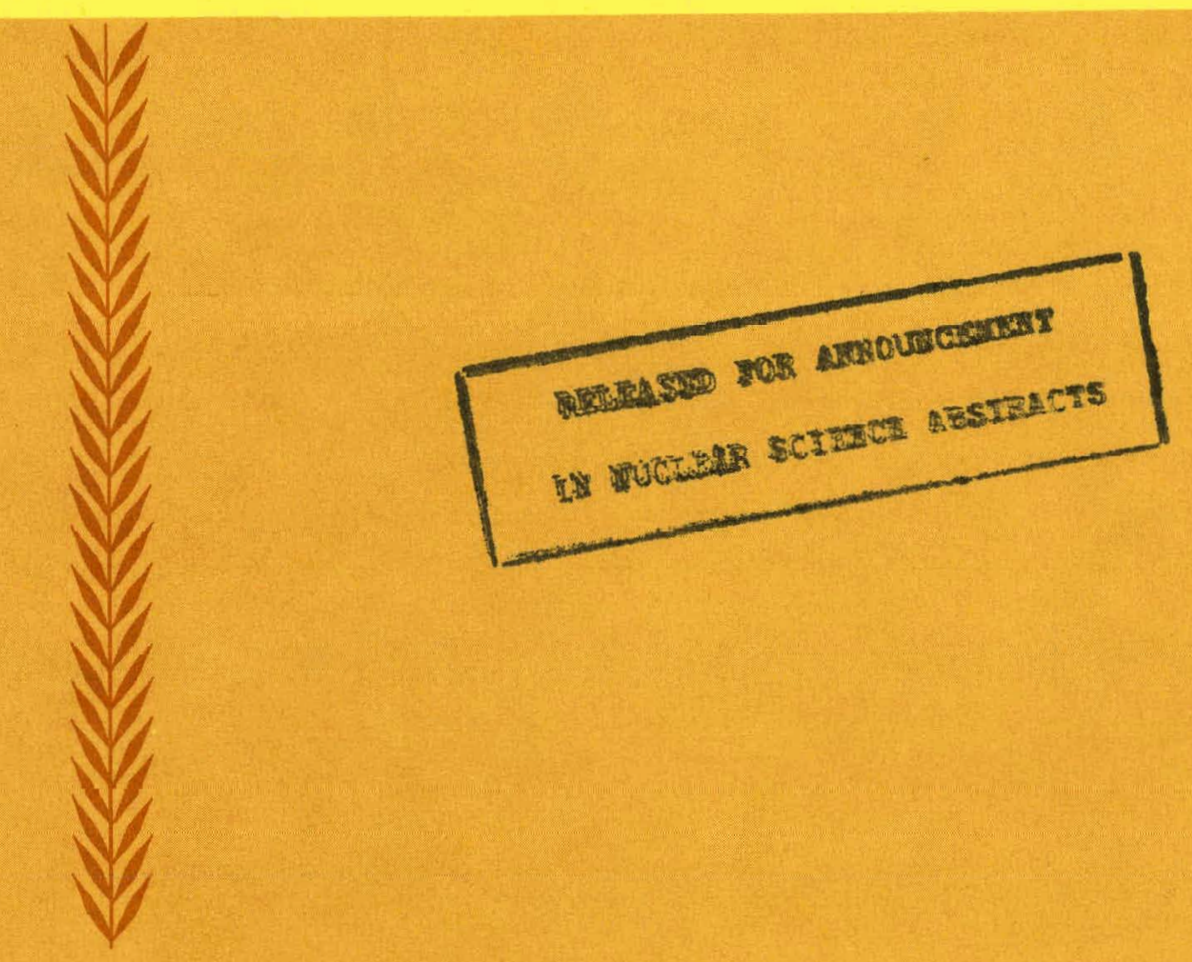

\section{IDAHO NUCLEAR CORPORATION NATIONAL REACTOR IESIING STATION IDAHO FALLS, IDAHO}

\section{U. S. ATOMIC ENERGY COMMISSION}




\section{DISCLAIMER}

This report was prepared as an account of work sponsored by an agency of the United States Government. Neither the United States Government nor any agency Thereof, nor any of their employees, makes any warranty, express or implied, or assumes any legal liability or responsibility for the accuracy, completeness, or usefulness of any information, apparatus, product, or process disclosed, or represents that its use would not infringe privately owned rights. Reference herein to any specific commercial product, process, or service by trade name, trademark, manufacturer, or otherwise does not necessarily constitute or imply its endorsement, recommendation, or favoring by the United States Government or any agency thereof. The views and opinions of authors expressed herein do not necessarily state or reflect those of the United States Government or any agency thereof. 


\section{DISCLAIMER}

Portions of this document may be illegible in electronic image products. Images are produced from the best available original document. 


\begin{abstract}
3.08
PRINTED IN USA. PRICE \$4,00. AVAILABLE FROM THE CLEARINGHOUSE FOR FEDERAL SCIENTIFIC AND TECHNICAL INFORMATION, NATIONAL BUREAU OF STANDARDS,

U. S. DEPARTMENT OF COMMERCE, SPRINGFIELD, VIRGINIA 22151
\end{abstract}

\title{
LEGAL NOTICE
}

This report was prepared as an account of Government sponsured work. Neither the United States, nor the Commission, nor any person acting on behalf of the Commission:

A. Makes any warranty or representation, express or implied, with respect to the accuracy, completeness, or usefulness of the information contained in this report, or that the use of any information, apparatus, method, or process disclosed in this report may not infringe privately owned rights; or

B. Assumes any liabilities with respect to the use of, or for damages resulting from the use of any information, apparatus, method, or process disclosed in this report.

As used in the above, "person acting on behalf of the Commission" includes any employee or contractor of the Commission, or employee of such contractor, to the extent that such employee or contractor of the Commission, or employee of such contractor prepares, disseminates, or provides access to, any information pursuant to his employment or contract with the Commission, or his employment with such contractor. 
H.C. $3.00 ; \quad 65$

IN-1032

Issued: December 1966

Waste Disposal and Processing

TID-4500

\section{LEGAL NOTICE}

This report was prepared as an account of Government sponsored work. Netther the United States, nor the Commisaion, nor any person acting on behalf of the Commission:

A. Makes any warranty or representation, expressed or implied, with respect to the accuraoy, completeness, or usefulness of the information contained in thie report, or that the use of any information, apparatus, metbod, or process disclosed in this report may not infringe privately owned rights; or

B. Assumes any liablittes with respect to the use of, or for damages resulting from the B. Assufos apparatus, method, or process disclosed in this report.

use of any infor As used in the above, "person acting on behaif of the Commission" includes any employee or contractor of the Con such employee or contractor of the commisslon, or employes of bis colosent or contract disseminates, or provides access to, any information pursuant
with the Commission, or his employment with such contractor.

MATHEMATICAL AND EXPERIMENTAL ANALYSIS OF HEAT DISSIPATION FROM CYLINDRICAL SOURCES BURIED IN SOIL

BY

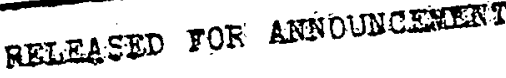

D. E. Black

B. R. Dickey

IN RUCLEE SCISECE AEETRACTS

\section{IDAHO NUCLEAR CORPORATION}

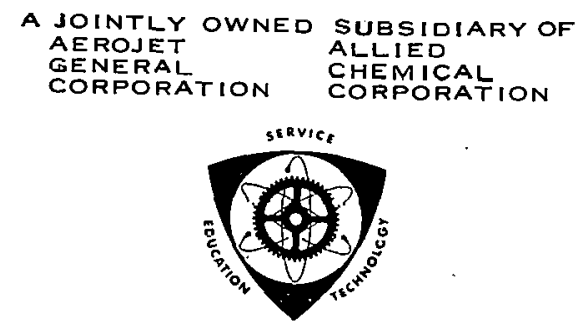

U. S. Atomic Energy Commission Research and Development Report

Issucd Under Contract AT(10-1)-123U

Idaho Operations Office 


\section{ACKNOWLEDGEMENTS}

The authors are indebted to the staff of the Computer Center for their assistance in preparing the computer programs and to Mr. B. L. Schmalz of the A EC's Idaho Operations Office for project assistanne. 


\begin{abstract}
Mathematical models are proposed for predicting the steady-state and transient temperature distributions in small- and large-diameter, cylindrical, nuclear heat sources and the surrounding soil. Computer programs are used to solve the two-dimensional, time-dependent heat-transfer equations resulting from the models. The thermal conductivity, specific heat, and moisture content were experimentally determined for soils at an experimental test site. These properties were required for calculating the temperatures in and surrounding a buried electrical heater. Agreement between calculated and measured temperatures was good, generally within a few degrees. The quantitative effects of soll and heat source thermal conductivity, time-dependent heat generation rate, heat source dimensions, and burial depth on the calculated temperature distributions in and surrounding buried heat sources are illustrated by numerical examples.
\end{abstract}


As part of a study of lower cost methods of radioactive waste management, a program was initiated to determine the effect of various factors on heat transfer from waste containers and simulated fuel elements buried directly in soll. This program included: (a) formulation of mathematical models for predicting steady (simulating long-term cooled wastes) and transient (appropriate for short-term cooled waste) temperature distributions, (b) development of computer programs for solving the resulting equations, (c) simulation of a buried fuel element using an electrical heater, (d) evaluation of the physical properties which affect heat transfer in soil, and (e) verification of the mathematical model by comparing the calculated and experimental temperatures.

Mathematical models were formulated for the steady and transient temperatures within and surrounding cylindrical heat sources buried in the soil. The significant simplifying assumptions used to limit the complexity of the mathematical models proposed in this study were as follows:

(1) The effect of soil moisture migration on the calculated temperatures was neglected and a homogeneous soil was assumed

(2) The rate of heat generation within the heat source was assumed to be independent of position

(3) Heat generated within the soil due to escaping gamma radiation was neglected

(4) The contact resistance between the source and soil was neglected

(5) An infinite thermal conductivity was assumed for the simulated fuel element.

(6) The medium in the region $r<$ the radius of the otorage vessel was assumed to have a thermal conductivity equal to that of the solidified waste.

The following procedure was used to ohtain the ralnollated temperatures, (a) based on the proposed mathematical model, the differential equation was derived describing the temperature distribution, (b) a finite Fourier sine transformation was used to eliminate one independent variable from the equations and boundary conditions, (c) an analytical solution was obtained for the steadystate temperatures, and (d) a digital computer program, based on numerical techniques, was employed for the calculation of the transient temperatures.

The models proposed in this study are satisfactory for dry soils (less than 5 volume percent moisture) such as those present at the National Reactor Testing Station. For heat transfer in moist soils, however, the models would not be as accurate. A more generalized model should be developed which would incorporate the effect of moisture migration (combined mass and heat transfer) on the calculated temperatures surrounding the heat source.

An analysis of the effect of escaping gamma radiation on the calculated temperature shows that it can be neglected for all but very small-diameter (less than a few inches) sources. The heat generated as a result of the gamma radiation 
is less than half of the total, and only a small portion escapes into the materials surrounding the container. The assumption that all of the gamma radiation is absorbed within the container results in calculated temperatures in the container which are somewhat higher than those actually existing and thus constitutes an inherent safety factor.

Although the assumptions made in this study did not lead to significant differences between the experimental and calculated temperatures, their use may result in significant errors in the calculated temperatures for other cases. Therefore, before applying the models proposed in this study, the validity of these assumptions should be established for the particular case of interest.

A small-diameter nuclear heat source of high thermal conductivity was simulated by burying a 1500-watt electrical heater in the soil. The temperature and moisture content of the soil were monitored at various depths and radial distances from the heater for two different power levels over a period of one year. The measured temperatures of the soil at radial distances greater than 30 feet from the heater were not affected by the heater. The soil temperatures at depths greater than ten feet were not appreciably affected by environmental changes such as rainfall, snowfall, or diurnal and seasonal temperature fluctuations.

The "steady-state" temperatures (simulating a long-term cooled element), calculated on the basis of the model, corresponded closely to the temperatures measured experimentally for both power levels. Maximum percent deviation between the experimental and calculated temperatures occurred within the simulated fuel element.

The effects on the calculated temperatures of (a) soil physical properties, (b) magnitude of the heat generation rate, (c) dimensions of the heat source, and (d) burial depth were illustrated by numerical examples. 


\section{CONTENTS}

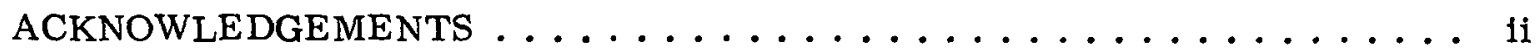

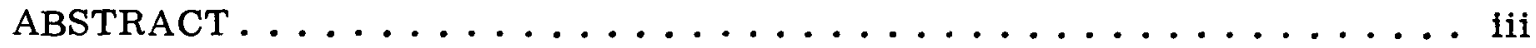

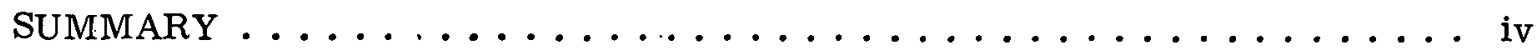

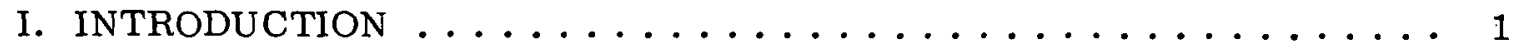

II. FORMULATION OF MATHEMATICAL MODELS . . . . . . . . . . 4

1. STEADY-STATE HEAT TRANSFER FROM A SMALL-

DIAMETER SOURCE OF HIGH THERMAL CONDUCTIVITY. . . . . . . 7

2. STEADY-STATE HEAT TR NNSFER FROM A LARGE-

DIAMETER SOURCE . ........................ 11

3. TRANSIENT HEAT TRANSFER FROM A SMALL-

DIAMETER SOURCE OF HIGH THERMAL CONDUCTIVITY. . . . . . 13

4. TRANSIENT HEAT TRANSFER FROM A LARGE-

DIAMETER SOURCE $\ldots \ldots \ldots \ldots \ldots \ldots \ldots \ldots$

III. ELECTRICAL SIMULATION OF BURIED NUCLEAR HEAT SOURCE . . . 17

IV. PHYSICAL PROPERTIES OF SOIL AT THE TEST SITE . . . . . . . 21

1. THERMAL CONDUCTIVITY.................... 21

2. SPECIFIC HEAT . . . . . . . . . . . . . . . . . . . . . .

3. DENSITY, POROSITY, SIZE DISTRIDUTION, AND

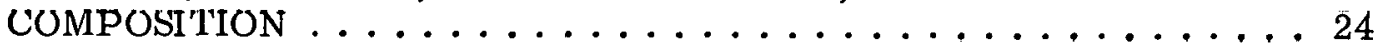

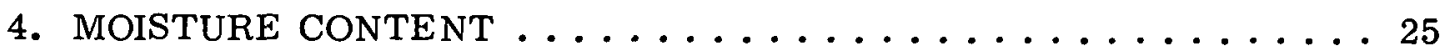

V. COMPARISON AND DISCUSSION OF EXPERIMENTAL AND

CALCULATED TEMPERATURE DiSTRIBUTIONS . . . . . . . . 26

1. STEADY-STATE TEMPERATURES IN AND SURROUNDING

A SIMULATED BURIED FUEL ELEMENT . . . . . . . . . . . . 26

2. STEADY-STATE TEMPERATURE DISTRIBUTIONS IN A

WASTE STORAGE BIN AND THE SURROUNDING SOIL . . . . . . . 32

3. TRANSIENT TEMPERATURES IN AND SURROUNDING

$\Lambda$ BURIED SIMULATED FUEL ELEMENT . . . . . . . . . . . . 34

4. TRANSIENT TEMPERATURE DISTRIBUTIONS IN A

WASTE STORAGE BIN AND THE SURROUNDING SOIL . . . . . . 35

VI. CONCLUSIONS AND RECOMMENDATIONS . . . . . . . . . . . 37 
VII. NOMENCLATURE $\ldots \ldots \ldots \ldots \ldots \ldots \ldots \ldots \ldots \ldots \ldots \ldots$

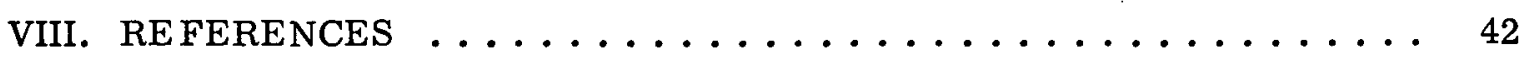

APPENDIX A -- JUSTIFICATION FOR NEGLECTING HEAT GENERATION IN THE SOIL DUE TO GAMMA RADIATION ESCAPING FROM THE HEAT SOURCE . . . . . . . . .

APPENDIX B -- DERIVATION OF THE NUMERICAL SOLUTION FOR THE TRANSIENT TEMPERATURE DISTRIBUTION SURROUNDING SMALL- AND LARGE -DIAMETER HEAT SOURCES ...................... 51

APPENDIX C -- PROPERTIES OF THE FINITE SINE TRANSFORM . . . . 63

APPENDIX D -- DFRIVATION OF SPACE-DEPENDENT DISTANCE

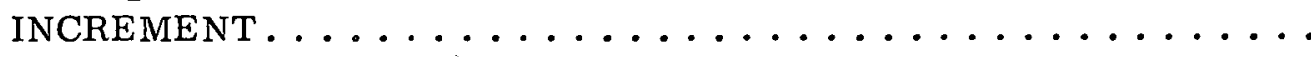

APPENDIX E -- STEADY-STATE TEMPERATURE DISTRIBUTION IN BURIED HEAT SOURCE AND THE SURROUNDING MEDIUM . . . .

APPENDIX F -- LOCATION OF BURIED ELECTRICAL HEATER

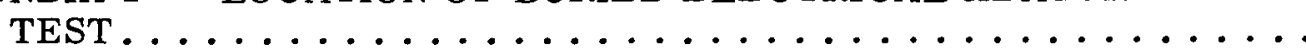

APPENDIX G -- EQUIPMENT USED FOR DETERMINATION AND

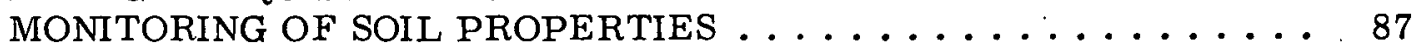

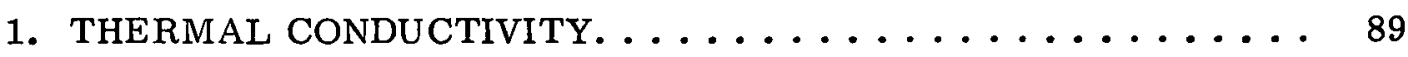

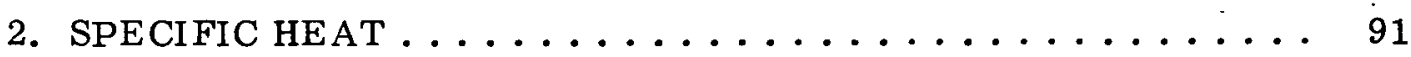

3. MOISTURE CONTENT $\ldots \ldots \ldots \ldots \ldots \ldots \ldots \ldots \ldots \ldots$

APPENDIX H -- FORTRAN NOMENCLATURE AND SOURCE

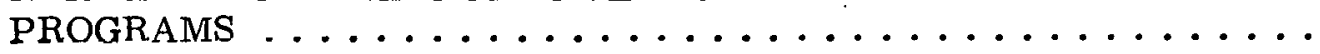

1. NOMENCLATURE FOR STEADY TEMPERATURES

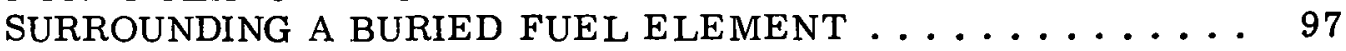

2. NOMENCLATURE FOR TEMPERATURES IN A BURIED BIN AT STFADY STATE $\ldots \ldots \ldots \ldots \ldots \ldots \ldots$

3. FORTRAN SOURCE PROGRAM -- STEADY -STATE FUEL

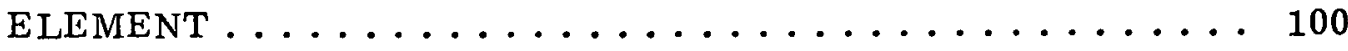

4. FORTRAN SOURCE PROGRAM -- STEADY-STATE BINS . . . .................... 103

5. NOMENCLATURE FOR TRANSIENT TEMPERATURE DISTRIBUTION SURROUNDING A BURIED FUEL ELEMENT. . . . 106

6. NOMENCLATURE FOR THE TRANSIENT TEMPERATURE DISTRIBUTION IN A CYLINDRICAL BIN AND THE SURROUNDING SOIL . . . . . . . . . . . . . . . . . 109 
7. FORTRAN SOURCE PROGRAM -- TRANSIENT TEMPERATURES IN AND SURROUNDING A BURIED FUEL ELEMENT. . . . . 110

8. FORTRAN SOURCE PROGRAM -- TRANSIENT TEMPERATURES IN AND SURROUNDING A CYLINDRICAL VESSEL CONTAINING SOLIDIFIED WASTE . . . . . . . . . . . 116

APPENDIX I - DATA INPUT FORMATS . . . . . . . . . . . . 123

1. STEADY-STATE TEMPERATURE DISTRIBUTION AROUND A BURIED FUEL ELEMENT . . . . . . . . . . . . . . 125

2. STEADY-STATE TEMPERATURE DISTRIBUTION. IN A BIN FILLED WITH SOLIDIFIED WASTE . . . . . . . . . . 126

3. TRANSIENT TEMPERATURES IN AND SURROUNDING A BURIED FUEL ELEMENT. . . . . . . . . . . . . . . 127

4. TRANSIENT TEMPERATURES IN A CYLINDRICAL BIN FILLED WITH RADIOACTIVE SOLIDIFIED WASTE . . . . . . . .

\section{FIGURES}

1. Typical waste storage factlity. ................... 4

2. Burial of simulated fuel element ................ 8

3. Convergence of calculated temperatures as a function of $\mathrm{L} \ldots \ldots$

4. Relationship between $L$ and the heat flux .............. 10

5. Relationship between $\mathrm{L}$ and the thermal conductivity of medium . . . . 10

6. Convergence of the calculated temperature as a function of the transform parameter, $n \ldots \ldots \ldots 11$

7. Upper soll layers at burled heater site . . . . . . . . . . . 17

8. Details of electrical heat source................ 18

9. Isometric sketch of buried heater site experiment . . . . . . . . 19

10. Details of thermowell and thermocouples ............. 20

11. Temperature response of ideal line heat source and probe . . . . . 20

12. Details of thermal conductivity probe . . . . . . . . . . . 22

13. Thermal conductivity of soll at test site .............. 23 
14. Measured temperatures surrounding the electrical heater for $350-$ and $950-$ watt levels . . . . . . . . . . . . . . .

15. Comparison of calculated and experimental steady -state temperatures for 350-watt simulated fuel element,

$\mathrm{k}_{\mathrm{S}}=0.4 \mathrm{Btu} / \mathrm{hr}-\mathrm{ft}-{ }^{\circ} \mathrm{F} \ldots \ldots \ldots \ldots \ldots \ldots \ldots \ldots \ldots \ldots \ldots \ldots \ldots \ldots \ldots . \ldots \ldots$

16. Comparison of calculated and experimental steady-state temperatures for 950-watt simulated fuel element,

$\mathrm{k}_{\mathrm{S}}=0.45 \mathrm{Btu} / \mathrm{hr}-\mathrm{ft}-{ }^{\circ} \mathrm{F} \ldots \ldots \ldots \ldots \ldots \ldots \ldots \ldots \ldots \ldots \ldots \ldots \ldots \ldots \ldots \ldots . \ldots \ldots$

17. Effect of heat flux on calculated steady-state temperatures

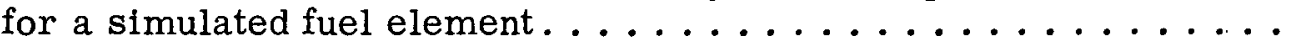

18. Effect of burial depth on calculated steady-state temperatures for a simulated fuel element. . . . . . . . . . . . . . . .

19. Effect of soil thermal conductivity on calculated steady-state temperatures for a simulated fuel element . . . . . . . . . . .

20. Effect of heat generation rate on calculated steady-state temperature distributions in and surrounding a wastestorage container ......................

21. Effect of source thermal conductivity on calculated steadystate temperature distributions in and surrounding a waste-

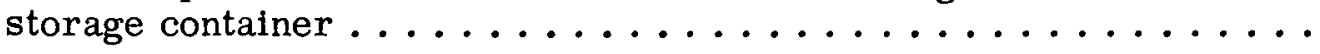

22. Effect of source radius on calculated steady-state temperature distributions in and surrounding a waste-storage container . . . . . .

23. Comparison of calculated and experimental transient temperatures for the 950-watt simulated fuel element shown in

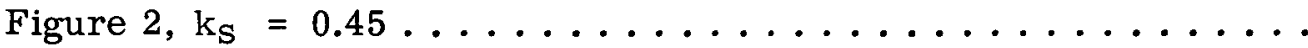

24. Calculated transient temperatures for the buried fuel element shown in Figure 2 having a specified time-dependent rate of heat generation, q" Btu/hr-ft $\ldots \ldots \ldots \ldots$

25. Calculated transient temperatures in a buried cylindrical bin filled with solidified waste ....................

26. Calculated transient temperatures in a buried cylindrical bin filled with solidified waste (theoretical MTR waste cooled 3 years $\ldots \ldots \ldots \ldots \ldots \ldots \ldots \ldots \ldots \ldots$

A-1. Relative flux distribuliun dround a point source . . . . . . . . . 48

A-2. Cumulative flux distribution around a line of sources . . . . . . . 49

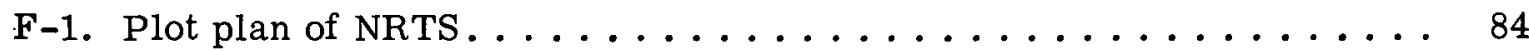

F-2. Site of buried heater test .................. 85 
G-1. Instrumentation for thermal conductivity probe . . . . . . . 89

G-2. Mean specific heat calorimeter . . . . . . . . . . . . 92

G-3. Soll moisture probe . . . . . . . . . . . . . . . 92

G-4. Neutron scaler . ........................ 92

\section{TABLES}

I. Dimensions of Typical Nuclear Waste Storage Containers. . . . . . . 5

II. Comparison of Actual and Assumed Nuclear Waste St.nrage

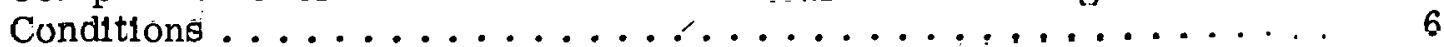

III. Mean Specific Heat of Various Soils $\left(B t u / 1 b-{ }^{\circ} \mathrm{F}\right) \ldots \ldots \ldots \ldots$

IV. Physical Properties of Soil at Test Site . . . . . . . . . . 26

V. Location of Thermocouples in "S-1" and "N-1" Thermowells ..... 28 


\section{MATHEMATICAL AND EXPERIMENTAL ANALYSIS OF HEAT DISSIPATION FROM CYLINDRICAL SOURCES BURIED IN SOIL}

\section{INTRODUCTION}

As a result of the reprocessing of spent nuclear fuels to reclaim plutonium and unfissioned uranium, more than 80 million gallons of high-level radioactive liquid waste have been accumulated to date in the United States. These wastes are currently stored in relatively complex and, therefore, expensive facilities. In addition to the liquid wastes, solid nuclear wastes are also being accumulated. These consist of products from the various waste solidification processes (such as the granular solids from the Idaho Waste Calcining Facility or WCF) and spent nuclear fuel elements which are uneconomical to process. As the nuclear power industry grows, the volume and, hence, total cost of waste management will sharply increase $[1,2,3,4]$. Thus, the search for safe and less expensive methods of waste storage must be intensified.

Currently, cooling of these wastes -- necessary because of the heat generated by the decay of radioactive fission products in the waste -- is accomplished by internal cooling coils (in the case of liquid waste) or by convective air cooling (as used at the WCF) $[5,6,7]$. The present waste-storage facilities generally consist of a central container or containers surrounded completely by an outer vault buried in the soll at varying depths. A significant reduction in the cost of future waste-storage facilities would be achieved if the internal cooling systems and the outer containment vault could be omitted. For such a simplified wastestorage facllity, all of the heat generated in the waste would be removed by conduction through the soil surrounding the single waste container. Because of fission product volatility and the limits of the container material, most nuclear wastes should not be permitted to exceed a specified maximum temperature [8]. Thus, the factors affecting the maximum temperature will strongly influence the design of future simplified storage facilities.

This study was undertaken to develop models for predicting the temperatures in the future simplified storage facilities and in the surrounding soil. The quantitative effects of the rate of heat generation, physical properties of the medium, and geometry of the storage facility on the calculated temperature distributions were also investigated. While the study of heat transfer through the soil is not a new subject, early investigators were primarily concerned with the small temperature gradients and heat fluxes associated with diurnal and seasonal temperature changes in the soil near the surface $[9,10]$. Recently, investigations involving much higher temperatures and heat transfer rates at greater depths in the soil have been undertaken, primarily due to the increased interest in the storage of high-level radioactive wastes [11, 12, 13, 14]. Most of the recent investigations have been based on simplified [a] mathematical models, each simulating only one waste-storage concept. None of these models has included all of the factors necessary to describe completely heat transfer from a buried nuclear source. In addition, no adequate experimental verification of these models has been provided. The intent of this study was to formulate

[a] Employing constant thermal conductivity, unidirectional heat flow, constant rates of heat generation, etc. 
mathematical models which could be used to adequately predict the temperature distributions within present and future solid waste-storage facilities.

The following main steps were included in this study: (a) formulation of mathematical models describing the temperature distribution in and surrounding cylindrical heat sources buried in soil, (b) derivation and solution of the heat transfer equations based on these models, (c) electrical simulation of a buried fuel element, (d) verification of the mathematical model for the buried fuel element by comparing the calculated and experimental temperatures, and (e) determination of the quantitative effect of various parameters on the calculated temperatures in and surrounding a buried cylindrical heat source. These steps are discussed briefly in the following paragraphs and in more detail in the remainder of this document.

An ideal mathematical model describing the temperature distribution in a buried nuclear heat source and the surrounding soil should contain provisions for the following:

(1) Transient heat transfer in the axial and radial direotiono (appropriate for short-term cooled wastes)

(2) Steady-state heat transfer in the axial and radial directions (simulating long-term cooled wastes)

(3) Variable thermal conductivity of the heat source and the surrounding medium (as a function of temperature)

(4) Adequate description of the boundary conditions at the axial and radial interfaces of the heat source and surrounding material

(5) The effect of soil molsture migration on the temperatures,

The models formulated in this study meet all but the last of these requifrements.

'I'he mathematical model for the temperature distribution surrounding a buried fuel element was verified by comparing the calculated temperatures with those from a buried simulated fuel element in the form of a small electric heater. Heat generated in a buried fuel element was simulated by an accurately controlled heat source located in a soil environment similar to that of an actual or anticipated storage site. Provision was also required for monitoring the temperature and moisture content in the medium surrounding the heat source.

Parameters affecting the maximum temperature within a vessel containing solidified waste strongly influence the design of the storage facility.

The following factors were believed to be pertinent:

(1) Physical properties of the waste and surrounding soil

(2) Dimensions of the heat source

(3) Magnitude of the heat generation rate

(4) Boundary conditions imposed on the model 


\title{
(5) Gamma radiation
}

\begin{abstract}
All but the last two factors were included in this study. An analysis of the effect of gamma radiation shows that it can be satisfactorily neglected. Since the soils at the National Reactor Testing Station (NRTS) are dry, any effect of moisture on the temperature should be small. The relative importance of the other factors was determined by the solution of numerical examples.
\end{abstract}




\section{FORMULATION OF MATHEMATICAL MODELS}

The factors characterizing "typical" nuclear waste-storage facilities and those assumed for the mathematical models are discussed in the following paragraphs.

The simplified storage concept as well as most of the present storage facilities for nuclear wastes can be approximately described as cylinders buried at varying depths below the surface of the soil. A schematic representation of these storage facilities is shown in Figure 1; the dotted portion indicates the cooling inlet and outlet lines used with present storage facilities.

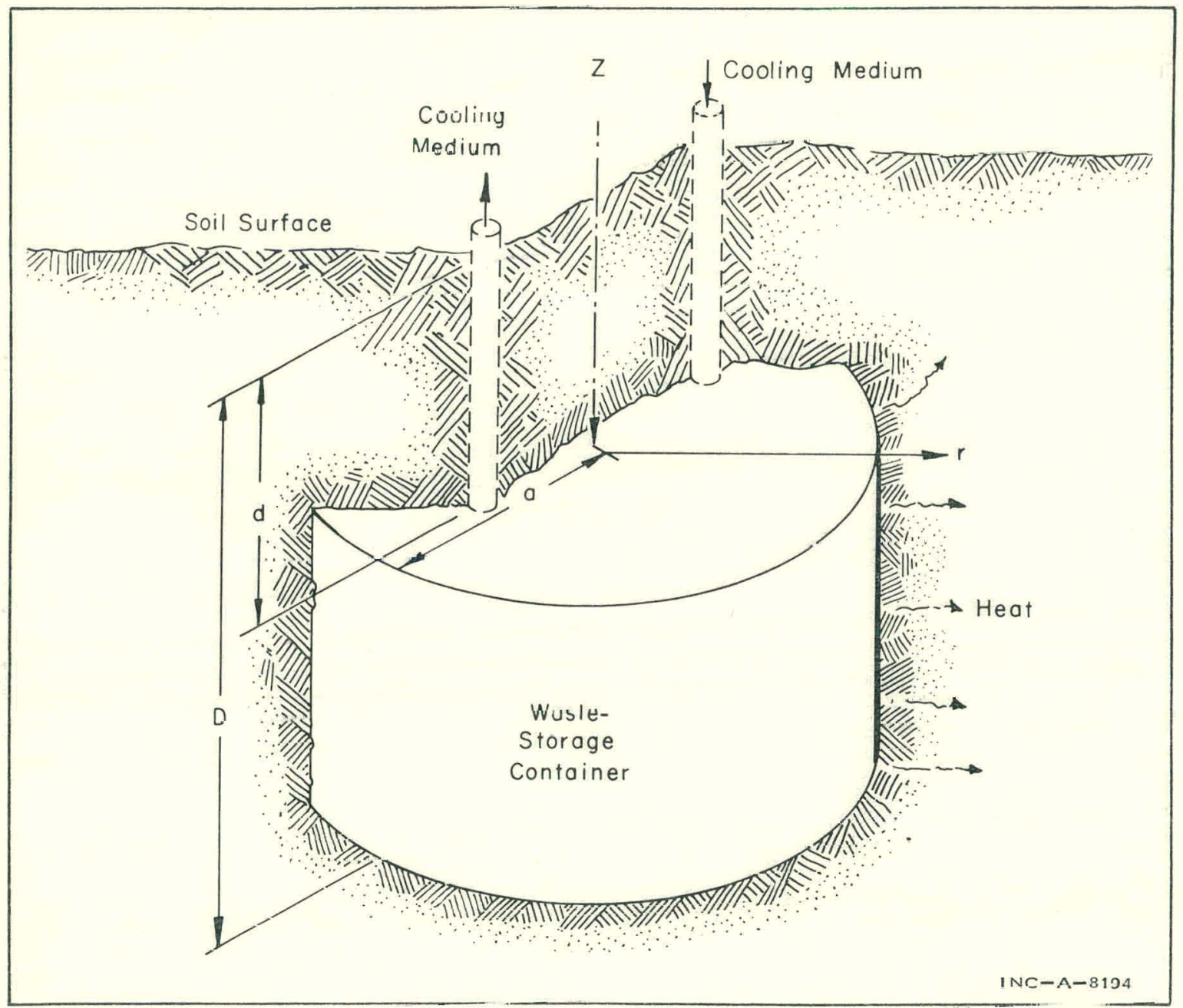

Fig. 1 Typical wasle storage facility.

Because of the low absorption (per unit thickness) of high-energy gamma radiation by most materials, a portion of the gamma radiation generated near the wall of the waste container escapes into the surrounding soil. The energy of the escaping radiation is then dissipated in these materials, increasing the effective diameter of the heat source. Thus, the dimensions of a waste-storage facility will not exactly correspond to the effective dimensions of the heat source. The error associated with assuming the diameters of the heat source and storage facility to be equal (as was done in this study) is small, and it. 
decreases as the diameter of the source increases, as shown in Appendix A. The dimensions of different storage containers vary according to the type of waste stored, as shown in Table I. The ends of the simulated fuel element were assumed

\section{TABLE I}

\section{DIMENSIONS OF TYPICAL NUCLEAR WASTE STORAGE CONTAINERS}

\begin{tabular}{|c|c|c|c|}
\hline Type of Storage Facility & $\begin{array}{c}\text { Burial Depth, d } \\
(\mathrm{ft})\end{array}$ & $\begin{array}{l}\text { Radius, a } \\
\text { (ft) }\end{array}$ & $\begin{array}{l}\text { Height, D-d } \\
(\mathrm{ft})\end{array}$ \\
\hline Single nuclear fuel element & 10 & $1 / 6$ & 4 \\
\hline $\begin{array}{l}\text { Vault cortaining solidified } \\
\text { nuclear waste }\end{array}$ & 20 & 25 & 60 \\
\hline Liquid waste storage tanks & 8 & 32 & 35 \\
\hline Simplified storage container & 10 to 20 & 2 to 20 & 20 to 60 \\
\hline
\end{tabular}

to be perfectly insulated in this study, and heat losses from the ends were neglected without affecting significantly the accuracy of the calculated temperatures. Normally, these losses are negligible for small-diameter containers, but are significant for larger diameter containers. Since there is a discontinuity in the media at the ends of large-diameter heat sources, boundary conditions should ideally be specified. However, the complexity of the mathematics is reduced if a continuous medium is assumed.

The thermal conductivity of the source and the surrounding soil significantly affects the maximum temperature in the waste and the temperature distribution in the soil surrounding the simplified storage container. While the physical properties of the soil may vary with location, only changes in the soil porosity and moisture content appreciably affect the thermal conductivities [15]. A homogeneous soil with constant physical properties (with the exception of the thermal conductivity dependence on temperature) was assumed in the mathematical model.

Moderate fluctuations in the temperature of the soil result from intermittent rain and snow and from seasonal and diurnal temperature changes in the atmosphere. These variances only affect the temperatures in the uppermost soil layers (down to a depth of approximately 5 feet) and the effects are small compared to the temperature gradients in the soil caused by the heat source; therefore, they were neglected in the model. As the burial depth of the source increases, the error associated with neglecting these changes diminishes.

A comparison of the factors characterizing the simplified and actual storage concepts with those used in the mathematical model is shown in Table II.

Complexity of the mathematical model describing the temperature distribution in and surrounding a buried nuclear heat source was reduced by use of the assumptions outlined in Table II. With only minor modifications, this model might be applied to a majority of the existing storage concepts. 
TABLE II

COMPARISON OF ACTUAL AND ASSUMED

NUCT,EAR WASTE STORAGE CONDITIONS

\begin{tabular}{|c|c|c|}
\hline Factor & $\begin{array}{l}\text { Actual Conditions for } \\
\text { Common Storage Facilities }\end{array}$ & Conditions Assumed for Model \\
\hline $\begin{array}{l}\text { Geometry and dimensions of heat } \\
\text { suurce }\end{array}$ & $\begin{array}{l}\text { Roughly cylindrical in shape and buried } \\
\text { at varying depths in soil }\end{array}$ & $\begin{array}{l}\text { Cylindrical source buried at } \\
\text { varying depths }\end{array}$ \\
\hline & $\begin{array}{l}\text { Diameter and height vary, from } 1 / 3 \text { to } 50 \\
\text { feet and } 4 \text { to } 60 \text { feet, respectively }\end{array}$ & $\begin{array}{l}\text { Variable source diameter and } \\
\text { height }\end{array}$ \\
\hline Zone of internal heat generation & $\begin{array}{l}\text { Zone of heat generation extends beyond } \\
\text { walls of storage container due to } \\
\text { gamma radiation }\end{array}$ & $\begin{array}{l}\text { All heat is generated within } \\
\text { confines of containment vault }\end{array}$ \\
\hline $\begin{array}{l}\text { Discontinuities in materials } \\
\text { within storage structure }\end{array}$ & $\begin{array}{l}\text { Internal geometry of present storage } \\
\text { structures are compley dus to cooling } \\
\text { requirements }\end{array}$ & $\begin{array}{l}\text { Neglectcd discontinuities in } \\
\text { Internel storage stiucture }\end{array}$ \\
\hline $\begin{array}{l}\text { Mhyicial jpuperties of material } \\
\text { surrounding heat source }\end{array}$ & $\begin{array}{l}\text { Properties, of coil vary, but only } \\
\text { thcrmal commoljivity and moisture } \\
\text { oontcnt } i x i t \text { slgilflcant influence } \\
\text { on the temperature distribution }\end{array}$ & $\begin{array}{l}\text { Neglected variances in all } \\
\text { propertips oxoopt temperaluit } \\
\text { dependence of thermal conduc- } \\
\text { tivity; neglected effect of } \\
\text { moistuic mlgration }\end{array}$ \\
\hline Climatic conditions & $\begin{array}{l}\text { Variance in diurnal and seasonal temp- } \\
\text { eratures and in rain and snowfall }\end{array}$ & $\begin{array}{l}\text { Neglected varianres in climatic } \\
\text { conditions }\end{array}$ \\
\hline $\begin{array}{l}\text { Heat losses from ends of heat } \\
\text { source }\end{array}$ & $\begin{array}{l}\text { Heat losses from ends of containers } \\
\text { with large length-to-diameter ratios } \\
\text { are negligible; as length-to-diameter } \\
\text { ratio decreases, heat losses from } \\
\text { ends become significant }\end{array}$ & $\begin{array}{l}\text { Heat losses from the ends were } \\
\text { neglected only in the case of } \\
\text { the small-diameter fuel } \\
\text { element }\end{array}$ \\
\hline $\begin{array}{l}\text { Container wall effects and con- } \\
\text { tact resistance }\end{array}$ & $\begin{array}{l}\text { Gamma radiation causes extra heating in } \\
\text { container walls; finite contact } \\
\text { resistance exists at source-soil } \\
\text { i.nterfase }\end{array}$ & $\begin{array}{l}\text { Neglected wall effects and con- } \\
\text { tact resistance }\end{array}$ \\
\hline
\end{tabular}

The general procenture used to oolve the equalions resulting from the models for the transient cases included the following steps:

(1) The equations and boundary conditions were transformed using a Fourier finite sine transformation

(2) The transformed equations were approximated by finite differences

(3) A computer code was used to solve the finite difference equations.

Since both long - and short-term cooled wastes were of interest in this study, equations were developed for predicting the steady-state (simulating long-term cooled waste) and transient (short-term cooled waste) temperature distributions in and surrounding large- and small-diameter containers. These equations are presented in the following sections and are derived in detail in Appendixes $B$ through E. 
1. STEADY-STATE HEAT TRANSFER FROM A SMALLDIAMETER SOURCE OF HIGH THERMAL CONDUCTIVITY

The steady-state temperature distribution in the material surrounding a cylindrical, homogeneous, constant heat source is defined by the following Fourier conduction equation in cylindrical geometry (a list of nomenclature used in all equations is given in Section VII, and the dimensions are shown in Figure 2):

$$
\frac{\partial^{2} T}{\partial r^{2}}+\frac{1}{r} \frac{\partial T}{\partial r}+\frac{\partial^{2} T}{\partial z^{2}}=0(r>a, 0<z<L) .
$$

If the diameter of the source is small compared with its length and if the effective thermal conductivity of the source is much greater than that of the surrounding material, the boundary conditions for this problem may be stated as follows:

$$
\begin{aligned}
-k_{S} \frac{\partial T}{\partial r}(a, z) & =q(a, z) \text { for } a<z<D \\
& =0 \text { elsewhere } \\
\operatorname{Lim}_{r \rightarrow \infty} T(r, z) & =0 \\
T(r, 0) & =0 \\
\operatorname{Lim}_{z \rightarrow \infty} T(r, z) & =0
\end{aligned}
$$

where $\mathrm{d}$ and $\mathrm{D}$ are the depths below the surface of the soil of the top and bottom of the heat source, respectively. Heat losses from the ends of the element and the finite thermal conductivity of the element are neglected in the mathematical model. The heat flux at the boundary, $r=a$, between the heat source and the surrounding medium is specified by Equation (1a). Equations (1b) through (1d) specify the temperature at the remaining boundaries.

The partial differential equation and boundary conditions (commonly termed a "boundary value problem") can be solved conveniently by the use of transform methods. The boundary conditions of the problem dictate the particular type of transformation which should be employed. Use of an infinite Fourier sine or cosine transformation (implying a semi-infinite medium in the " $z$ " direction) to eliminate the independent variable, " $z$ ", [16] requires the numerical evaluation of a complicated inversion integral containing modified Bessel and trigonometric, functions. Though a method has been devised by Filon [17] for evaluating integrals of this type, the calculation for even a few points within the system is extremely laborious. If the range of the independent variable, " $\mathrm{z}$ ", is limited to $0<\mathrm{z}<\mathrm{L}$, where $L$ is a finite length, evaluation of a complicated inversion integral is not required. Since the temperature is specified at the boundaries in the $\mathrm{z}$ direction, the finite Fourier sine transformation should be used. The finite length " $L$ ", is the distance at which a further increase in $L$ results in a negligible change in the calculated temperatures; the final value of $\mathrm{L}$ is normally much greater than the burial depth of the source. 


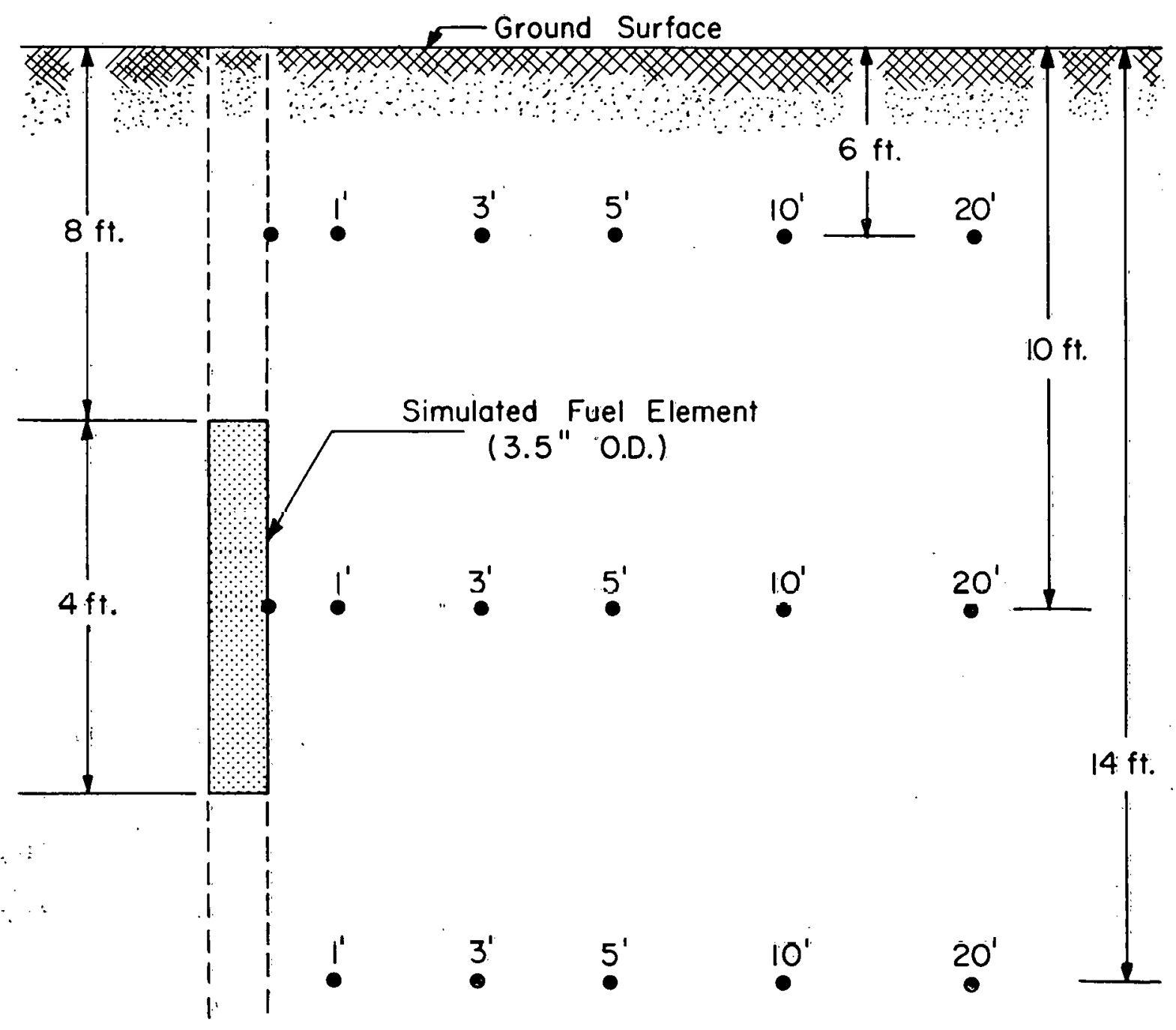

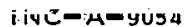

\section{- Location Of Thermocouples}

Fig. 2 Burial of simulated fuel element,

Applying the finite Fourier sine transformation to the boundary value problem described by Equations (1) through (1d) yields the following analytical solution for the steady-state temperatures in the soil surrounding a small-diameter heat source of high thermal conductivity:

$$
T(x, z)=\frac{2 q L}{\pi^{2} k_{s}} \sum_{n=1}^{\infty} \frac{K_{0}\left(\frac{r n \pi}{L}\right)\left[\cos \frac{n \pi d}{L}-\cos \frac{n \pi D}{L}\right] \sin \left(\frac{n \pi z}{L}\right)}{n^{2} K_{L}\left(\frac{a n \pi}{L}\right)}
$$


where

$\mathrm{a}=$ radius of heat source

$\mathrm{q}=\mathrm{a}$ specified constant heat flux in the range $\mathrm{d}<\mathrm{z}<\mathrm{D}$

d, D = depth below the surface of the top and bottom of the heat source, respectively

$r=$ radial distance from center of heat source

$\mathrm{k}_{\mathrm{S}}=$ thermal conductivity of the soil

$\mathrm{K}_{\mathrm{O}}(\mathrm{X}), \mathrm{K}_{1}(\mathrm{X})=$ modified Bessel functions of the second kind for argument $\mathrm{X}$

$\mathrm{L}=$ that depth at which an increase, $\Delta \mathrm{L}$, results in a negligible change in the calculated temperature

$\mathrm{n}=$ finite sine transform parameter, an integer.

The calculational procedure for solution of Equation (2) requires that the initial value of $L$ be increased incrementally until the change in the calculated temperatures is less than a specified quantity. An arbitrarily large initial value of $L$ cannot be used since the number of $\mathrm{n}$ required increases with increasing L. Convergence of the calculated temperature as a function of $L$ is shown in Figure 3. The final value of $L$ used in a calculation is primarily dependent on the strength of the heat source, the thermal conductivity of the surrounding medium, and the specified accuracy of

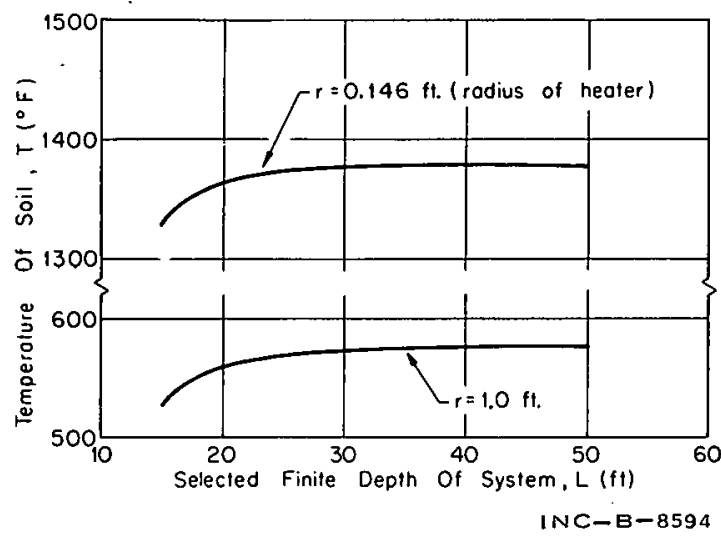

Fig. 3 Convergence of calculated temperatures as a function of $L$. the temperature. The final value of $\mathrm{L}$ as

a function of the heat flux and the thermal conductivity of the surrounding medium is shown in Figures 4 and 5 , respectively.

The convergence of the temperature as a function of the transform parameter, $n$, is analogous to that of a typical Fourier series expansion as shown in Figure 6. For the proper value of $\mathrm{L}$ (large enough that the temperature is no longer dependent on $L$ ), the temperature oscillations are small, and the required value of $\mathrm{n}(\approx 200$ for the case shown in Figure 6$)$ is dependent only on the desired accuracy of the calculated temperature. For values of $\mathrm{L}$ which are too small, the oscillations are much more pronounced.

The convergence of the calculated temperature as a function of $\mathrm{L}$ and $\mathrm{n}$ were analogous for each of the cases studied though the final values of the parameters varied with each problem. 


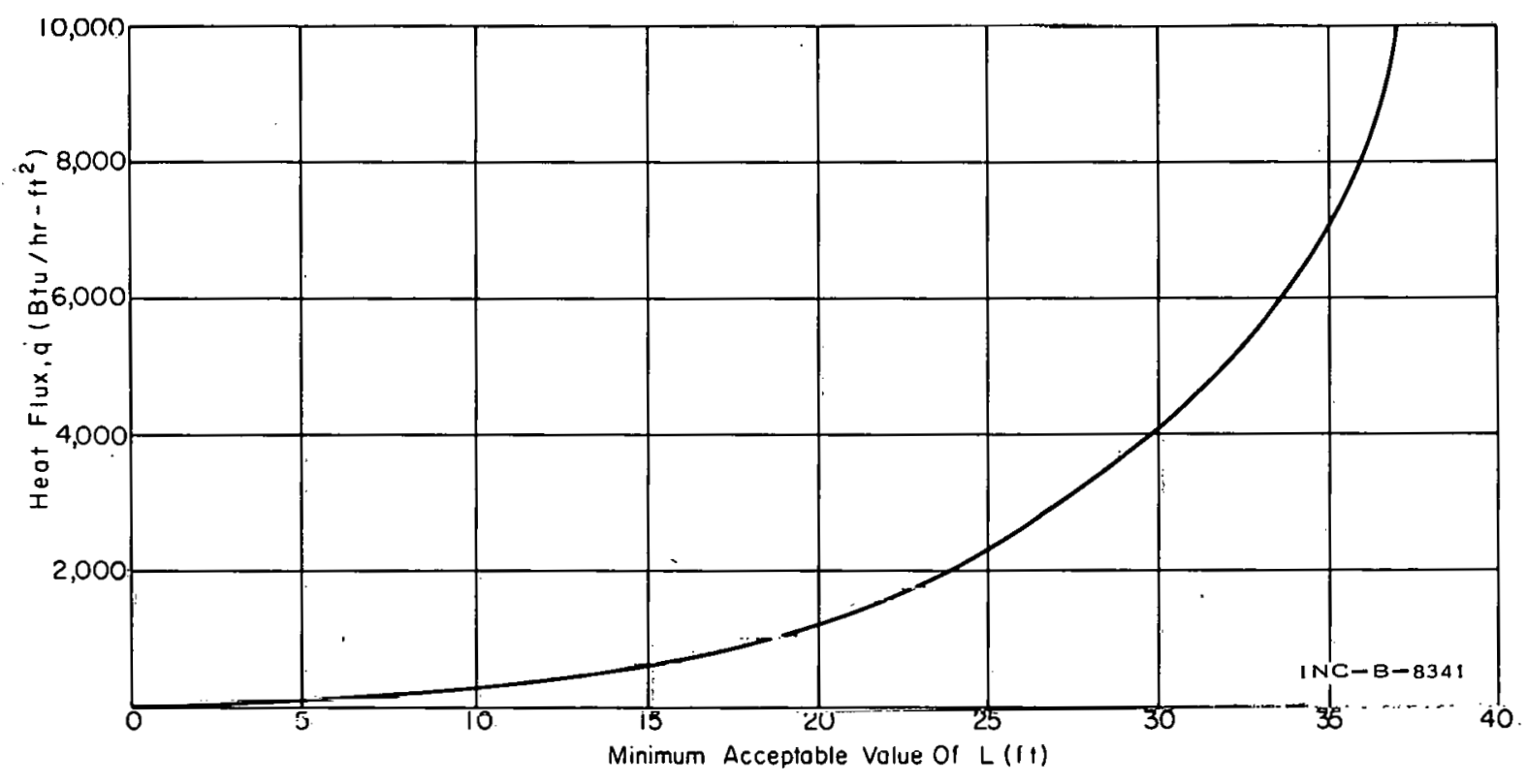

Fig. 4 . Relationship between $\mathrm{L}$ and the heat flux.

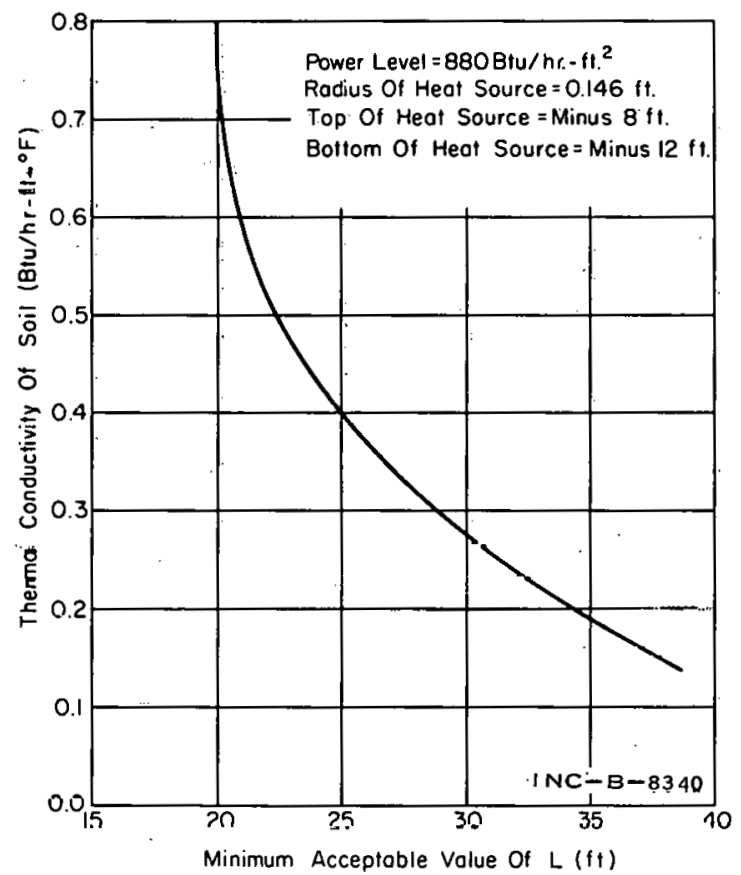

Fig. 5 Relationship between $\mathrm{L}$ and the thermal conductivity of medium. 


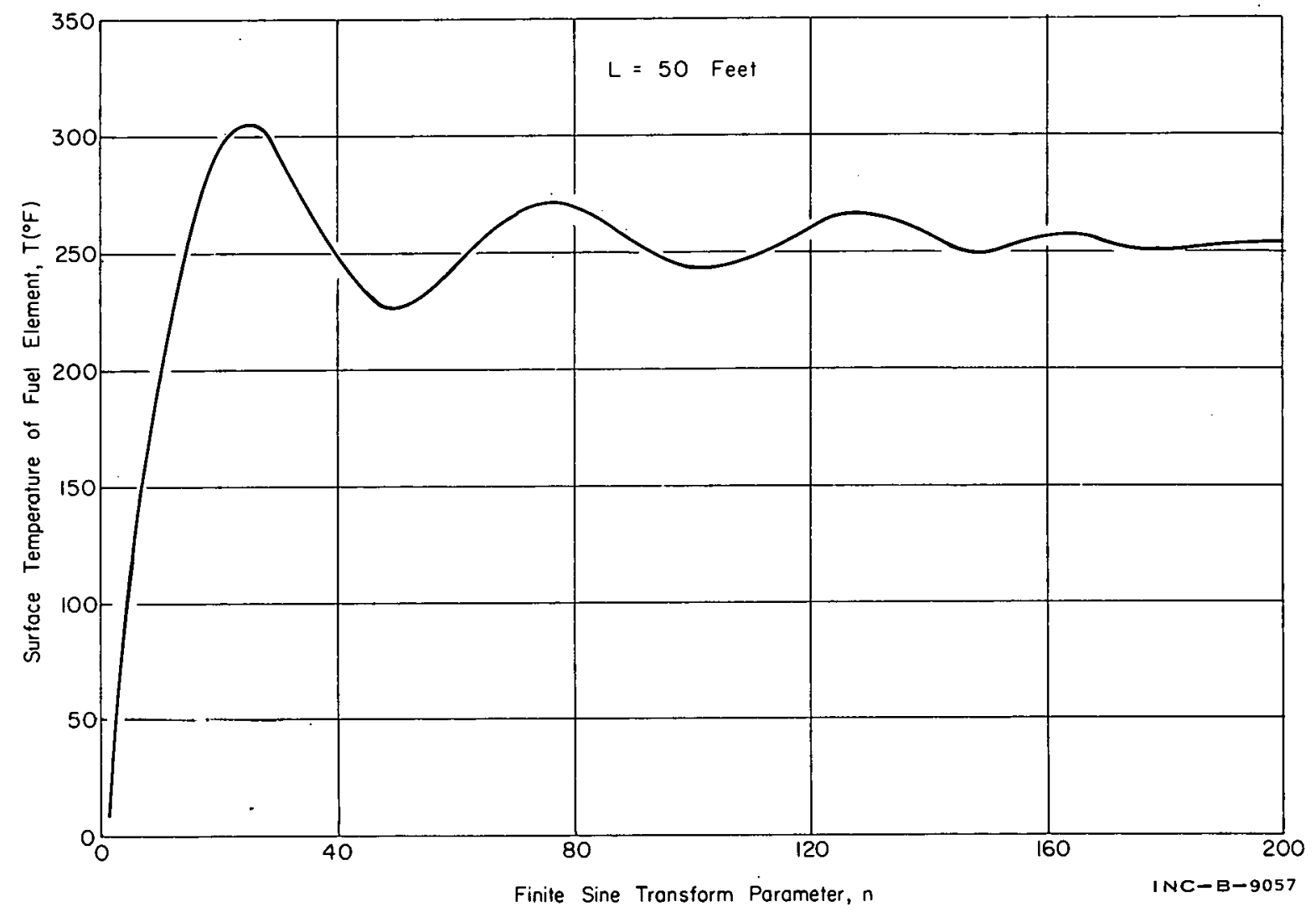

Fig. 6 Convergence of the calculated temperature as a function of the transform parameter, $n$.

\section{STE ADY-STATE HE AT}

TRANSFER FROM A LARGE-DIAMETER SOURCE

The steady-state temperature distribution in a large-diameter waste container (such as the solids storage facilities shown in Figure 1) and the surrounding environment can be obtained by methods similar to those used in the preceding example. Although the interiors of present containment structures are geometrically complex, a homogeneous heat source was assumed for the mathematical model in this study.

Since the thermal conductivities of the soil and solidified waste are often approximately equal, let the thermal conductivity in the region $0<r<R_{B}$, where $R_{B}$ is the radius of the bin, be independent of the variable, " $z$ ". This eliminates specification of the boundary conditions at the top and bottom of the bin where a discontinuity in the material normally exists. If the rate of heat generation within the homogeneous source is independent of time and if the soil surrounding the container is considered as a semi-infinite medium, the boundary value problem for the temperature distribution in the bin and the surrounding medium is given by the following equations:

$$
\frac{\partial^{2} T_{1}}{\partial r^{2}}+\frac{1}{r} \frac{\partial T_{1}}{\partial r}+\frac{\partial^{2} T_{1}}{\partial z^{2}}+\frac{q^{\prime \prime}(r, z)}{k_{c}}=0
$$


For $\left(0 \leq r \leq R_{B}, d<z<D\right)$ :

where $\mathrm{q}^{: !}=0$ for $\mathrm{z}<\mathrm{d}$, and $\mathrm{z}>\mathrm{D}$, and

$$
\begin{aligned}
& \frac{\partial^{2} \mathrm{~T}_{2}}{\partial x^{2}}+\frac{1}{r} \frac{\partial \mathrm{T}_{2}}{\partial r}+\frac{\partial^{2} \mathrm{~T}_{2}}{\partial z^{2}}=0 \\
& \text { For }\left(r \geq \mathrm{R}_{\mathrm{B}} \text { and any } \mathrm{z}^{\prime}\right)
\end{aligned}
$$

and the boundary conditions

$$
\begin{aligned}
\mathrm{T}_{1}(r, 0)=l_{2,}(r, 0) & =0 \\
\operatorname{Lim}_{\mathrm{z} \rightarrow \infty} \mathrm{T}_{1}(r, z)=\mathrm{T}_{2}(r, z) & =0 \\
\operatorname{Lim}_{r \rightarrow \infty} \mathrm{T}_{2}(r, z) & =0 \\
\mathrm{~T}_{1}\left(\mathrm{R}_{\mathrm{B}}, z\right) & =\mathrm{T}_{2}\left(\mathrm{R}_{\mathrm{B}}, z\right) \\
\mathrm{k}_{\mathrm{C}} \frac{\partial \mathrm{T}_{1}}{\partial r}\left(\mathrm{R}_{\mathrm{B}}, z\right) & =\mathrm{k}_{\mathrm{S}} \frac{\partial \mathrm{T}_{2}}{\partial r}\left(\mathrm{R}_{\mathrm{B}}, \mathrm{z}\right) \\
\mathrm{T}_{1}(0, z) & =\text { Finite. }
\end{aligned}
$$

Continuity of the temperature and the heat flux hetwcen the two rogions is yiven by.Equations (3d) and (3e). A finite temperature at $r=0$ is expressed by Equation (3f), and the remaining boundary conditions state the specific temperalure at the physical boundaries of the environment.

The solution of the boundary value problem (shown in Appendix E) can be obtained by finite sine transformation in a manner analogous to the case of a small-dianneter source of high thermal conduotivity. The boundary, L, in the $\bar{z}$ direction is a distance such that an increase, $\Delta \mathrm{L}$, will result in a negligible change in the calculated temperatures. The steady-state solution (for a constant heat generation rate) for the temperature distribution in the cunlaluer is given by the following equation:

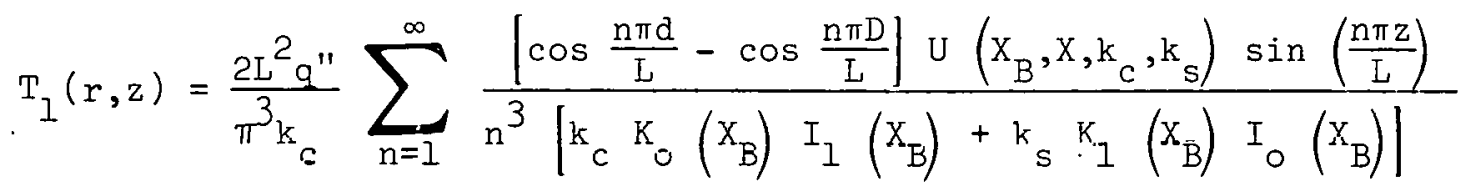


and for the soll

$T_{2}(r, z)=\frac{2 L^{2} q^{\prime \prime}}{\pi^{3}} \sum_{n=1}^{\infty} \frac{\left[\cos \frac{n \pi d}{L}-\cos \frac{n \pi D}{L}\right]\left[I_{I}\left(x_{B}\right) K_{0}(x)\right] \sin \left(\frac{n \pi z}{L}\right)}{n^{3}\left[k_{c} K_{0}\left(x_{B}\right) I_{l}\left(x_{B}\right)+k_{s} K_{l}\left(X_{B}\right) I_{0}\left(X_{B}\right)\right]}$

where

$$
\begin{aligned}
\mathrm{q}^{\prime \prime}= & \text { the heat generation rate, } \mathrm{Btu} / \mathrm{hr}-\mathrm{ft}^{3} \\
\mathrm{k}_{\mathrm{c}}, \mathrm{k}_{\mathrm{S}}= & \begin{array}{l}
\text { thermal conductivities of solidified waste and soil, } \\
\text { respectively, } \mathrm{Btu} / \mathrm{hr}-\mathrm{ft}-{ }^{\circ} \mathrm{F}
\end{array} \\
\mathrm{I}_{\mathrm{o}}(\mathrm{X}), \mathrm{I}_{1}(\mathrm{X})= & \begin{array}{l}
\text { modified Bessel functions of the first kind of the zero } \\
\text { and first order, respectively }
\end{array} \\
\mathrm{K}_{\mathrm{o}}(\mathrm{X}), \mathrm{K}_{1}(\mathrm{X})= & \begin{array}{l}
\text { modified Bessel functions of the second kind of the zerc } \\
\text { and first order, respectively }
\end{array} \\
\mathrm{U}\left(\mathrm{X}_{\mathrm{B}}, \mathrm{X}, \mathrm{k}_{\mathrm{c}}, \mathrm{k}_{\mathrm{S}}\right)= & \mathrm{k}_{\mathrm{c}} \mathrm{K}_{\mathrm{o}}\left(\mathrm{X}_{\mathrm{B}}\right) \mathrm{I}_{1}\left(\mathrm{X}_{\mathrm{B}}\right)+\mathrm{k}_{\mathrm{s}} \mathrm{K}_{1}\left(\mathrm{X}_{\mathrm{B}}\right)\left[\mathrm{I}_{\mathrm{o}}\left(\mathrm{X}_{\mathrm{B}}\right)-\mathrm{I}_{\mathrm{o}}(\mathrm{X})\right] \\
\mathrm{X}= & \frac{\mathrm{rn \pi}}{\mathrm{L}} .
\end{aligned}
$$

3. TRANSIENT HEAT TRANSFER FROM A SMALLDIAMETER SOURCE OF HIGH THERMAL CONDUCTIVITY

Since the heat generation rate is highly time dependent for short-cooled wastes in large- and small-diameter containers, an accurate calculation of the temperature distribution requires the solution of the more complex transient problem. Application of a Fourier sine or cosine transform (depending on the hnundary conditions) to the indejendenl variable, "z", yields a new boundary value problem with the number of independent variables reduced by one. The Laplace transformation could be applied with respect to time, "t", and the original partial differential equation reduced to an ordinary differential equation in the radial variable, $r$. Solution of the ordinary differential equation in terms of the transform parameters can then be readily obtained. The inversion of the complicated Laplace transform to the original variables, however, requires contour integration in the complex plane followed by :numericali evaluation of an integral containing trigonometric functions and modified Bessel functions. Because of these complexities and the tempcrature dependency of thermal conductivity, a numerical solution of the boundary value problem is justified.

The boundary value problem for transient temperature distributions surrounding a buried, small-diameter source of high thermal conductivity is stated by Equations (5) through (5e).

$$
\frac{\partial^{2} \mathrm{~T}}{\partial \mathrm{r}^{2}}+\frac{1}{r} \frac{\partial \mathrm{T}}{\partial \mathrm{r}}+\frac{\partial^{2} \mathrm{~T}}{\partial \mathrm{z}^{2}}=\frac{1}{\alpha_{2}} \frac{\partial \mathrm{T}}{\partial t} \quad(\mathrm{r} . \geq \mathrm{a})
$$




$$
\begin{aligned}
T\left(r, z, 0^{+}\right) & =T_{s} \\
-k_{s} \frac{\partial T(a, z, t)}{\partial r} & =: q(a, z, t) \quad(d<z<D) \\
& =0 \text { elsewhere } \\
\operatorname{Lim}_{r \rightarrow \infty} T(r, z, t) & =T_{s} \\
\operatorname{Lim}_{z \rightarrow \infty} T(r, z ; t) & =T_{s} . \\
T(r, o, t) & =T_{E}
\end{aligned}
$$

Equation (5a)'specifies' the initial temperature, and Equation (5b) specifies the time-dependent heat flux. Application of the finite Fourier sine transform to. the boundary vàlue prubleim, fülowcd by a finite differense approximation of the new problem results in the following system of equations which must be solved at each time step for each value of the transform parameter, $n$ :

$$
\begin{aligned}
-\phi_{1} \bar{u}_{1, t+\Delta t}+2 \bar{u}_{2, t+\Delta t} & =-\beta_{I} \bar{u}_{1, t}-Q(n) \\
\theta_{m} \bar{u}_{m-1, t+\Delta t}-\phi_{m} \bar{u}_{m, t+\Delta t}+\sigma_{m} \bar{u}_{m+1, t+\Delta t} & =-\beta_{m} \bar{u}_{m, t} \\
\theta_{M-1} \bar{u}_{M-2, t+\Delta t}-\phi_{M-1} \bar{u}_{M-1, t+\Delta t} & =-\beta_{M-1} \bar{u}_{M-1, t}
\end{aligned}
$$

where

$$
\begin{aligned}
& \mathrm{M}=\text { outermost nodal point in the radial direction } \\
& \mathrm{m}=2,3, \ldots \mathrm{M}-2
\end{aligned}
$$$$
\bar{u}_{\mathrm{m}, t+\Delta t}=\text { transformed temperature at point } m \text { at time } t+\Delta t
$$$$
{ }^{\theta} \mathrm{m}, \phi_{\mathrm{m}}, \sigma_{\mathrm{m}}, \beta_{\mathrm{m}}=\text { known scaler quantities defined in Appendix } \mathrm{B} \text {. }
$$

The quantities, $\bar{u}_{m}, t$, are known at time, $t=0$, and can be calculatcd at subsequent times. The scaler quantities, $\theta_{\mathrm{m}}$ and $\sigma_{\mathrm{m}}$, are functions of the radial distance increment, $\Delta \mathrm{r}$. The quantities, $\beta_{\mathrm{m}}$ and $\phi_{\mathrm{m}}$, arc functions of the thermal properties of the system, the time increment, the radial distance, $r$, and the transform parameter, $n$. If the thermal properties of the medium are constant, the matrix of coefficients in Equation (6) has a unique inverse, dependent only on $n$ and the timc inorement, $\Delta t$. Temperature-dependent the rmal properties necessitate the calculation of a new inverse matrix after each time increment. 'I'he solution of the above system of finite, difference equations can best be obtained by the method of Thomas [18], as outlined in Appendix B. Inversion to the original independent variables is obtained by application of the inversion formula for the finite sine transfuim. Thus, for caoh point at which the transient temperature is desired, the following formula must be applied to the transformed temperature at the end of each time step:

$$
T(r, z, t)=\frac{2}{\pi} \sum_{n=1}^{\infty} \bar{u}(r, n, t) \sin \left(\frac{n \pi z}{L}\right)
$$


where

$\bar{u}(r, n, t)=$ the transformed temperature at the point, $r$, at time, $t$.

\section{TRANSIENT HEAT TRANSFER FROM A LARGE-DIAMETER SOURCE}

The boundary value problem for the transient temperature distribution in a large-diameter source and the surrounding medium is described by the following equations:

$$
\begin{aligned}
& \frac{\partial^{2} \mathrm{~T}_{1}}{\partial \mathrm{r}^{2}}+\frac{1}{r} \frac{\partial \mathrm{T}_{1}}{\partial r}+\frac{\partial^{2} \mathrm{~T}_{1}}{\partial \mathrm{z}^{2}}+\frac{\mathrm{q}^{\prime \prime}(r, z, t)}{\mathrm{k}_{\mathrm{C}}}=\frac{1}{\alpha_{1}} \cdot \frac{\partial \mathrm{T}_{1}}{\partial t} \\
& \quad \text { For }\left(0 \leq r \leq \mathrm{R}_{B}, d<z<D\right)
\end{aligned}
$$

where $q^{\prime \prime}=0$ for $z<d$ and $z>D$, and

$$
\begin{aligned}
& \frac{\partial^{2} \mathrm{~T}_{2}}{\partial \mathrm{r}^{2}}+\frac{1}{\mathrm{r}} \frac{\partial \mathrm{T}_{2}}{\partial r}+\frac{\partial^{2} \mathrm{~T}_{2}}{\partial \mathrm{z}^{2}}=\frac{1}{\alpha_{2}} \frac{\partial \mathrm{T}_{2}}{\partial t} \\
& \text { For }\left(r \geq \mathrm{R}_{\mathrm{B}} \text { and any } z\right)
\end{aligned}
$$

and the boundary conditions

$$
\begin{aligned}
& \mathrm{T}_{1}\left(r, z, \circ^{+}\right)=\mathrm{T}_{2}\left(\mathrm{r}, \mathrm{z}, \mathrm{\circ}^{+}\right)=0 \\
& T_{1}(r, o, t)=T_{2}(r, o, t)=0 \\
& \operatorname{Lim}_{z \rightarrow \infty} T_{1}(r, z, t)=T_{2}(r, z, t)=0 \\
& \operatorname{Lim}_{r \rightarrow \infty} T_{2}(r, z, t)=0 \\
& T_{1}\left(R_{B}, z, t\right)=T_{2}\left(R_{B}, z, t\right) \\
& k_{c} \frac{\partial T_{1}}{\partial r}\left(R_{B}, z, t\right)=k_{s} \frac{\partial T_{2}}{\partial r}\left(\dot{R}_{B}, z, t\right) \\
& \mathrm{T}_{1}(0, z, t)=\text { Finite }
\end{aligned}
$$

This boundary value problem was solved by a method analogous to that used for a small-diameter time-dependent heat source and yielded the following system of equations which must be solved at each time step for a given $\mathrm{n}$ :

$$
\begin{aligned}
-\phi_{1} \bar{u}_{1, t}+4 \bar{u}_{2, t} & =-\beta_{1} \bar{u}_{1, t-\Delta t-Q_{l}(n)} \\
\theta_{m} \bar{u}_{m=1, t}-\phi_{m} \bar{u}_{m, t}+\sigma_{m} \bar{u}_{m+1, t} & =-\beta_{m} \bar{u}_{m, t-\Delta t}-Q_{m}(n) \\
(\text { for } m & =2,3, \ldots M l-2)
\end{aligned}
$$




$$
\begin{aligned}
& \theta_{M I-1} \bar{u}_{M 1-2, t}-\bar{\phi}_{M 1-1} \bar{u}_{M l-1, t}+\bar{\sigma}_{M l-1} \bar{u}_{M l+1, t}=-\beta_{M 1-1} \bar{u}_{M l-1, t-\Delta l}-Q_{M l-1}(n) \\
& \bar{\theta}_{\mathrm{Ml}+1} \overline{\mathrm{u}}_{\mathrm{Ml}-1, \mathrm{t}}-\bar{\phi}_{\mathrm{Ml}+1} \overline{\mathrm{u}}_{\mathrm{Ml}+1, \mathrm{t}}+\sigma_{\mathrm{Ml}+1} \overline{\mathrm{u}}_{\mathrm{Ml}+2, \mathrm{t}}=-\beta_{\mathrm{Ml}+1} \overline{\mathrm{u}}_{\mathrm{Ml}+1, t-\Delta \mathrm{t}} \\
& \theta_{m} \bar{u}_{m-1, t}-\phi_{m} \bar{u}_{m, t}+\sigma_{m} \bar{u}_{m+1, t^{\prime}}=-\beta_{m} \bar{u}_{m, t-\Delta t} \\
& \text { ( for } m=M l+2, M l+3, \ldots M-2 \text { ) } \\
& \theta_{M-1} \bar{u}_{M-2, t}-\phi_{M-1} \bar{u}_{M-1, t}=-\beta_{M-1} \bar{u}_{M-1, t-\Delta t}
\end{aligned}
$$

where

$$
\begin{aligned}
& \text { M1 = outermost nodal point in region } 0<r<R_{B} \\
& \mathbf{M}=\text { outermost nodal point in the radial direction } \\
& { }^{\overline{0}_{\mathrm{M} 1}}-{ }_{\mathrm{M} 1} \mathrm{c}^{2} /\left(1-\mathrm{c}^{2}\right) \\
& \bar{\phi}_{M 1-1}=\text { the quantity } \phi_{M 1-1}-\left(\frac{\sigma_{M 1-1}{ }^{c k}}{c k_{C}+k_{S}}\right) \\
& \text { c }=\text { mesh size multiplier (a constant) } \\
& \bar{\sigma}_{\mathrm{M} 1-1}=\text { the quantity } \frac{\sigma_{\mathrm{M} 1-1} \mathrm{k}_{\mathrm{S}}}{\mathrm{ck_{ \textrm {C } }}+\mathrm{k}_{\mathrm{S}}} \\
& { }^{\bar{\theta}}{ }_{\mathrm{M} 1+1}=\text { the quantity } \frac{{ }^{\theta} \mathrm{M} 1+1{ }^{\mathrm{ck}} \mathrm{c}}{\mathrm{ck}_{\mathrm{c}}+\mathrm{k}_{\mathrm{S}}} \\
& \bar{\psi}_{M 1+1}=\text { the quant1ty } \phi_{M 1+1}-\left(\frac{{ }_{M 1}{ }^{\circ}+1{ }^{k}}{c k_{c}+k_{S}}\right) \\
& \phi_{1}=\text { the quantity }\left[4.0+\beta_{1}+\left(\frac{n \pi: \wedge r_{1}}{L}\right)\right. \\
& Q_{m}(n)=\frac{q^{\prime \prime}}{k_{c} n}\left[\cos (n \pi d / L)-\cos \left(\frac{n m \cdot}{T_{1}}\right)\right] \cdot\left[\frac{e^{2 m-2}+c^{2 m-3}}{2}\right]\left[\Delta r_{1}\right]^{2} \\
& \beta_{\mathrm{m}}=\left[\frac{c^{2 m-2}+c^{2 m-3}}{2 \alpha \Delta t}\right]\left[\Delta \mathrm{r}_{1}\right]^{2}
\end{aligned}
$$

The complex expressions resulting from the various boundary value problems. were solved using a digital computer. The computer codes (generated for an IBM -7040) require the following input data: (a) heat generation rate within the source, (b) dimensions of the source, (c) physical properties of the soil and source, (d) specification of grid distances (for transient problems only), (e) specification of the points in the media at which the temperature is desired, and (f) specification of time and inversion frequencies (for printout).

The electrical simulation experiment used to determine the accuracy of the calculated transient and steady-state temperatures for the small-diameter source is described in the following section. 


\section{ELECTRICAL SIMULATION OF BURIED NUCLEAR HEAT SOURCE}

The test site for electrically simulating a buried nuclear fuel element was located at the National Reactor Testing Station (NRTS) approximately 45 miles west of Idaho Falls, Idaho. A more detailed description of the location is given in Appendix $\mathrm{F}$.

The upper surface layer (varying in thickness from several inches to more than 100 feet) at the NRTS consists of layers of gravel, sand, and silt overlying an extensive basaltic base $[19,20]$. This layer is approximately 60 feet thick at the test site, and it is comprised of the materials shown in Figure 7. The surface of the site is semiarid (rainfall of approximately 7.5 inches per year [21]) with several small surface inflow drainages disappearing into a number of sinks north of the site. Thus, the upper layer of soil is generally quite dry. At depths of 200 to 800 feet, a general subterranean movement of water in a southeasterly direction occurs through aquifers in the basalt $[22,23]$. Rates of natural moisture migration are negligible, however, at depths of interest in this study[24].

A schematic diagram of the buried heater experiment is shown in Figure 8. A buried nuclear heat source was simulated by burying a 1500-watt electrical heater rod (centered at a depth of ten feet) in the soil. The effective heat generation diameter of the rod was increased from $1 / 2$ to approximately 3 inches by surrounding the heated length of the rod with carbon steel shot. Details of the buried electrical heat source are shown in Figure 8.

While carbon steel has a thermal conductivity lower than many of the materials currently used in nuclear fuel elements, the effective conductivity of the shot approaches that of a fuel element due to the cooling channels present in most elements. Convective heat losses through the interior of the pipe to the surface of the soil were eliminated by filling the void in the pipe above the heater with soil. Axial heat losses through the pipe to the surface were minimized by using thin-wall pipe.

Temperatured of the soil surrounding the electrical heater were monitored at various radial distances along a northsouth line through the heater as shown in Figure 9. Standard type "CA" thermocouples were located 6,10 , and 14 feet

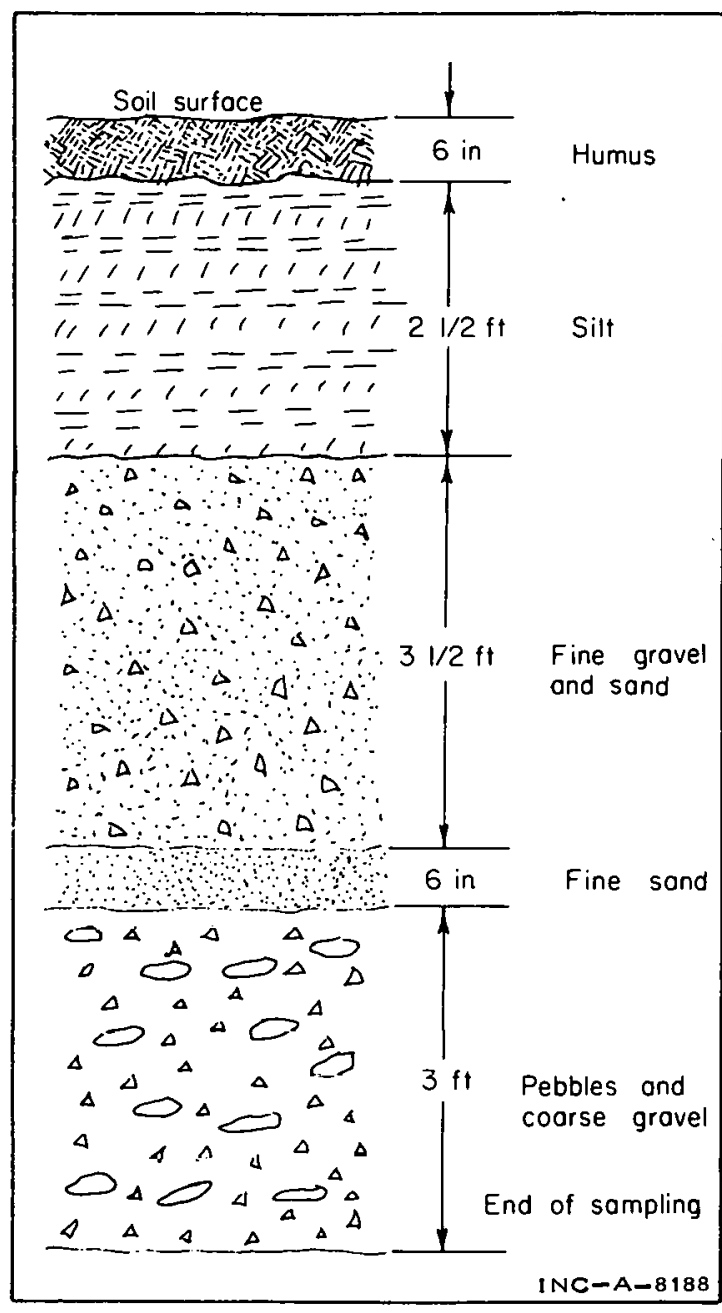

Fig. 7 Upper soil layers at buried heater site. below the surface of the soil in each of the thermowells. Details of the thermowells and thermocouples are shown in Figure 10. The hollow cores of the 


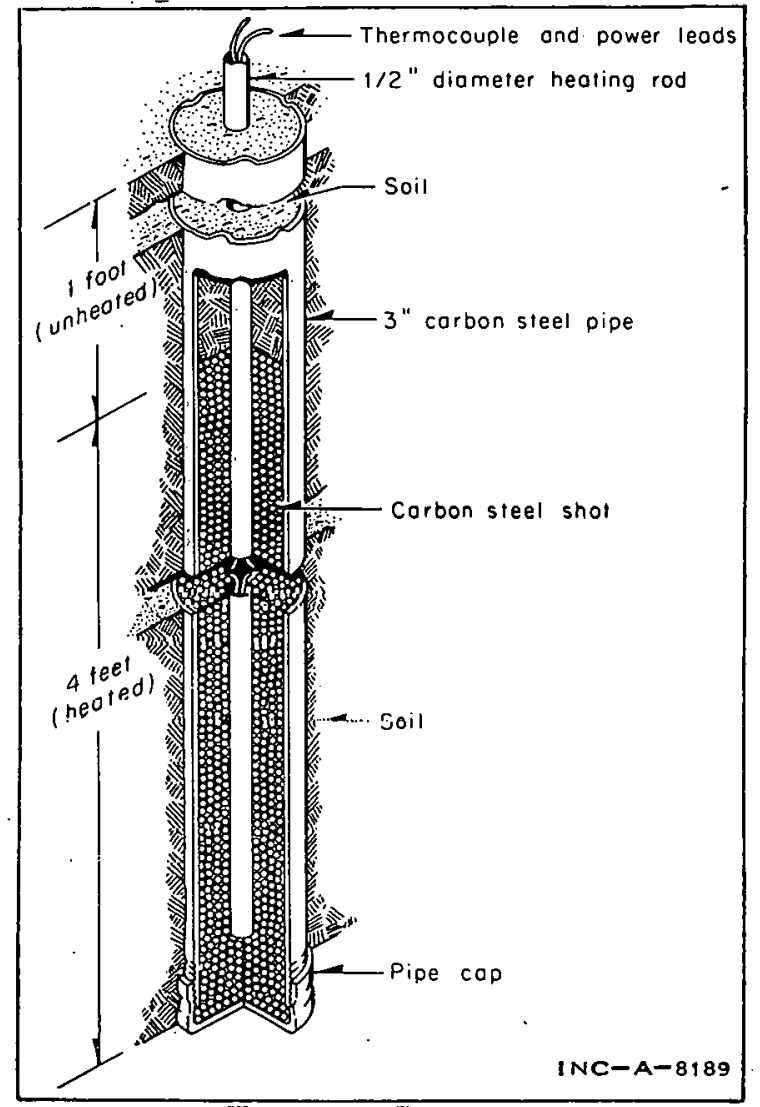

Fig: 8 Details of electrical heat source. thermowells were also filled with soil to prevent convective heat losses through the pipe interior to the surface of the soil. The thermowells were aligned above the surface in a vertical position and then driven into the soil with an airhammer. Extra-heavy-wall pipe was used to prevent bending of the thermowells as they were driven into the soil. The extra-heavy-wall pipe used for the thermowells did not significantly decrease the accuracy of the thermocouples [25]. Leads from the thermocouples terminated at a junction board inside a small shed located at the test site. Instriumentation for conlrulling llie power supply to the electric heater and a circuit breaker for preventing heater burnout were also located in the shed.

Core holes for monitoring the moisture content of the soil were located 15,25 , and 35 feet from the buried electrical heater (see Figure 9). As a contingency, a spare core hole was provided for installation of a new electrical heater. 


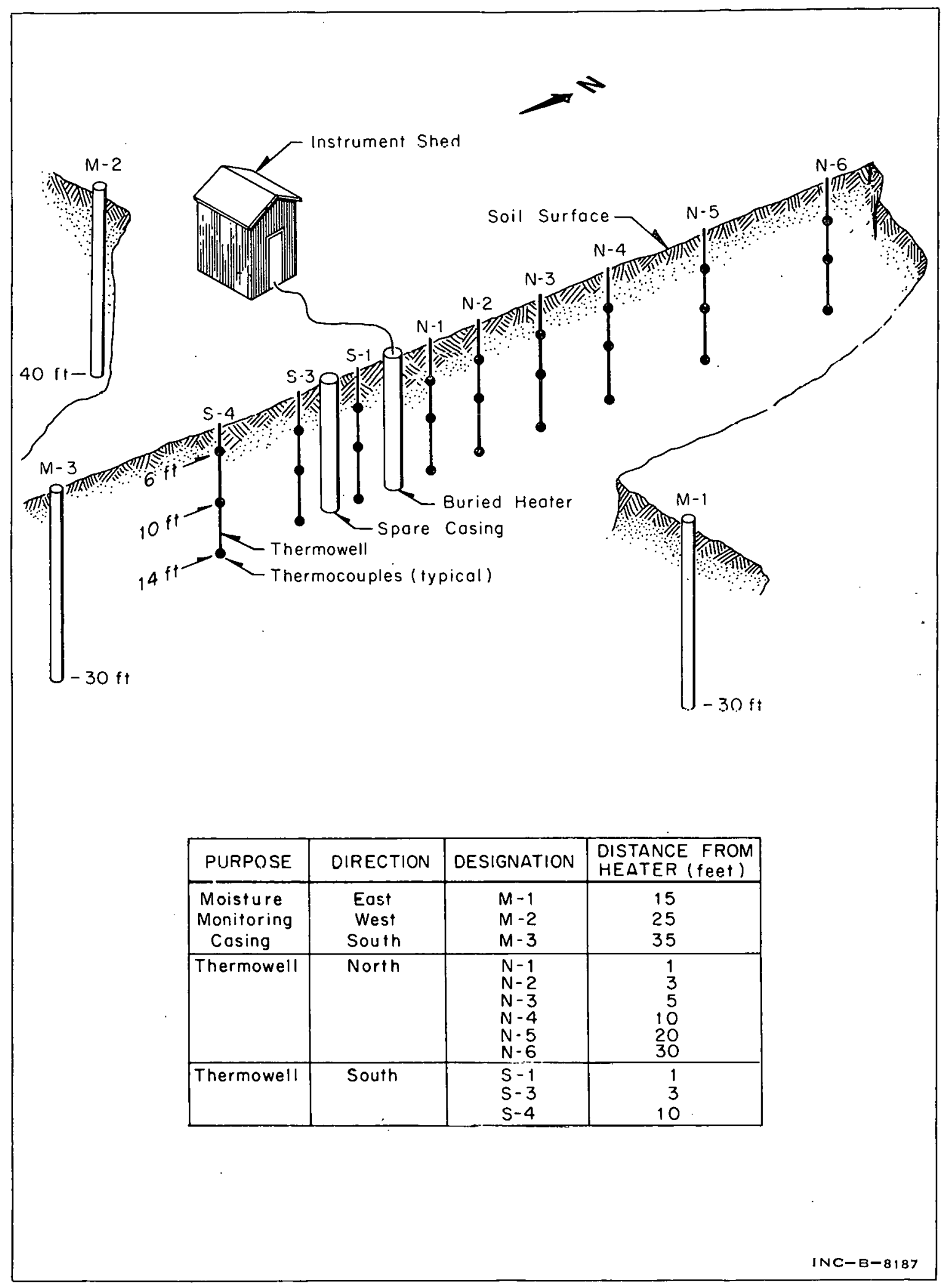

Fig. 9 Isometric sketch of buried heater site experiment. 


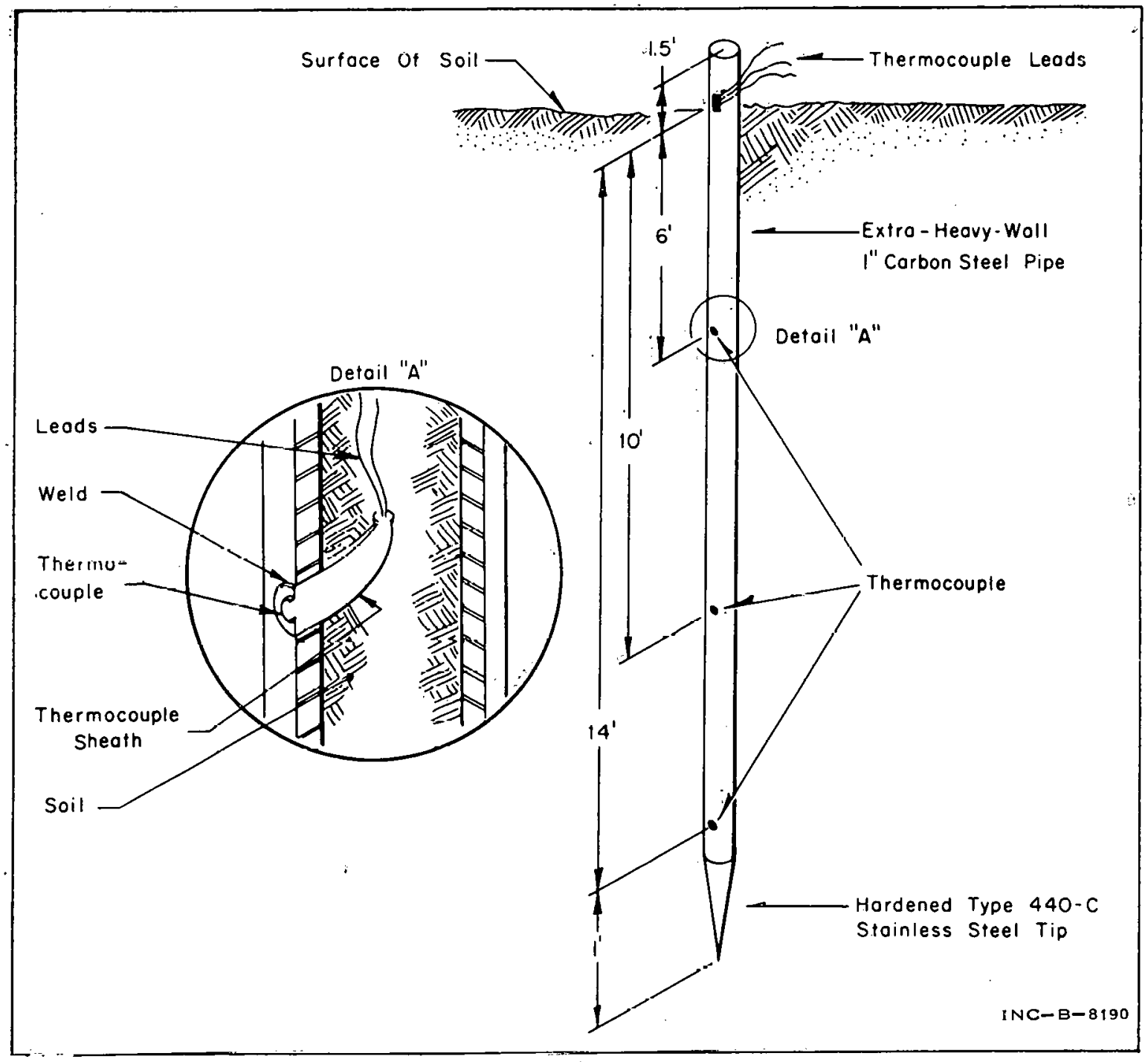

Fig. 10 Detalls of thermowell and thermocouples.

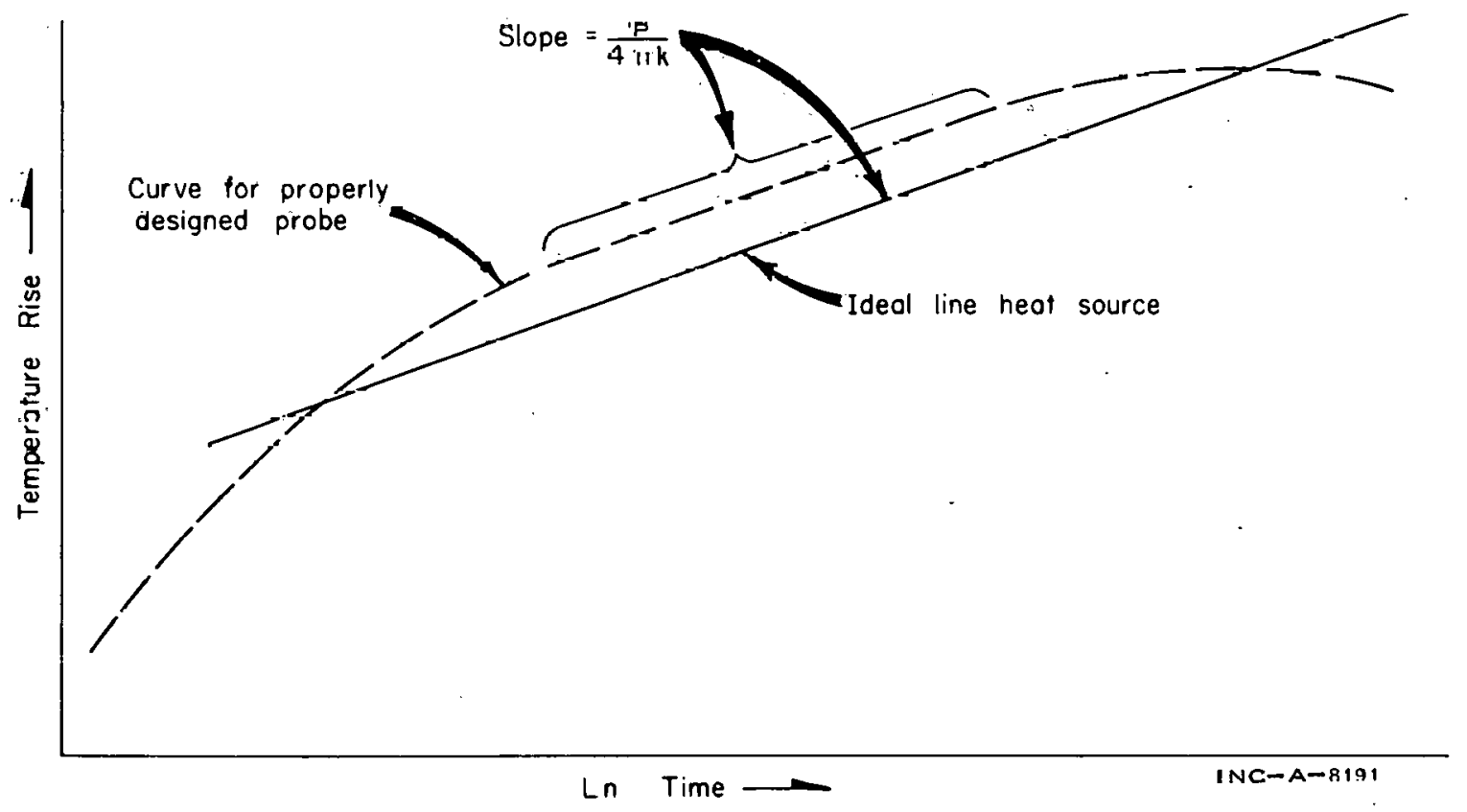

Fig. 11 T'emperature response of ideal linc heat source and probe. 


\section{PHYSICAL PROPERTIES OF SOIL AT THE TEST SITE}

Early investigators found that heat transfer through soil was affected primarily by soll moisture content and porosity [9]. Since, as shown by Figure 7 , the upper layers of soil at the NRTS are not homogeneous, the physical properties of the soil vary with location. Due to this variance, the investigations were limited to soils of a type found at the buried heater location. A brief description of the techniques and equipment used to determine the physical properties of the soil at this location is presented in the following paragraphs; a summary of the test results is shown in Table IV at the conclusion of this section. A more detailed description of the equipment and techniques used is given in Appendix $G$.

\section{THERMAL CONDUCTIVITY}

While various methods are available for determining thermal conductivities (References [26 through 31]), only one -- the line heat source method -- is suitable for the in situ determinations necessary for soils[31]. In situ measurements are required since removal of the soils from their original location invariably changes the porosity and possibly the moisture content, both vital properties with respect to thermal conductivity. Both the theoretical and practical application of the probe technique have been documented by previous investigators (References [32 through 39]). Briefly, the temperature response of a properly designed probe inserted in a low conductivity material approaches that of an ideal line heat source. The temperature response of an ideal line heat source for a given power input is given by the following equation:

$$
\Delta T=\frac{P}{4 \pi k} \ln \frac{t_{2}}{t_{1}}
$$

where

$$
\begin{aligned}
& \Delta \mathrm{T}=\text { temperature rise of line heat source, }{ }^{\circ} \mathrm{F} \\
& \mathrm{P}=\text { power input to source, Btu/hr-ft } \\
& \mathbf{k}=\text { thermal conductivity of material surrounding probe, Btu/hr-ft- }{ }^{\circ} \mathrm{F} \\
& \mathrm{t}=\text { time, hours. }
\end{aligned}
$$

Thus, for a properly designed probe, the thermal conductivity of the material surrounding the probe can be determined from the slope of a plot of the probe temperature rise versus the logarithm of the elapsed time. Response curves for an ideal line heat source and a properly designed probe are shown in Figure 11 (Page 20). A more detailed discussion of the theory and operation of the thermal conductivity probe is given in Appendix G.

A diagram of the probe used in this study is shown in Figure 12. The probe consists of a 12-inch-long, stainless steel tube approximately $1 / 4$ inch in diameter. The stainless steel tube, containing a 12-inch-long heater element, was sheathed with silver. Three platinum resistance temperature sensors are located 


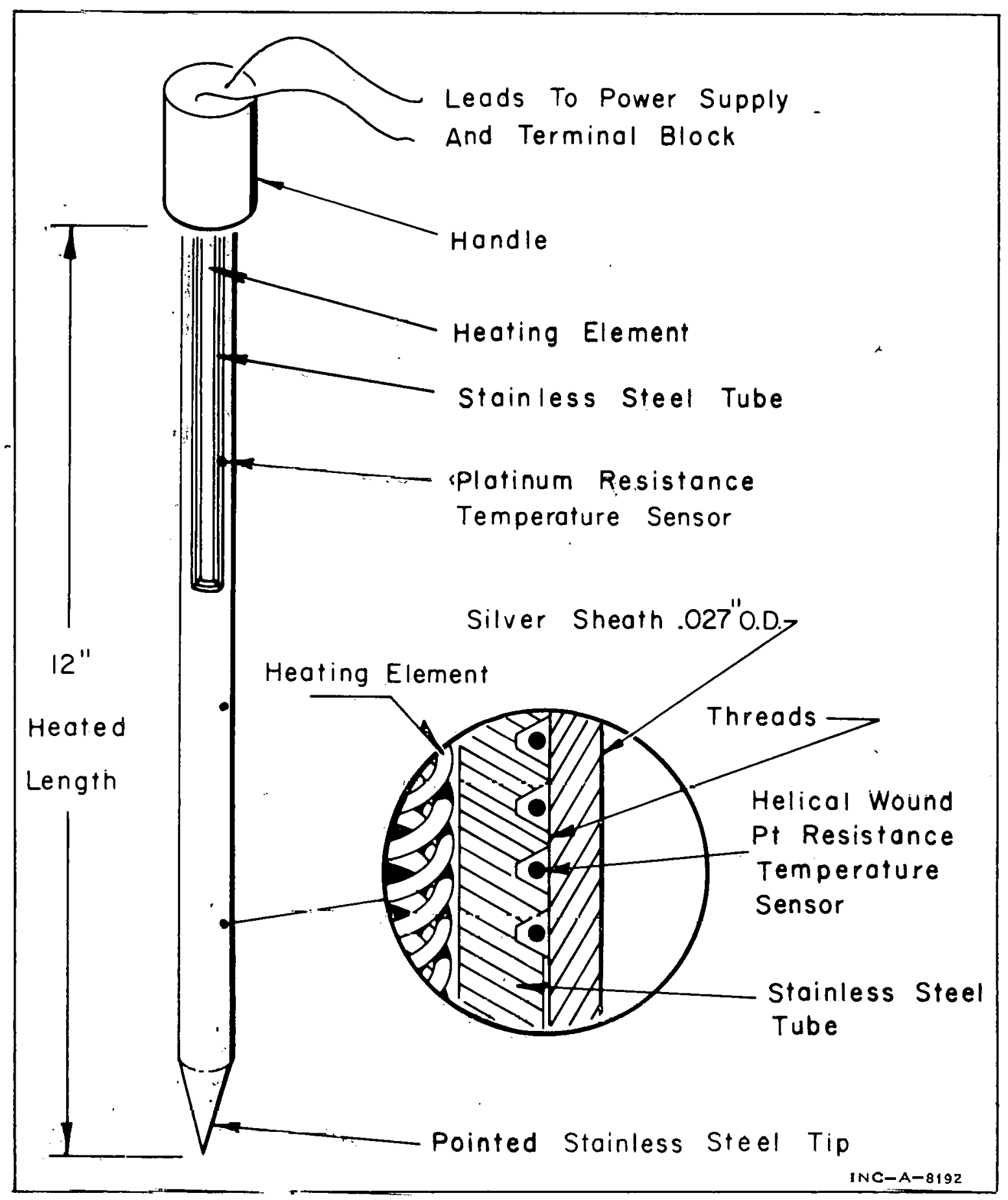

Fig. 12 Details of thermal conductivity probe.

between the stainless steel tube and the sheath. Materials of construction used in this probe limit its effective temperaturc range from 40 to $525^{\circ} \mathrm{F}$.

The thermal conductivity of the soll as a function of temperature was measured by inserting the probe at various radial distances from the electrical heater. This technique is not.strictly correct since the boundary value problem from which Equation (8) was obtained specifies a uniform initial temperature in 


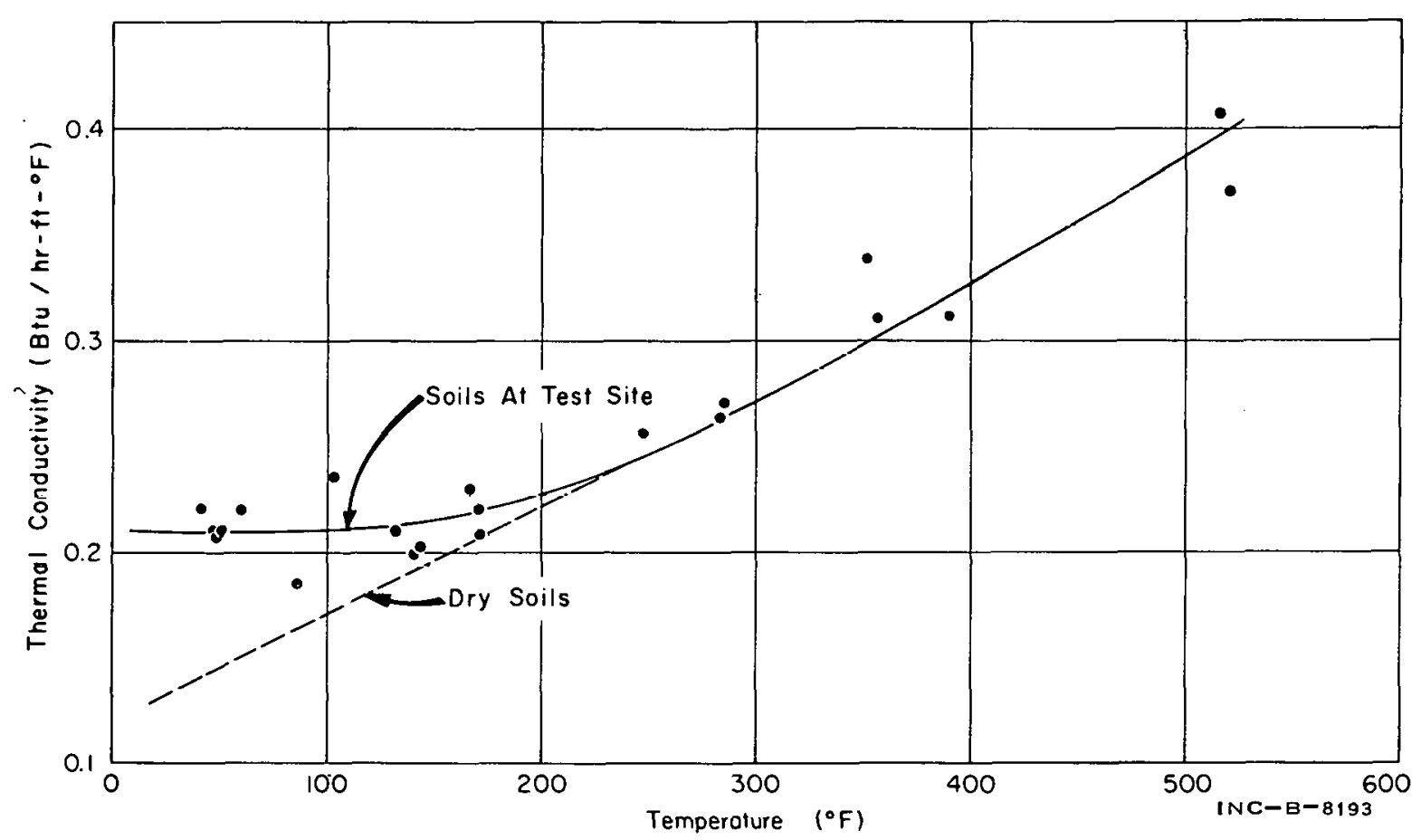

Fig. 13 Thermal conductivity of soil at test site.

the medium being tested. This discrepancy, however, does not appear to seriously affect the results of the determination. A plot of the experimentally determined thermal conductivity of the soil at the test site as a function of temperature is shown in Figure 13. The flattening of the solid curve between 50 and $200^{\circ} \mathrm{F}$ is believed to be due to the presence of moisture in the soil, which increases the effective thermal conductivity. As the temperature increases, moisture is driven off, and the slope of the curve approaches that of a dry soll. If no moisture were present in the soil, the plot would probably follow the dashed line at temperatures lower than $200^{\circ} \mathrm{F}$. 


\section{SPECIFIC HEAT}

Mean specific heat data for soil samples taken from the test site were obtained using a standard drop calorimeter. This procedure follows the classical "Method of Mixtures" technique adopted by the ASTM [39]. A summary of the mean specific heat of these samples as a function of temperature is shown in Table III. The maximum operating temperature of the calorimeter was limited

\section{$\underline{\text { TABLE III }}$}

MEAN SPECIFIC HEAT OF VARIOUS SOILS ${ }^{[a]}$

$\left(\mathrm{Btu} / \mathrm{lb}-{ }^{\circ} \mathrm{F}\right)$

\begin{tabular}{|c|c|c|c|c|}
\hline Material & $95^{\circ} \mathrm{F}$ & $144^{\circ} \mathrm{F}$ & $194^{\circ} \mathrm{F}$ & $245^{\circ} \mathrm{F}$ \\
\hline Sand & --- & 0.19 & ---- & ---- \\
\hline Sandy gravel & ---- & 0.18 & ---- & $=--$ \\
\hline Silty sand & --- & 0.22 & 0.21 & 0.21 \\
\hline Silty sand and gravel & 0.18 & 0.19 & ---- & 0.20 \\
\hline
\end{tabular}

[a] At average temperatures.

to $400^{\circ} \mathrm{F}$ - a mean sample temperature of $245^{\circ} \mathrm{F} \mathrm{--}$ by the material of construction used. Specific heats were determined at mean temperatures varying from 90 to $24 \mathrm{~b}^{\circ} \mathrm{F}$ for samples of four different types of geological material. The mean specific heat used for the calculations was $0.2 \mathrm{Btu} / 1 \mathrm{~b}-{ }^{\circ} \mathrm{F}$ since the data indicate only a slight increase with increasing temperature over the entire range studied. In general, the mean specific heat values appear to increase with an increase in the quantity of fines in the soil material. This may reflect differences in the relative amounts of moisture retained by the various samples when heated.

\section{DENSITY, POROSITY, SIZE DISTRIBUTION, AND COMPOSITION}

Since the U. S. Geological Survey (USGS) had previously determined the density, porosity, and size distribution of soils from a number of locations at the NRTS, it was not necessary to redetermine these properties for this study. A description of the techniques employed and the location of the sampling sites is given elsewhere $[40,41]$. A summary of the USGS findings is given in Table IV.

While an assay of the soil constituents was not made for this study, the composition of the soils at the NRTS was estimated with a reasonable degree of certainty from the work of others [42]. Accurate determination of the soil composition is not necessary since the composition does not markedly affect the soll thermal conductivity. 


\section{MOISTURE CONTENT}

Moisture contents at varying depths in the soil were determined with a soll moisture probe (or neutron moisture detector). Results of the determinations were in good agreement with laboratory analysis of samples dried in a furnace. This device consists of a canister containing a "fast" neutron source and a detector which is sensitive only to "slow" neutrons. As the neutrons pass through the material surrounding the probe, they are slowed down (moderated) by water or other hydrogeneous materials. The moisture content of the soll can thus be related to the number of returning "slow" neutrons. Results of the moisture determinations over the 1-year test period showed that only the soll from the surface to a depth of approximately 5 feet was significantly affected by rain and snowfall. While the moisture content of the upper layer varied from 2 to 8 percent, the soil layers from 5 to 30 feet below the surface varied only from 2 to 4 percent. At any depth, the moisture content of the soil did not vary significantly in the radial direction.

A summary of the physical properties of the soll and of the techniques employed in their determination is shown in Table IV.

\section{TABLE IV}

PHYSICAL PROPERTIES OF SOIL AT TEST SITE

\begin{tabular}{|c|c|c|c|c|c|}
\hline Soil Property & Units & Value & $\begin{array}{c}\text { Temperature } \\
\text { Range } \\
\left.{ }^{\circ} \mathrm{F}\right) \\
\end{array}$ & $\begin{array}{c}\text { Number of } \\
\text { Determinations }\end{array}$ & Technique Employed \\
\hline Thermal conductivity & $\mathrm{Btu} / \mathrm{hr}-\mathrm{ft}-{ }^{\circ} \mathrm{F}$ & 0.2 to 0.4 & 50 to 520 & 21 & Thermal conductivity probe \\
\hline Mean specific heat & Btu $/ 1 b-{ }^{\circ} F$ & 0.18 to 0.22 & 90 to 250 & 23 & Drop calorimeter \\
\hline Density & $1 \mathrm{~b} / \mathrm{ft}^{3}$ & 80 to 125 & -- & 6 & Gravimetric \\
\hline Porosity & Percent & 25 to 30 & -- & 150 & Saturation method \\
\hline Size distribution & Wt\% & & & & \\
\hline 0.75 to 3 inches & & 70 & --- & 24 & Standard sieve screen \\
\hline 0.08 to 0.75 inch & & 24 & & & \\
\hline$<0.08$ inch & & $\underline{6}$ & & & \\
\hline & & otal 100 & & & \\
\hline Composition & Wt: & & --- & 80 & Wet chemical analysis \\
\hline $\mathrm{SiO}_{2}$ & & 57 & & & \\
\hline $\mathrm{Al}_{2} \mathrm{O}_{3}$ & & 16 & & & \\
\hline $\mathrm{Fe}_{2} \mathrm{O}_{3}$ & & 6 . & & & \\
\hline $\mathrm{FeO}$ & & 6 & & & \\
\hline $\mathrm{MgO}$ & & 2 & & & \\
\hline $\mathrm{CaO}$ & & 7 & & & \\
\hline $\mathrm{Na}_{2} \mathrm{O}$ & & 2 & & & \\
\hline $\mathrm{K}_{2} \mathrm{O}$ & & 3 & & & \\
\hline $\mathrm{TiO}_{2}$ & ' & 1 & & & \\
\hline & & otal 100 & & & \\
\hline Moisture content & Vol\% & 2 to 8 & 35 to 130 & 200 & Neutron moisture detector \\
\hline
\end{tabular}




\section{COMPARISON AND DISCUSSION OF \\ EXPERIMENTAL AND CALCULATED TEMPERATURE DISTRIBUTIONS}

The time-temperature profiles obtained from the electrical simulation of a buried nuclear fuel element for two power levels are shown in Figure 14. These curves represent the temperatures at three depths below the soil surface $(6,10$, and 14 feet) and six radial distances $(1,3,5,10,20$, and 30 feet) from the heat source for two different power levels (950 and 350 watts). Curves for several of the thermocouples have been omitted since they closely coincided with those shown. The power levels used correspond approximately to 85and 135-day cooled fuel elements from the Materials Testing Reactor at the NRTS [43].

"True" vertical placement of the thermowells in the soll was difficult due to the large stones (up to 4 inches in diameter) in the soil at the test site. Location of the thermowells near the heat source is critical since the temperature gradients in this region are large. In most cases, the thermowells (which had hardened tips) were driven through the rocks and remained in a "true" vertical position; in at least two cases, however, thermowells (Numbers " $\mathrm{N}-1$ " and "S-1") were deflected from the true vertical while being driven into the soil. During the in situ thermal conductivity measurements, their location with respect to the heating source was determined and is shown in Table V. Location of other thermowells is not as critical since the temperature gradients decrease with increasing distance from the heat source.

The electrical heater was replaced once during the test program when the power leads to the heater shorted to the soil. Although the same amount of power was being dissipated to the ground during the time the power supply was shorted, the location and shape of the effective heat generation volume were changed to unknown values. Temperatures obtained during this time reflected the change in source geometry. The temperatures, however, returned to near normal levels after the heater was replaced.

Temperature fluctuations in the soil due to the daily atmospheric temperature changes were not apparent, but those due to the seasonal temperature changes were. The maximum soil temperatures were recorded in mid-August for the shallower depths and in September at the deeper levels. The rain and snowfall did not appreciably affect the temperature profiles in the soil below the minus 6-foot level.

The experimental temperatures shown in Figure 14 were used to test the validity of the steady-state and transient models for the temperatures resulting from a buried fuel element. A comparison of the experimental and calculated temperature distributions, based on the mathematical models, is given in the following sections. The quantitative effects of various factors on the calculated temperatures resulting from a buried heat source is also presented.

1. STE ADY-STATE TEMPERATURES IN AND SURROUNDING A SIMULATED BURIED FUE L E LEMENT

The steady-state temperatures obtained experimentally and those calculated from Equation (2) are compared in Figures 15 and 16 for power levels of 350 

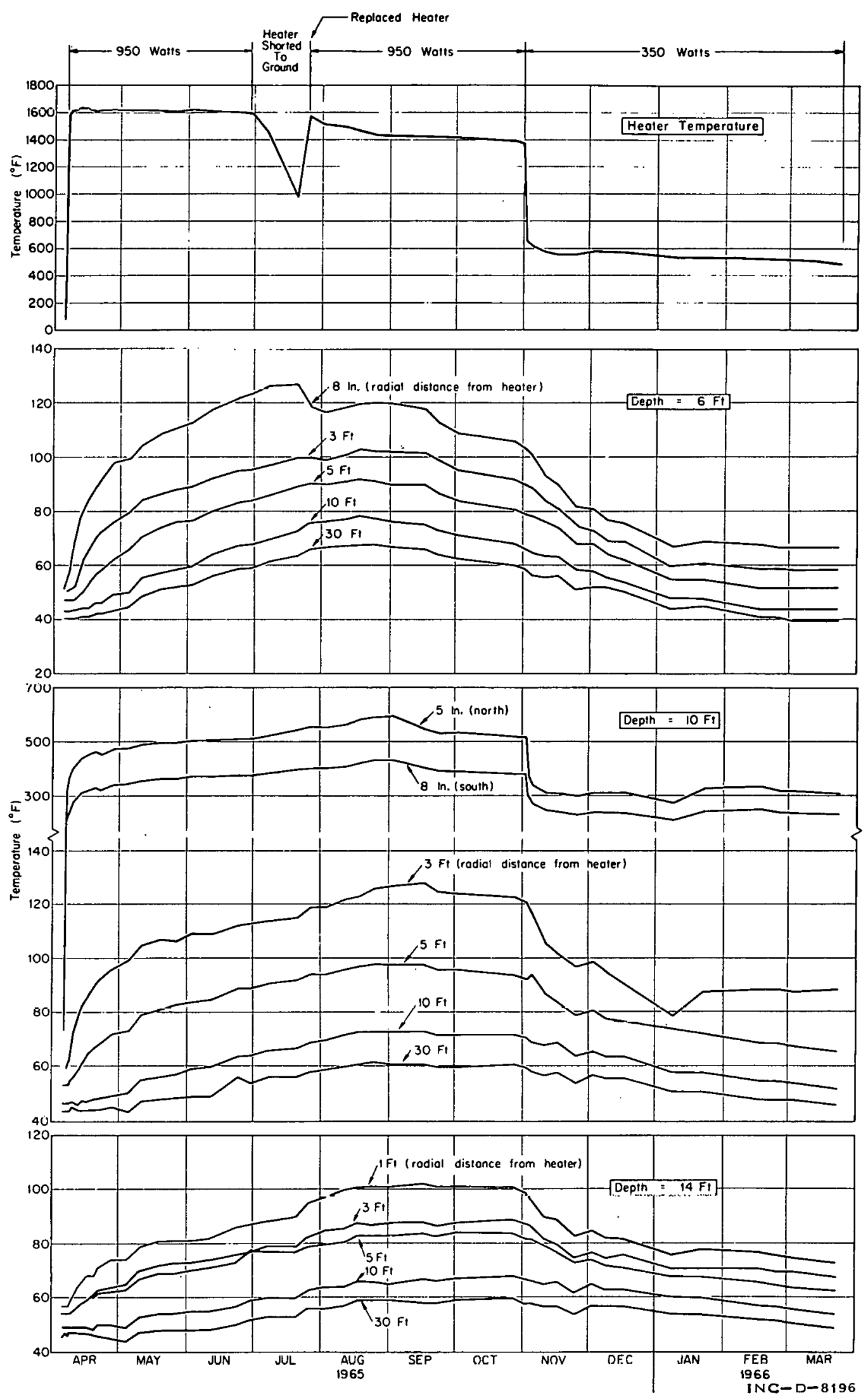

Fig. 14 Measured temperatures surrounding the electrical heater for 350 - and 950 -watt levels. 
TABLE V

LOCATION OF THERMOCOUPLES IN "S-I" AND "N-I" THERMOWELLS

\begin{tabular}{ccc}
\hline Thermowel1 & $\begin{array}{c}\text { Depth of } \\
\text { Thermocouple } \\
\text { Below Surface } \\
\text { (feet) }\end{array}$ & $\begin{array}{c}\text { Distance } \\
\text { to Source } \\
\text { (inches) }\end{array}$ \\
\cline { 2 - 2 } N-1 & -6 & 8.0 \\
N-1 & -10 & 5.25 \\
N-1 & -14 & 4.0 \\
S-1 & -6 & 9.5 \\
S-1 & -10 & 8.0 \\
S-1 & -14 & 7.0 \\
\hline
\end{tabular}

and 950 watts (equivalent to 329 and $880 \mathrm{Btu} / \mathrm{hr}-\mathrm{ft}^{2}$ for the fuel element), respectively. The maximum deviation between the experimental and calculated temperatures occurred within the simulated element at a depth of 10 feet. This error can be attributed, in part, to the assumption of a negligible contact resistance between the fuel element and the soil. The calculated and experimental temperatures in other regions are in good agreement, often to within a few degrees. The calculational procedure for this model requires the use of a constant mean thermal conductivity. Arithmetic mean thermal conductivities of 0.40 and $0.50 \mathrm{Btu} / \mathrm{hr}-\mathrm{ft}-{ }^{\circ} \mathrm{F}$ were used for power levels of 350 and 950 watts (or 329 and $880 \mathrm{Btu} / \mathrm{hr}-\mathrm{ft}^{2}$ ), respectively. The agreement between the calculated and experimental temperatures could possibly be improved if the temperature dependence of thermal conductivity was included in the model.

As shown by the general agreement between the calculated and experimental temperature distributions, the model for the temperatures within and surrounding a buried fuel element is valid. The quantitative effects of the rate of heat generation, burial depth, and soil thermal conductivity on the temperature distributions surrounding the fuel element have been calculated for conditions of practical interest using the validated model. The results of these calculations for a simulated fuel element 3 inches in diameter and 4 feet long are shown in Figures 17, 18, and 19. As anticipated, the heat generation rate and the soil thermal conductivity strongly influence the calculated temperature distributions. Increasing the burial depth beyond that required for radiation shielding (5 to 10 feet for wastes cooled several years) does not change the calculated temperature distribution. This can be attributed to the fact that as the burial depth increases, the boundary conditions in the $\mathrm{z}$ direction approach those for an infinite medium. 


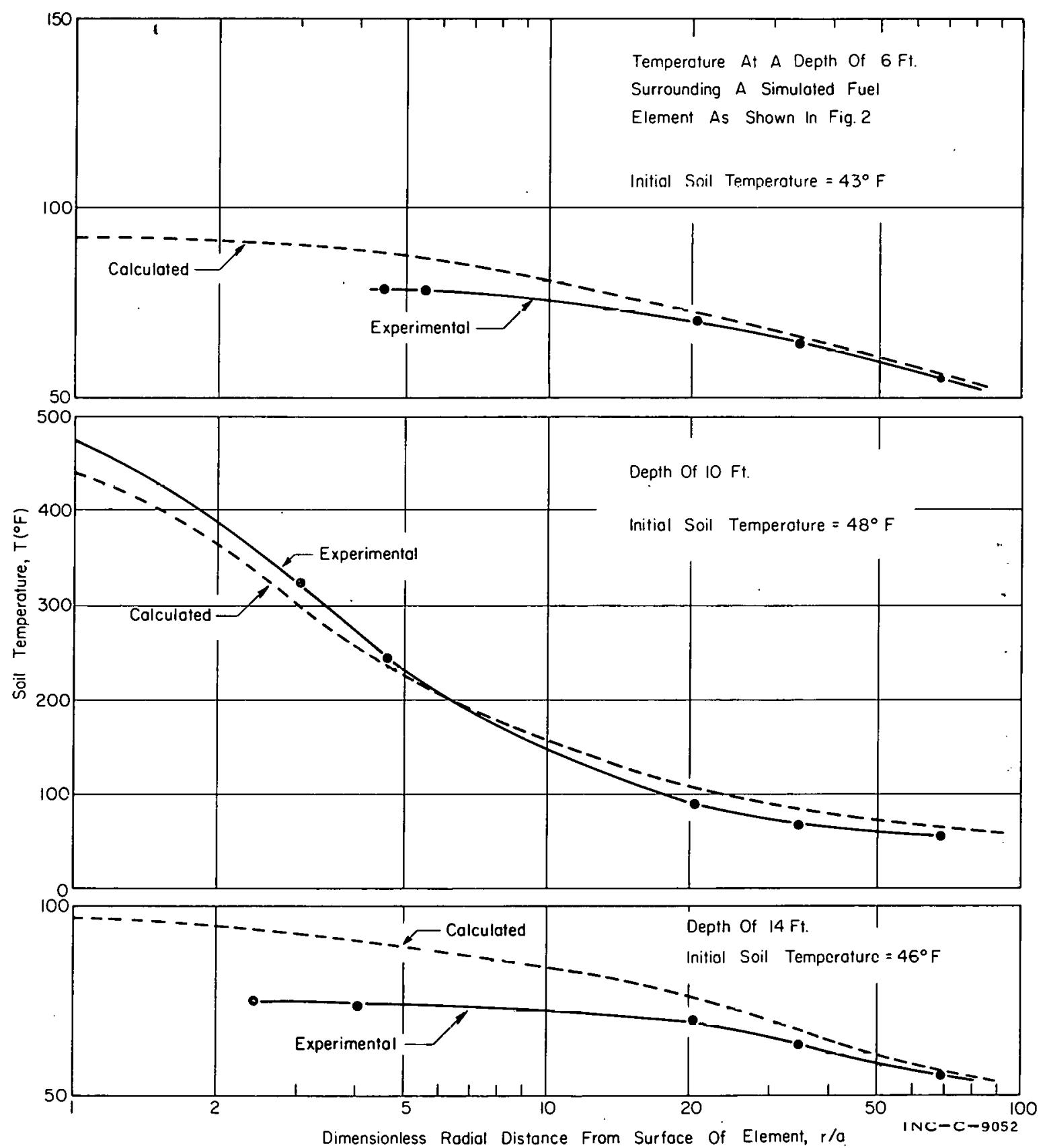

Fig. 15 Comparison of calculated and experimental steady-state temperatures for 350-watt simulated fuel element, $\mathrm{k}_{\mathrm{\theta}}=0.4 \mathrm{Btu} / \mathrm{hr}-\mathrm{ft}-{ }^{\circ} \mathrm{F}$. 


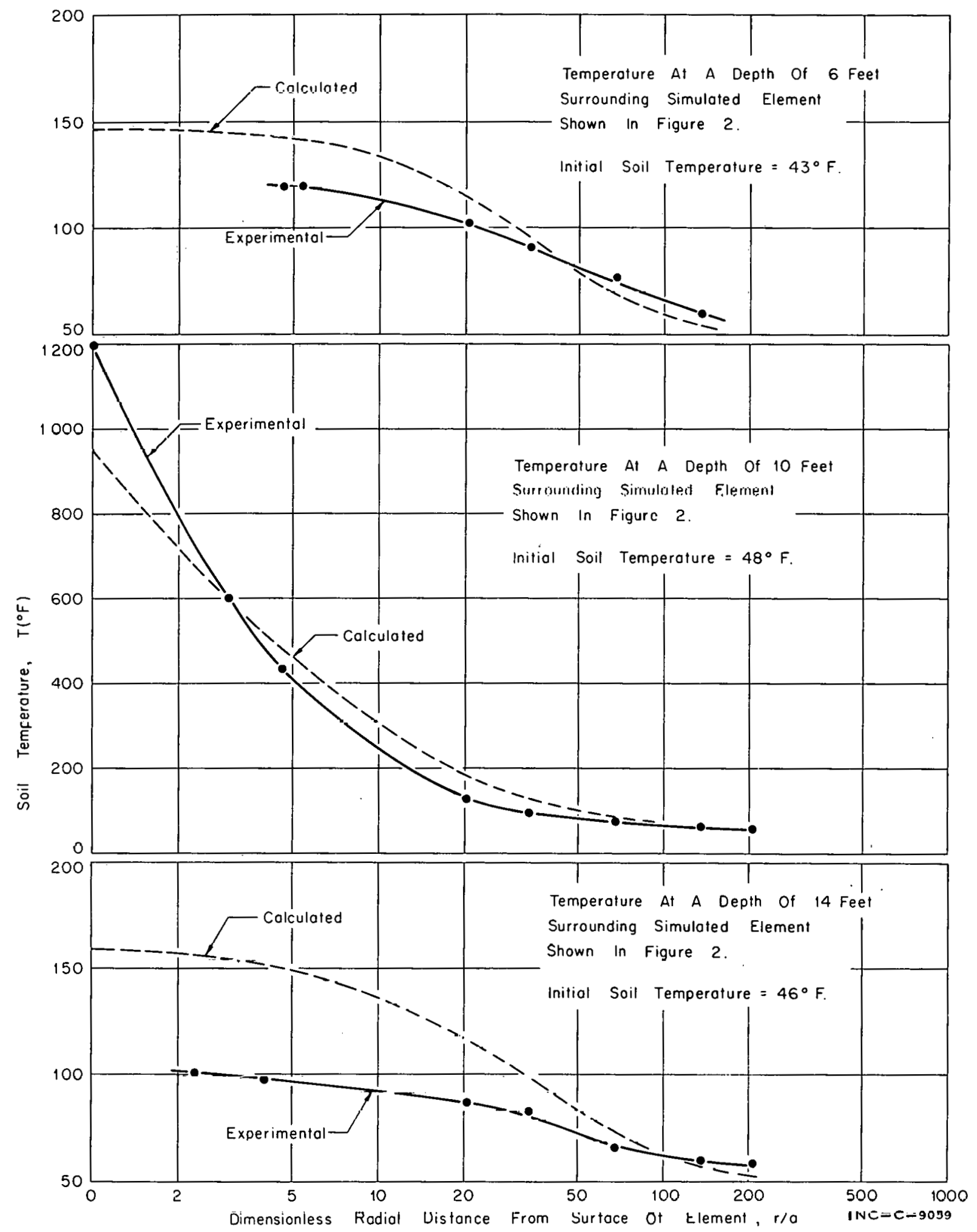

Fig. 16 Comparison of calculated and experimental steady-state temperatures for 950-watt simulated fuel element, $\mathrm{k}_{\mathrm{s}}=0.45 \mathrm{Btu} / \mathrm{hr}-\mathrm{ft}-{ }^{\circ} \mathrm{F}$. 


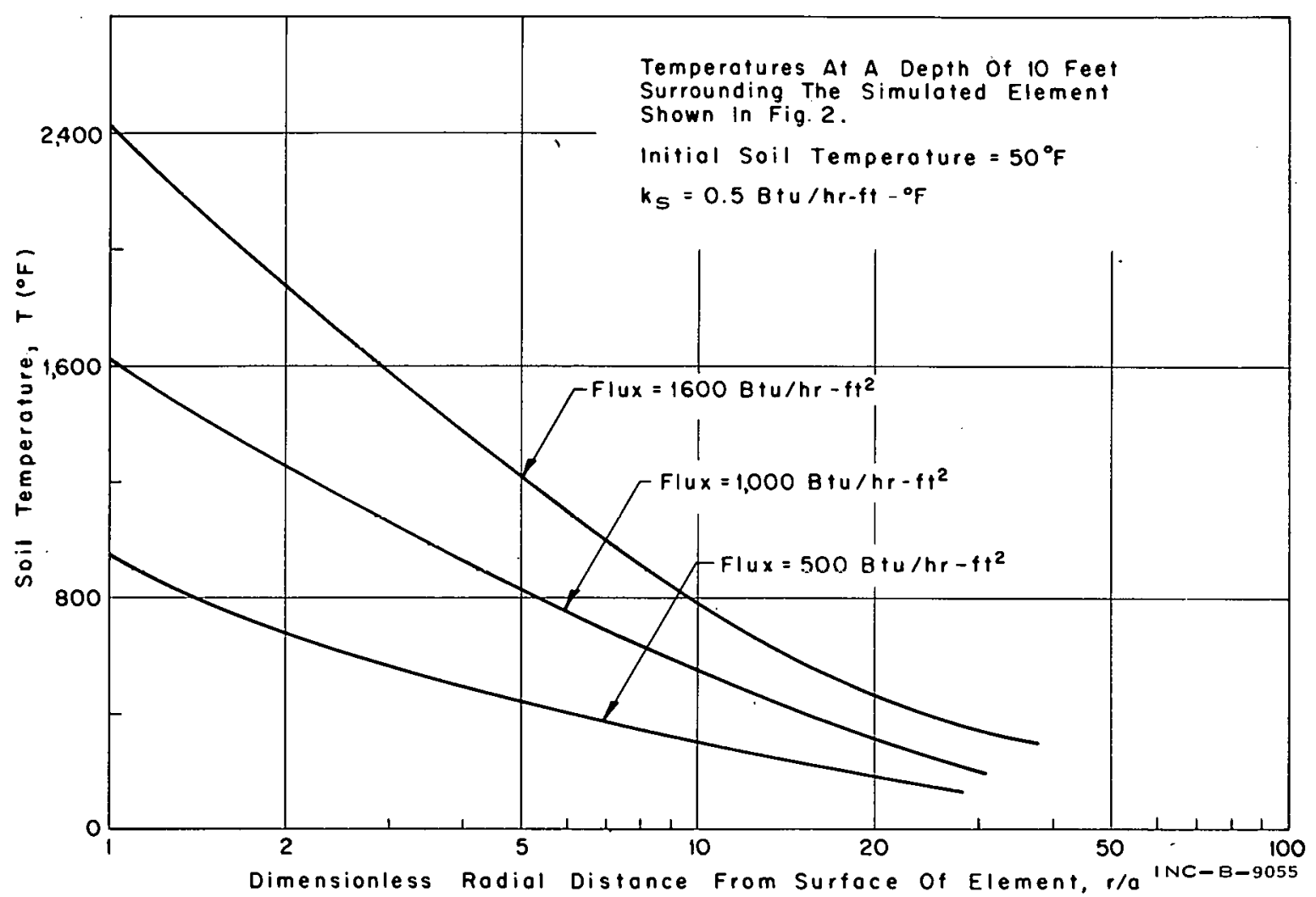

Fig. 17 Effect of heat flux on calculated steady-state temperatures for a simulated fuel element.

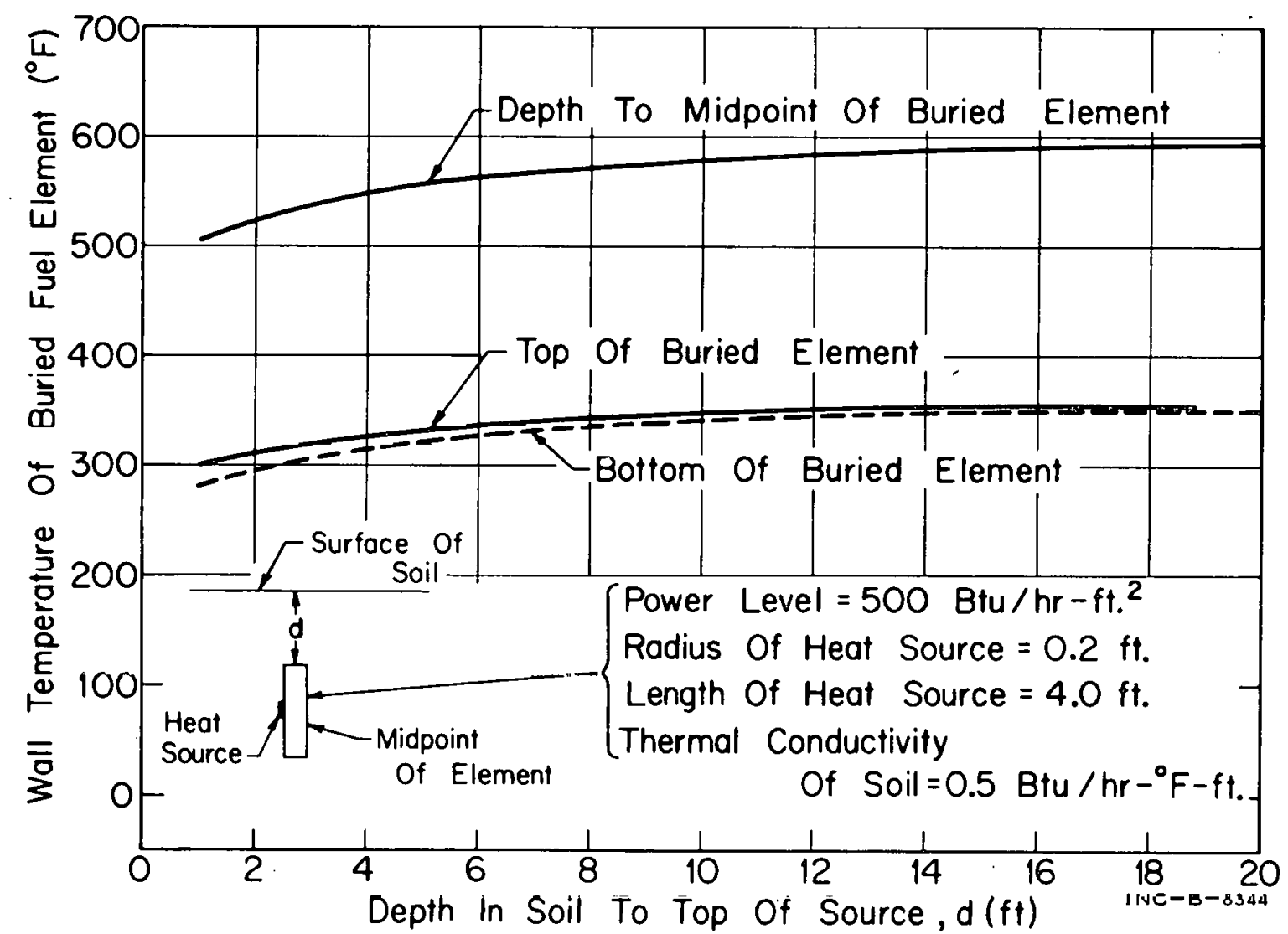

Fig. 18 Effect of burial repth on calculated steady-state temperatures for a simulated fuel element. 


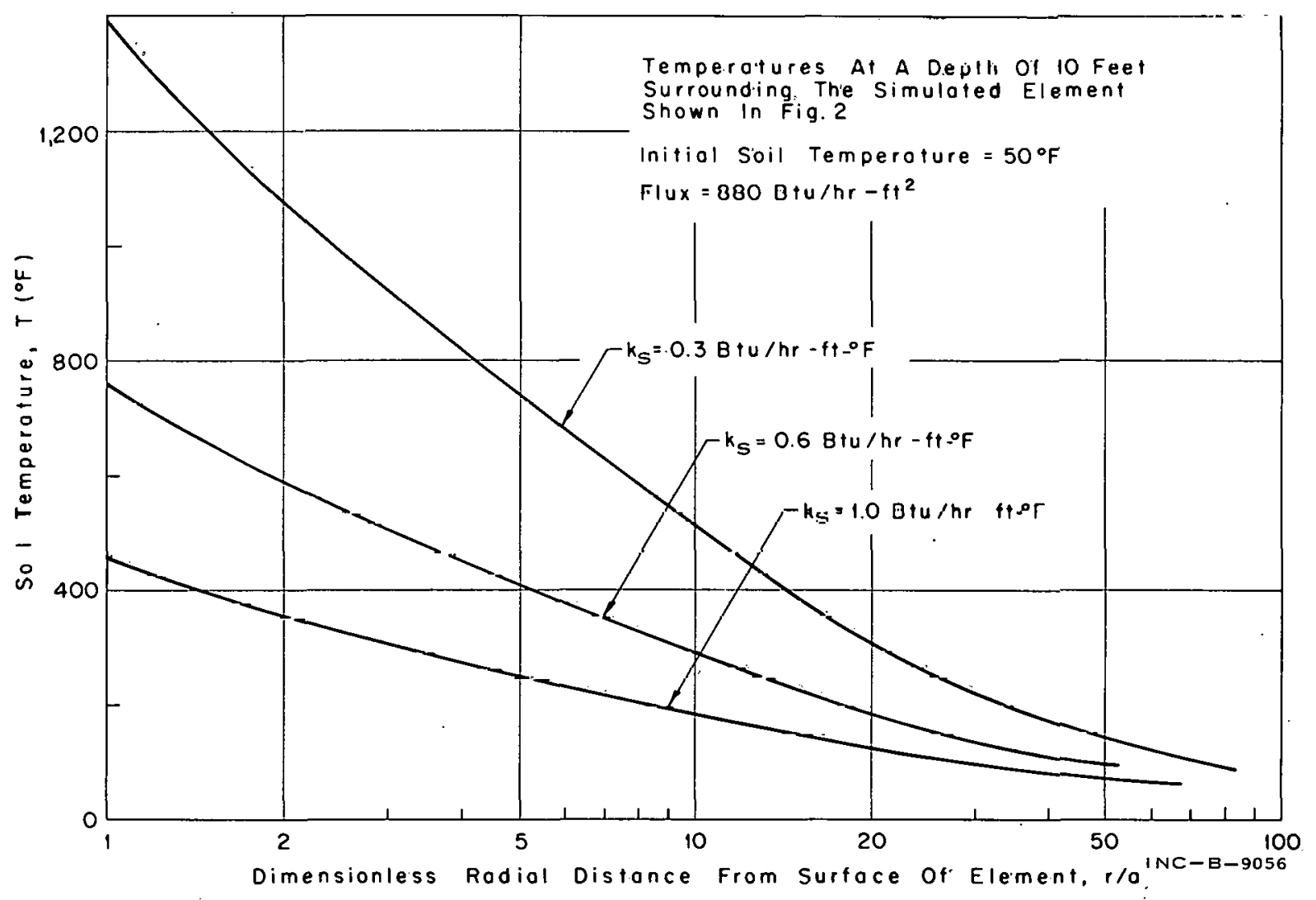

Fig. 19 Effect of soil thermal conductivity on calculated steady-state temperatures for a simulated fuel element:

2. STEADY-STATE TEMPERATURE DISTRIBUTIONS IN A WASTE STORAGE BIN AND THE SURROUNDING SOIL

The model describing the temperature distribution within and surrounding a waste-storage bin was not validated experimentally. However, the temperature calculated on the basis of this model should be valid since the heat losses from the ends of the bin and the thermal conductivity of the heat generating medium were included. The temperature distributions in and surrounding the bins were calculated as a function of the heat generation rate, the thermal conductivity of the waste and soll, and the radius of the bin using Equations (4) and (4a). The calculated temperatures, using typical values of these parameters, are shown in Figures 20,21, and 22, respectively. All three factors significantly affect the calculated temperature distributions. 


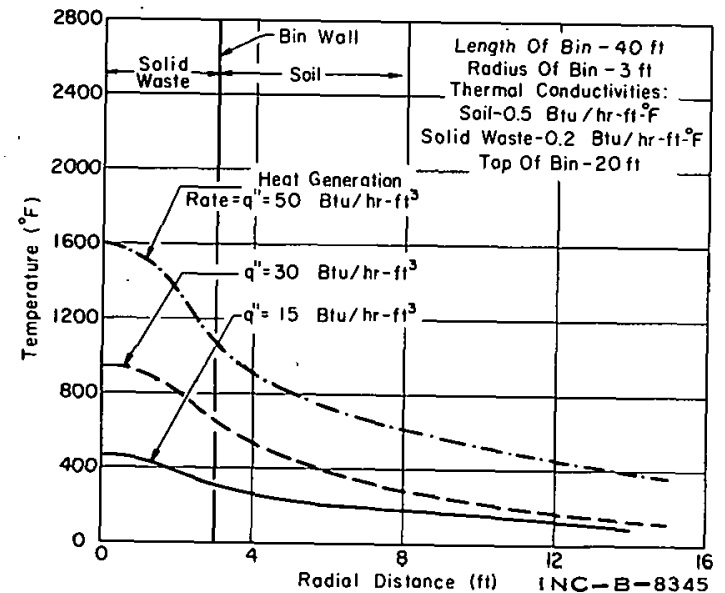

Fig. 20 Effect of heat generation rate on calculated steady-state temperature distributions in and surrounding a waste-storage container.

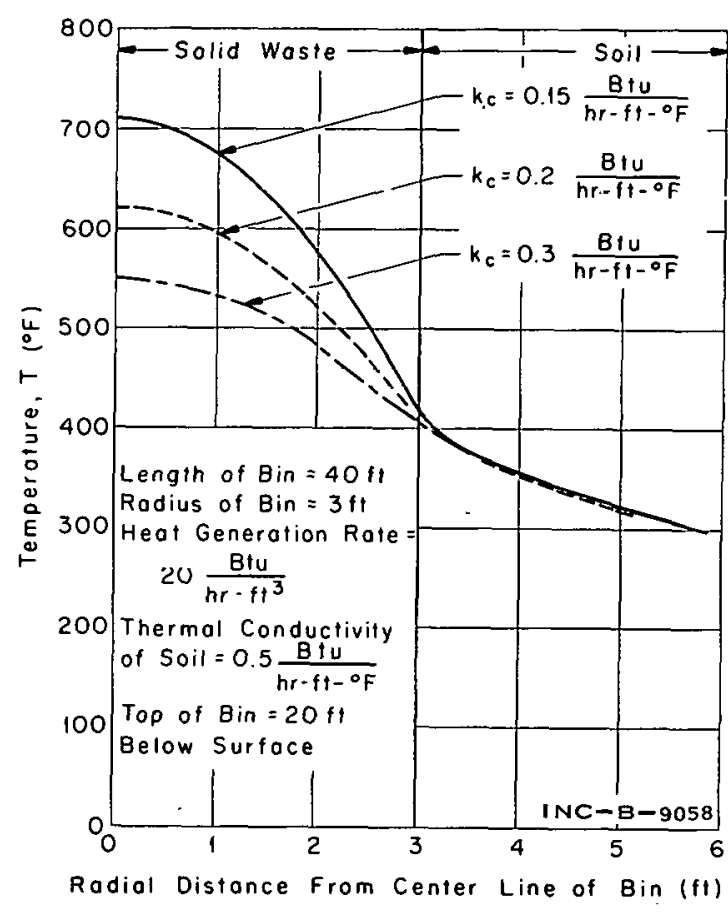

Fig. 21 Effect of source thermal conductivity on calculated steady-state temperature distributions in and surrounding a waste-storage container.

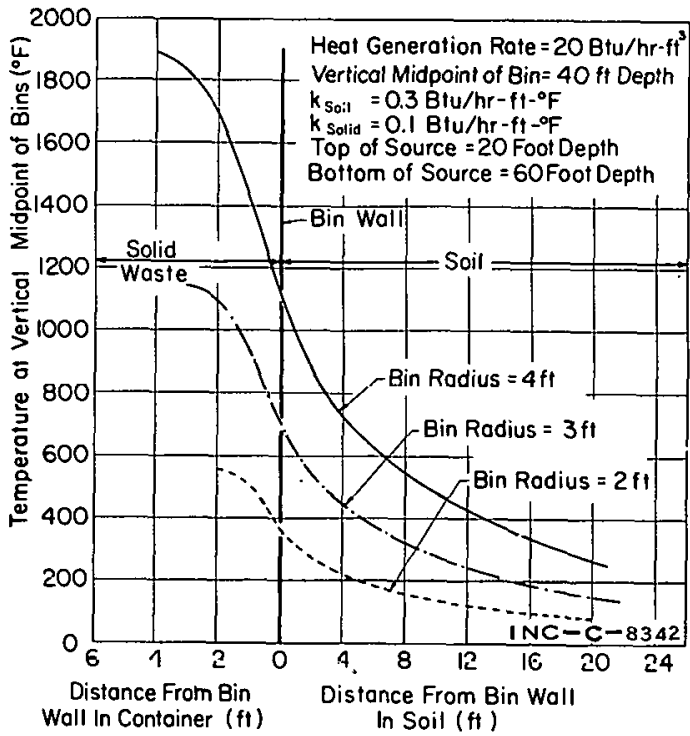

Fig. 22 Effect of source radius on calculated steady-state temperature distributions in and surrounding a waste-storage container. 


\section{TRANSIENT TEMPERATURES IN AND}

\section{SURROUNDING $\Lambda$ BURIED SIMULATED FUEL ELEMENT}

The validity of the mathematical model for the transient temperature distribution in the soil surrounding the buried simulated fuel element was demonstrated by comparing the experimental and calculated temperatures, as shown in Figure 23. For the radial distances shown, the agreement is excellent. Calculated temperatures, based on a thermal conductivity which varied linearly with temperature, did not differ apprectably from temperatures calculated on the basis of a mean thermal conductivity. Unfortunately, no thermocouples were located at radial distances between 0.66 and 3.0 feet which would have permitted a more detailed comparison in the region of large temperature gradients. The calculated and experimental temperatures at a radial distance of 30 feet were only slightly affected by the heat source. Better agreement between the experimental and calculated temperatures could have been achieved during the initial time period it smaller time increments were specified; this, however, would have resulted in increased computation time. The agreement between the experimental and calculated temperatures establishes the validity of the overall calculational procedure.

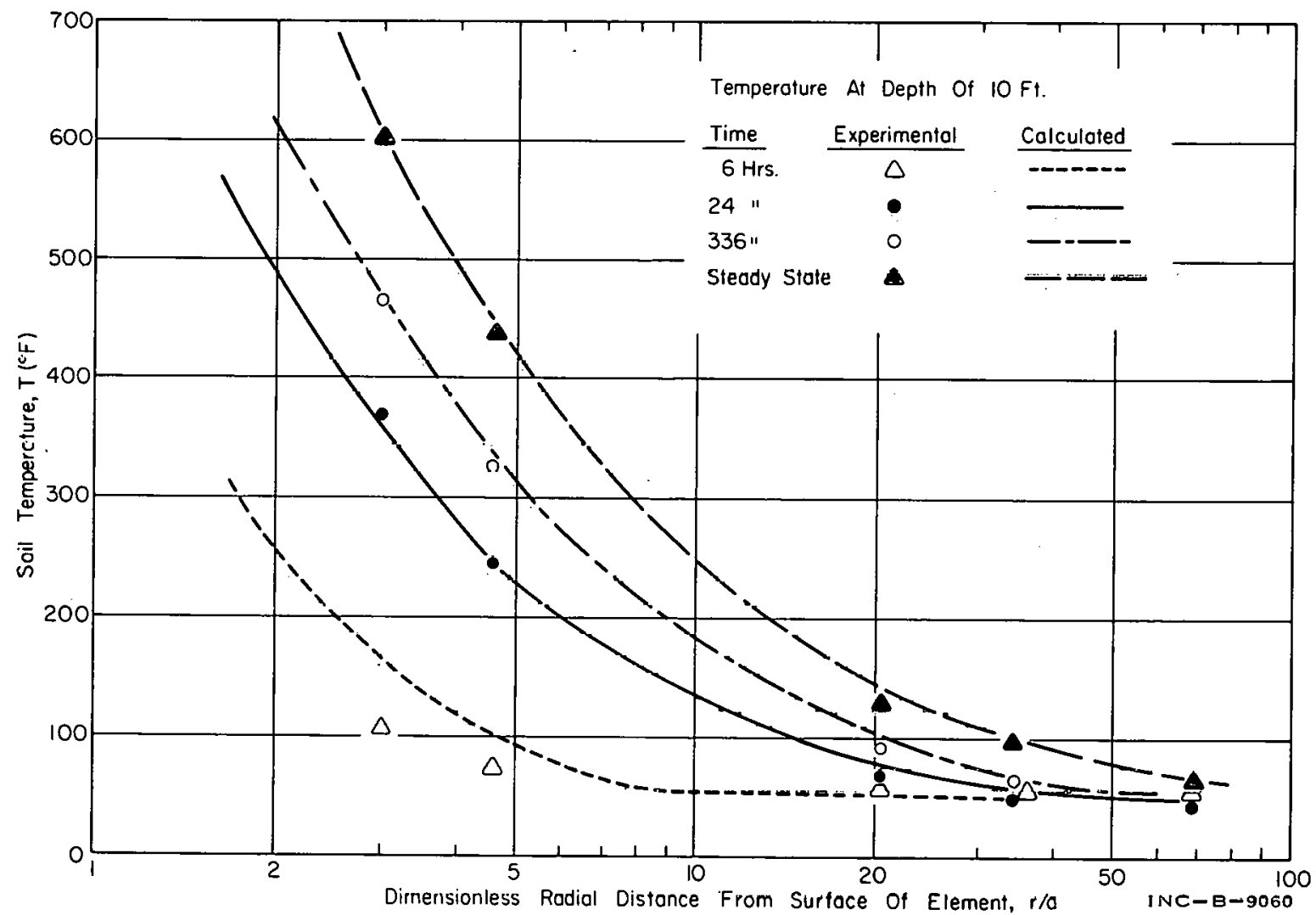

Fig. 23 Comparison of calculated and experimental transient temperatures for the 950-watt simulated fuel element shown in Figure $2, \mathrm{k}_{\mathrm{s}}=0.45$.

The model can also be used to calculate the transient temperature distribution around a source with a time-dependent heat generation rate. Transient temperatures surrounding a simulated fuel element, treated as an exponentially decaying cylindrical heat source, are shown in Figure 24. 


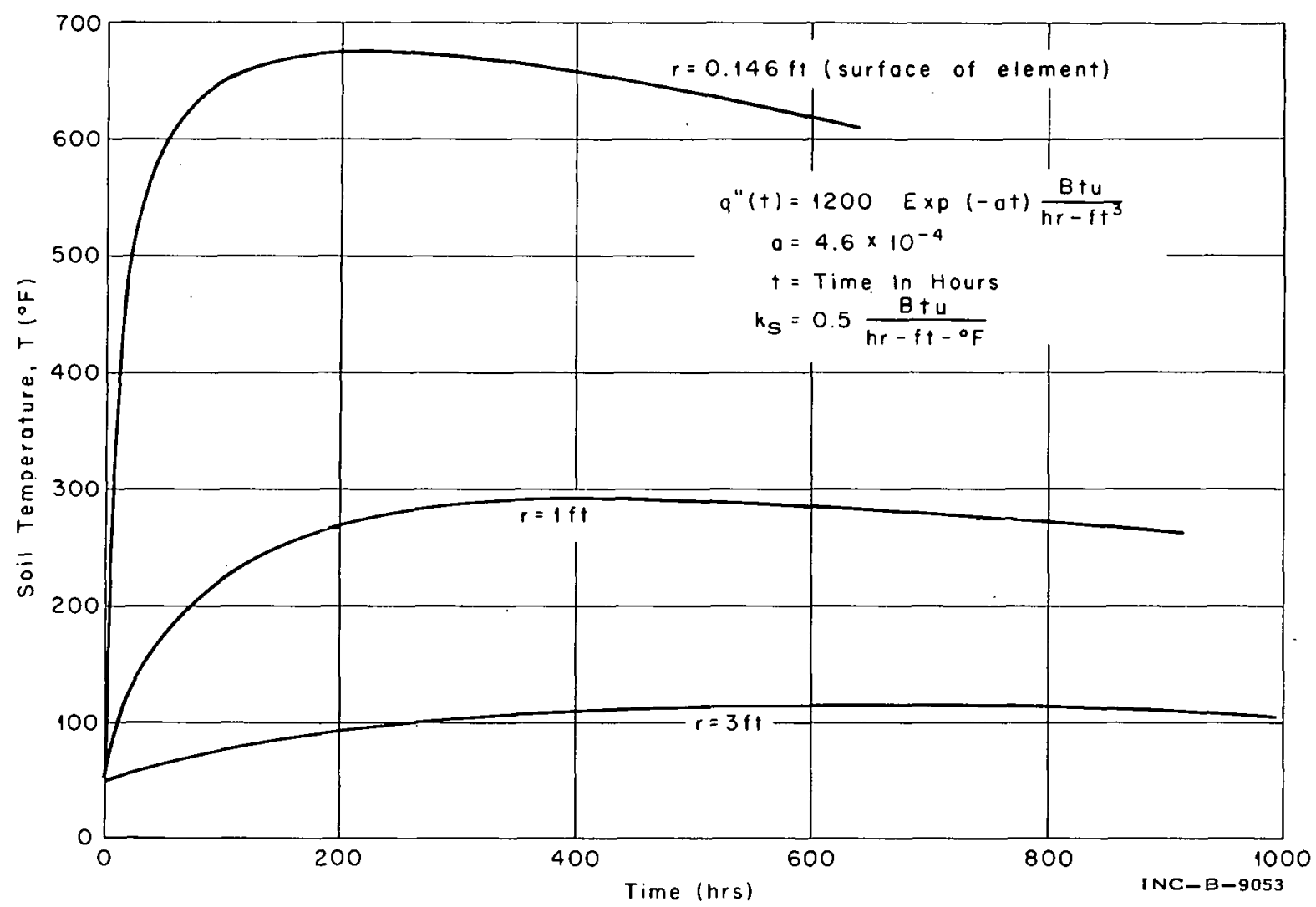

Fig. 24 Calculated transient temperatures for the buried fuel element shown in Figure 2 having a specified time-dependent rate of heat generation, $\mathrm{q}^{11} \mathrm{Btu} / \mathrm{hr}-\mathrm{ft}^{3}$.

4. TRANSIENT TEMPERATURE DISTRIBUTIONS

IN A WASTE STORAGE BIN AND THE SURROUNDING SOIL

The transient temperatures in a cylindrical vessel containing solidified ladiuaclive waste were calculated using Equation (9). For this case, the mathematical model was not validated by experimental data; however, based on the results from the simulated fuel element, the calculated temperatures should reasonably approximate the actual temperatures in and surrounding a bin. As in the case of a buried fuel element with a specified constant rate of internal heat generation, the transient temperatures eventually approach the steady-state value. The approach to steady state for a bin of specified size and internal heat generation rate is shown in Figure 25. Because of the large capacitance of the system, approximately two months are required for the approach to steady state. Equation (9) can also be used to calculate the temperature as a function of position and time in a solidified waste in which the heat generation is decaying at a specified decreasing rate as shown in Figure 26. 


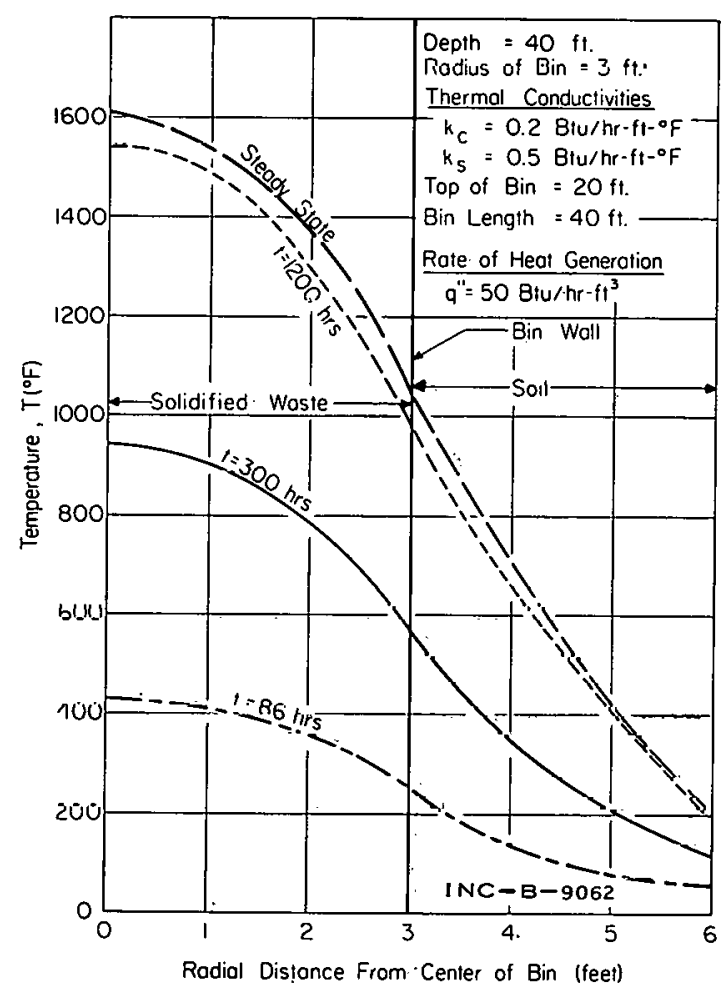

Fig. 25 Calculated transient temperatures in a buried cylindrical bin filled with solidified waste.

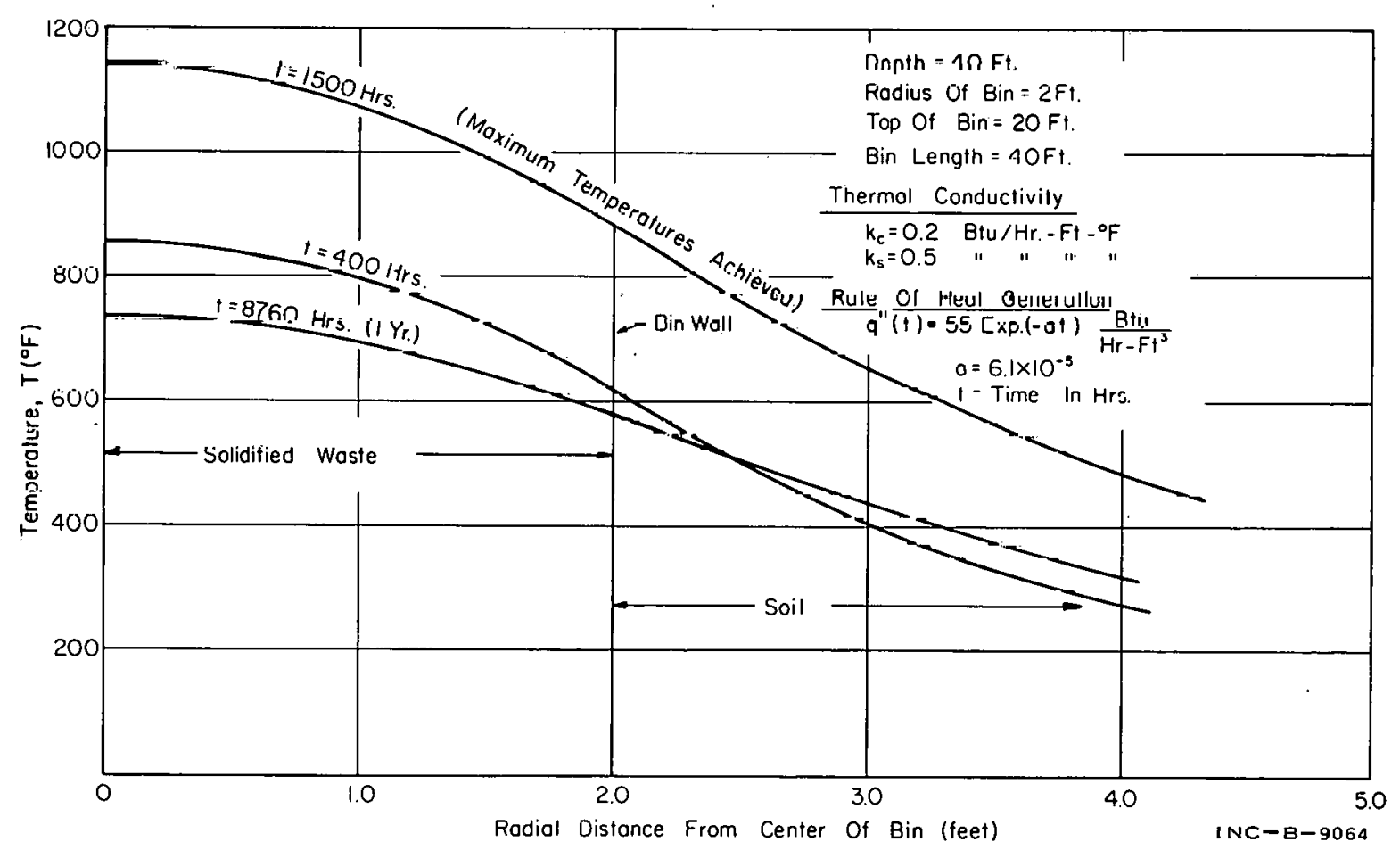

Fig. 26 Calculated transient temperatures in a buried cylindrical bin filled with solidified waste (theoretical MTR waste cooled 3 years). 


\section{CONCLUSIONS AND RECOMMENDATIONS}

Based on the temperature distributions calculated in the numerical examples, the direct burial of spent fuel elements or solidified nuclear waste in the soil without external cooling is possible. The safety implications, however, must be investigated. The models developed in this study can be used to calculate reasonably accurate temperature distributions for cases similar to those for which the models were developed. The maximum temperature in the stored material is strongly influenced by the thermal conductivity of the waste, the rate of heat generation, the dimensions of the container, and the thermal conductivity of the soil.

Calculated temperatures based on the steady-state and transient models proposed in this study are in good agreement with the experimentally measured temperatures in a simulated fuel element and the surrounding soil. The effect on the calculated temperature distribution of moisture migration and the heat generated by escaping gamma radiation was neglected. These assumptions did not significantly affect the accuracy of the calculated temperatures for the dry soil employed in this test. Neglecting the contact resistance between the simulated fuel element and the soil and the use of an infinite thermal conductivity within the element resulted in a maximum deviation of 20 percent between the calculated and experimental temperatures at the center of the simulated fuel element. Heat losses from the ends of a buried fuel element may be neglected without seriously affecting the accuracy of the calculated temperatures. At practical burial depths and heat generation rates, a change in the burial depth did not affect the calculated temperature of the simulated element.

Additional study of the following factors is recommended to establish firmly the limitations on direct burial of radioactive waste in the soil:

(1) The effect of moisture migration (vaporization and combined mass and heat transfer) on the temperature distributions in and surrounding a buried heat source. Inclusion of this effect would improve the accuracy of the models when applied to heat transfer in moist soils. Additionally, it would allow evaluation of the continued injection of water into the soil surrounding a buried heat source as a means of decreasing the maximum temperature in a buried heat source.

(2) Experimentally simulate a buried fuel element with a decaying rate of heat generation using a buried electrical heater. Results of this test could be used to determine the validity of the mathematical model for a time-dependent heat generation rate.

(3) Determine the thermal conductivities and the heat capacities of snil and solidified waste using refined techniques employing the thermal conductivity probe. The factors affecting the accuracy of the "probe" are not well defined, particularly for in situ determinations.

(4) Evaluate the accuracy of model for calculating the temperatures within a storage bin using data obtained from existing solid waste-storage facilities at the Idaho Chemical Processing Plant. 


\section{NOMENCLATURE}

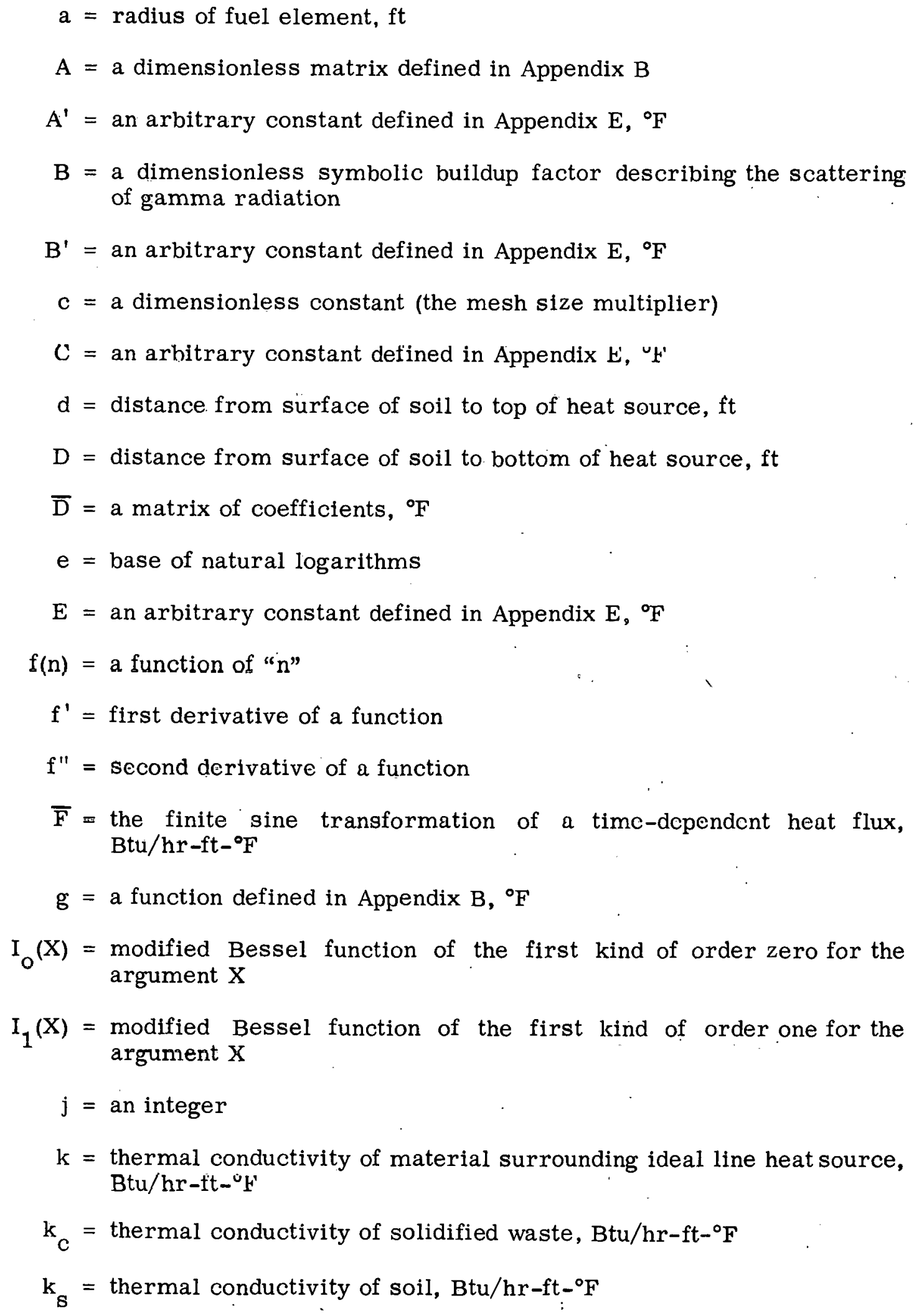
argument $\mathrm{X}$ $I_{1}(X)=\underset{\text { modified Bessel function of the first kind of order one for the }}{\text { argument } X}$

$\mathrm{j}=$ an integer

$\mathrm{k}=$ thermal conductivity of material surrounding ideal line heat source, $\mathrm{Btu} / \mathrm{hr}-\mathrm{ft}-{ }^{\circ} \mathrm{F}$

$\mathrm{k}_{\mathrm{C}}=$ thermal conductivity of solidified waste, $\mathrm{Btu} / \mathrm{hr}-\mathrm{ft}-{ }^{\circ} \mathrm{F}$

$\mathrm{k}_{\mathrm{s}}=$ thermal conductivity of soil, Btu/hr-ft- ${ }^{\circ} \mathrm{F}$ 


$$
\begin{aligned}
& \mathrm{K}_{\mathrm{O}}(\mathrm{X})=\text { modified Bessel function of the second kind of the order zero for } \\
& \mathrm{K}_{1}(\mathrm{X})=\text { modified Bessel function of the second kind of the order one for the } \\
& \mathrm{m}=\mathrm{a} \text { nodal point in the radial direction } \\
& M=\text { the outermost nodal point in the radial direction } \\
& \text { M1 = outermost nodal point in the region } 0<r<R_{B} \\
& M_{n}=\text { a function of " } n \text { " defined in Appendix } E, \mathrm{ft}^{-1} \\
& \mathrm{n}=\text { an integer (finite sine transform parameter) } \\
& \mathrm{N}=\text { the total number of radial distance increments } \\
& \mathrm{P}=\text { power supplied to ideal line heat source, } \mathrm{Btu} / \mathrm{hr}-\mathrm{ft} \\
& \mathrm{q}=\text { heat flux, Btu/hr-ft }{ }^{2} \\
& \mathrm{q}^{\prime \prime}=\text { internal heat generation rate of source, } \mathrm{Btu} / \mathrm{hr}-\mathrm{ft}^{3} \\
& \mathrm{Q}_{\mathrm{m}}(\mathrm{n})=\text { finite sine transform of a constant heat flux or heat generation } \\
& \mathrm{r}=\text { radial distance from the heat source, } \mathrm{ft} \\
& \Delta \mathrm{r}_{\mathrm{m}}=\text { radial distance increment, } \mathrm{ft} \\
& \Delta \cdot r_{1}=\text { first radial distance increment, } \mathrm{ft} \\
& \mathrm{R}=\text { radius of thermal conductivity sample, } \mathrm{ft} \\
& R_{B}=\text { radius of waste storage bin, } \mathrm{ft} \\
& \mathrm{S}_{\mathrm{v}}=\text { source strength of gamma point source, } \mathrm{sec}^{-1} \\
& \mathrm{~S}_{\mathrm{n}}=\text { a quantity defined in Appendix } \mathrm{E},{ }^{\circ} \mathrm{F} / \mathrm{ft}^{2} \\
& \mathrm{t}=\text { time, } \mathrm{hr} \\
& \mathrm{T}=\text { temperature, }{ }^{\circ} \mathrm{F} \text {. } \\
& \mathrm{T}_{1}=\text { temperature of source, }{ }^{\circ} \mathrm{F} \\
& \mathrm{T}_{2}=\text { temperature of soil, }{ }^{\circ} \mathrm{F} \\
& \mathrm{T}_{\mathrm{S}}=\text { initial temperature of soil, }{ }^{\circ} \mathrm{F}
\end{aligned}
$$




$$
\begin{aligned}
\mathrm{u} & =\text { a variable defined as } \mathrm{T}-\mathrm{T}_{\mathrm{s}},{ }^{\circ} \mathrm{F} \\
\overline{\mathrm{u}}_{\mathrm{m}} & =\text { transformed temperature at point } \mathrm{m} \\
\overline{\mathrm{u}}_{1} & =\text { transformed temperature of solidified waste } \\
\overline{\mathrm{u}}_{2} & =\text { transformed temperature of soil } \\
\mathrm{U}\left(\mathrm{X}_{\mathrm{B}}, \mathrm{X}, \mathrm{k}_{\mathrm{C}}, \mathrm{k}_{\mathrm{S}}\right) & =\text { a function defined as }\left\{\mathrm{k}_{\mathrm{C}} \mathrm{K}_{\mathrm{o}}\left(\mathrm{X}_{\mathrm{B}}\right) \mathrm{I}_{1}\left(\mathrm{X}_{\mathrm{B}}\right)+\right. \\
\overline{\mathrm{U}} & =\text { a matrix of transformed temperatures } \\
\mathrm{w} & =\text { a dimensionless function defined in Appendix } \mathrm{B} \\
\mathrm{x} & =\text { distance from snurce, cm } \\
\mathrm{X} & =\text { a dimcnoionlcoo variablo defined as }\left(\frac{\mathrm{rn} \pi}{\mathrm{L}}\right) \\
\mathrm{y} & =\text { a space coordinate, ft } \\
\mathrm{z} & =\text { axial distance below surface of earth }
\end{aligned}
$$

\section{GREEK SYMBOLS}

$$
\begin{aligned}
& \alpha_{1}=\text { thermal diffusivity of source, } \mathrm{ft}^{2} / \mathrm{hr} \\
& \alpha_{2}=\text { thermal diffusivity of soil, } \mathrm{ft}^{2} / \mathrm{hr} \\
& \mathrm{B}_{1}=\mathrm{a} \text { dimensionless quantity defined in Appendix } \mathrm{B} \\
& \beta_{m} \text { - a known dimensionless scalar quantity (a function of the thermal } \\
& \text { properties) defined in Appendix B } \\
& \Delta=\text { an incremental change } \\
& \theta_{\mathrm{m}}=\begin{array}{l}
\text { a known dimensionless scalar quantity (a function of the radial } \\
\text { distance) defined in Appendix B }
\end{array} \\
& \mu=\text { macroscopic cross section of material surrounding point source, } \\
& \mathrm{eni}^{-1} \\
& \xi=\text { a dimensionless variable defined as } \xi=\frac{\pi \mathrm{z}}{\mathrm{L}} \\
& \pi=3.1416 \ldots \\
& \sigma_{\mathrm{m}}=\mathrm{a} \text { known dimensionless scalar quantity (a function of the radial } \\
& \phi \text {. gamma radiation flux, gammas } / \mathrm{cm}^{2}-\mathrm{sec}
\end{aligned}
$$




$$
\begin{gathered}
\phi_{\mathrm{m}}=\begin{array}{l}
\text { a known dimensionless scalar quantity (a function of the thermal } \\
\text { properties and the transform parameter, } \mathrm{n} \text { ) defined in Appendix B }
\end{array} \\
\phi(c)=\text { a dimensionless function defined in Appendix D } \\
\phi^{\prime}(\mathrm{c})=\text { a dimensionless function defined in Appendix D }
\end{gathered}
$$


VIII. REFERENCES

1. B. R. Wheeler, J. A. Buckham, and J. A. McBride, A Comparison of Various Calcination Processes for Processing High-Level Radioactive Wastes, IDO14622 (April 1964).

2. E. Doud and H. W. Stivers, Limitations for Existing Storage Tanks for Radioactive Wastes from Separations Plants, HW-59919 (October 1959).

3. F. R. Bruce, "Waste Treatment and Disposal Problems of the Future Nuclear Power Industry", In Hearings before the Special Subcommittee on Radiation of the Joint: Committee on Atomic Energy, Congress of the United States, Eighty-Sixth Congress, First Session on Industrial Radioactive Waste Disposal, January 28, 29, 30; February 2 and 3, 1959. Vol. 3. Washington, D. C.: Joint Committee on Atumic Energy, 1959, pp 2345-2356.

4. J. O. Blomeke et al, The Costs of Permanent Disposal of Power-Reactor Fuel-Processing Wastes in Tanks, ORNL-2873 (September 1965).

5. L: T. Lakey and J. R. Bower (eds.), ICPP Waste Calcining Facility Safety Analysis Report, IDO-14620 (December 1963).

6. A. M. Platt, The Retention of High Level Radioactive Wastes, HW-49543 A (April 1957).

7. E. Doud, Design of Underground Storage Tanks for Radioactive Wastes, HW -57282 (1959).

8. M. W. Wilding and D. W. Rhodes, Stability Studies of Highly Radioactive Alumina Calcine During High Temperature Storage, IDO-14670 (January 1966).

9. L. D. Baver, Soll Physics, Wiley, New York (1963) p 373-384.

10. H. E. Patten, Heat Transference In Soils, U. S. Department of Agriculture Bureau, Solls Bulletin 59 (1909).

11. J. J. Perona and M. E. Whatley, Calculation of Temperature Rise in Deeply Buried Radioactive Cylinders, ORNL-2812 (February 1960).

12. J. Crowell and F. L. Parker, A Thermal Problem Associated with Underground Storage of Radioactive Wastes, ORNL-3002 (November 1960).

13. R. L. Bradshaw, J. J. Perona, and J. O. Blomeke, Demonstration Disposal of High-Level Radioactive Solids in Lyons, Kansas, Salt Mine: Background and Preliminary Design of Experimental Aspects, ORNL-TM-734 (January 1964).

14. A. M. Platt (ed.), Research and Development Activities. Fixation of Radioactive Rcsidues, Quarterly Progress Report, January - March 1964, HW-81862 (April 1964).

15. L. D. Baver, op cit, p. 373-379.

16. I. N. Sneddon, Fourter Transforms, New York: McGraw-Hill Book Company, Inc., 1951. 
17. C. J. Tranter, Integral Transforms in Mathematical Physics, 2nd ed. New York: John Wiley \& Sons, Inc., 1956.

18. L. Lapidus, Digital Computation for Chemical Engineers, New York: McGraw-Hill Book Company, Inc., 1962, pp 254-257.

19. R. L. Nace et al, Geography, Geology, and Water Resources of the National Reactor Testing Station, Idaho. Part II. Geography and Geology, IDO22033-2USGS (1956).

20. Survey on Fort Peck, Montana and Pocatello, Idaho Sites, for United States Atomic Energy Commission, Prepared by Smith, Hinchman and Grylls, Inc., Detroit, Michigan, Contract No. AT-(49-1)-311 (March 1949).

21. G. A. DeMarrais, The Climatology of the National Reactor Testing Station, rDO-12003 (June 1958).

22. R. L. Nace et al, Geography, Geology and Water Resources of the National Reactor Testing Station, Idaho. Part III. Hydrology and Water Resources, IDO-22034-3-USGS (1959).

23. U. S. Department of the Interior, Geological Survey, Hydrology of Waste Disposal, National Reactor Testing Station, Idaho, Annual Progress Report, 1962, IDO-22044-USGS (April 1963).

24. W. O. Smith, Mechanism of Gravity Drainage and its Relation to Specific Yield of Uniform Sands, Geological Survey Professional Paper 402-A (1961).

25. J. W. Rizika and W. M. Rohsenow, "Thermocouple Thermal Error", Ind. Eng. Chem., 44 (May 1952) pp 1168-1171.

26. W. J. Parker et al, "Flash Method of Determining Thermal Diffusivity, Heat Capacity, and Thermal Conductivity", J. Appl. Phys., 32 (September 1961) pp 1679-1684.

27. D. R. Stephens, High-Temperature Thermal Conductivity of Six Rocks, UCRL7605 (November 1963).

28. ASTM, "Standard Method of Test for Thermal Conductivity of Refractories", Designation: C201-47 (1958), in American Society for Testing and Materials, 1966 Book of ASTM Standards, Part 13, Philadelphia: ASTM, 1966. pp 174-181.

29. H. H. Lettan and B, Davidson (eds.), Exploring the Atmosphere's First Mile. Vol. I. Instrumentation and Data Evaluation: Proceedings of the Great Plains Turbulence Field Program. 1 August to 8 September 1953, O'Neill, Nebraska, New Ynrk: Pergamon Press, 1957.

30. R. G. Morris et al, "Magnetic Field Dependence of Thermal Conductivity Measured by a Corbino-Disk Method", a paper presented at the Fifth Thermal Conductivity Conference, Denver, Colorado (October 1965).

31. T. C. Grimm and K. R. Kreder, "High Temperature Guarded Hot Plate", a paper presented at the Fifth Thermal Conductivity Conference, Denver, Colorado (October 1965). 
32. A. E. Wechsler and M. A. Kritz, "Laboratory and Fleld Measurements of the Thermal Conductivity of Soils Using the Probe Method", a paper presentcd at the Fifth Conference on Thermal Conductivity, Denver, Colorado (October 1965).

33. A. E. Wechsler and M. A. Kritz, "Development and Use of Thermal Conductivity Probes for Soils and Insulations", a paper presented at the Fifth Conference on Thermal Conductivity, Denver, Colorado (October 1965).

34. J. C. Jaeger, "Conduction of Heat in an Infinite Region Bounded Internally by a Circular Cylinder of a Perfect Conductor", Austral. J. Phys., 9 n 2 (June 1956) pp 167-179.

35. J. H. Blackwell, "A Transient-Flow Method for Determination of Thermal Constants of Insulating Materials in Bulk", I. Appl. Phys., 25 (February 1954) pp 137-144.

36. J. H. Blackwell, "The Axial-Flow Error in the Thermal-Conductivity Probe", Canad. J. Phys., 34 n 4 (April 1956) pp 412-417.

37. D. A. deVries and A. J. Peck, "On the Cylindrical Probe Method of Measuring Thermal Conductivity with Special Reference to Solls. I. Extension of Theory and Discussion of Probe Characteristics", Austral. J. Phys., 11 n 2 (June 1958) pp 255-271.

38. A. E. Wechsler and P. E. Glaser, Thermal Conductivity of Non-Metallic Materials, summary report prepared by Arthur D. Little, Inc., for NASA George C. Marshall Space Flight Center under contract No. NASA-1567 (1964),

39. ASTM, "Standard Method of Test for Mean Specific Heat of Thermal Insulaling Materials", Designation: C351-61, in American Society for Testing Materials, 1966 Book of ASTM Standards.

40. D. B. Hawkins and D. C. Foster, A Comparison of 'Two Methods of Sampling Gravel for the Evaluation of a Ground-Disposal Site for Radioactive Liquid Waste, IDO-12027 (March 1963).

41. U. S. Department of the Interior, Geological Survey, Hydrology of Waste Disposal, National Reactor Testing Station, Idaho, Annual Progress Report, 1962, IDO-22044-USGS (April 1963).

42. B. Mason, Principles of Geochemistry, 2nd ed. New York: John Wiley \& Sons, Inc., 1958.

43. S. Glasstone and A. Sesonke, Nuclear Reactor Engineering, Princeton, N. J., D. Van Nostrand Company, Inc., 1963.

44. T. Rockwell III, Reactor Shielding Design Manual, Princeton, N. J., D. Van Nostrand Company, Inc., 1956.

45. S. Glasstone, op cit, p 54 . 


\section{APPENDIX A \\ JUSTIFICATION FOR NEGLECTING \\ HEAT GENERATION IN THE SOIL DUE TO \\ GAMMA RADIATION ESCAPING FROM THE HEAT SOURCE}


THIS PAGE

\section{WAS INTENTIONALLY LEFT BLANK}




\section{APPENDIX A-- \\ JUSTIFICATION FOR NEGLECTING \\ HEAT GENERATION IN THE SOIL DUE TO \\ GAMMA RADIATION ESCAPING FROM THE HEAT SOURCE}

Due to the high absorption of beta radiation per unit thickness of most materials, essentially all of the beta radiation generated within the container will be absorbed. The same, however, is not true for gamma radiation since a portion of the gamma radiation generated near the container wall escapes into the surrounding medium.

The gamma flux at any distance " $x$ " from a point source is given by Reference 44 as follows:

$$
\phi=\phi_{0} \frac{\mathrm{BS}_{\mathrm{V}} \mathrm{e}^{-\mu \mathrm{x}}}{4 \pi \mathrm{x}^{2}}
$$

where

$$
\begin{aligned}
\phi & =\text { gamma flux at point } \mathrm{x}, \text { gamma } / \mathrm{cm}^{2}-\mathrm{sec} \\
\phi_{0} & =\text { gamma flux at } \mathrm{x}=0, \text { gamma } / \mathrm{cm}^{2}-\mathrm{sec} \\
\mathrm{B} & =\text { symbolic buildup factor } \\
\mathrm{S}_{\mathrm{V}} & =\text { source strength }=1.0 \\
\mu \mathrm{x} & =\text { relaxation length, } \mathrm{cm}^{-1} \\
\pi & =3.141 \ldots \\
\mathrm{x} & =\text { distance from point source, } \mathrm{cm} .
\end{aligned}
$$

To determine the relative effect of the escaping gamma radiation, assume that a series of point sources of equal strength are arranged in a straight line along the radius of a cylinder with each source separated from its nearest neighhnrs by une "relaxation length" $\left(\mu \times x_{)}\right.$. The terms $B$ and $x^{2}$ may be removed from the equation since they depend only on the distances from the source and, therefore, have the same relative contribution to the flux for each of the various sources in the line. The $S_{\mathrm{V}}$ and $4 \pi$ terms may also be deleted since their contribution is identically the same for all sources. The pseudo or relative gamma flux around a single point source of unit strength may thus be defined as

$$
\phi=\phi_{0} e^{-\mu x}
$$

The pseudo gamma flux distribution obtained from Equation (A-2) for any individual point source is shown in Figure A-1. If similar distribution curves are drawn for each of the sources and then added, the cumulative flux distribution will be as shown in Figure A-2. 


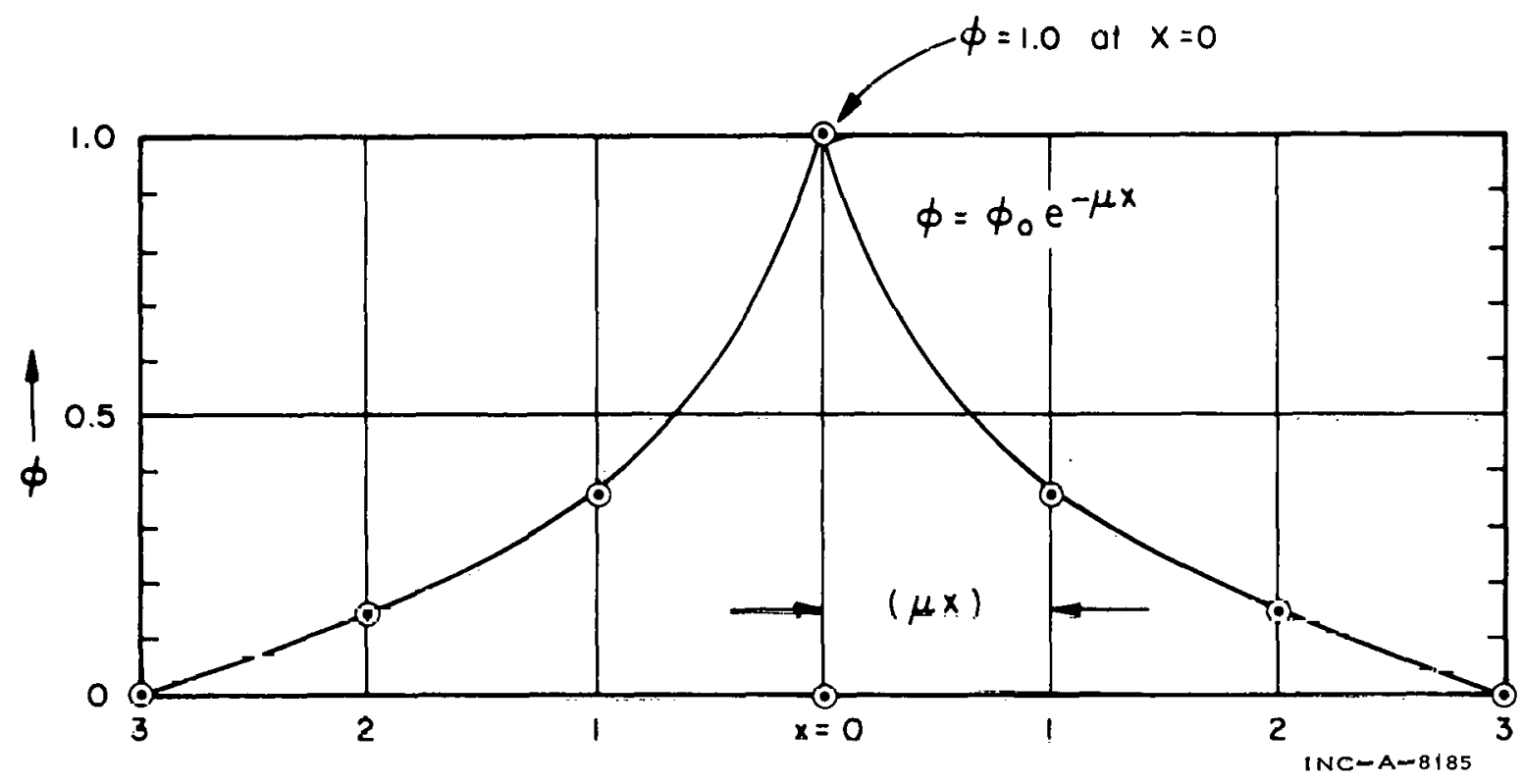

Fig. A-1 Relative flux distribution around a point source.

As shown in Figure A-2, all of the gamma radiation generated from the container center line to within two relaxation lengths (several inches for most solid wastes) of the container wall is absorbed within the container. Depending on the distance from the wall, from 0 to 25 percent of the gamma radiation generated within two relaxation lengths of the container wall escapes into the material surrounding the solids. Some of the escaping gamma radiation is stopped in the soil within one to two inches of the wall, depending on the energy of the radiation [45]. For a container one relaxation length in diameter, or 4 inches for common wastes, approximately 10 percent of the total gamma radiation escapes into the surrounding medium. For a conlalner len relaxation lengtho in diameter (or 40 inches), less than two percent of the gamma radiation excapes. Because the gamma radiation is normally responstble fur less than one-half the total heat generated in radioactive wastes, less than 5 percent of the total heat escapes, even for the case of a 4-inch-diameter container.

Based on the preceding discussion, the effect of the escaping gamma radiation is negligible for all but containers less than several inches in diametcr. Because the actual temperature distribution in small-diameter sources is slightly lower than that calculated by neglecting the escaping gamma radiation, an inherent safety tactor is provided. 


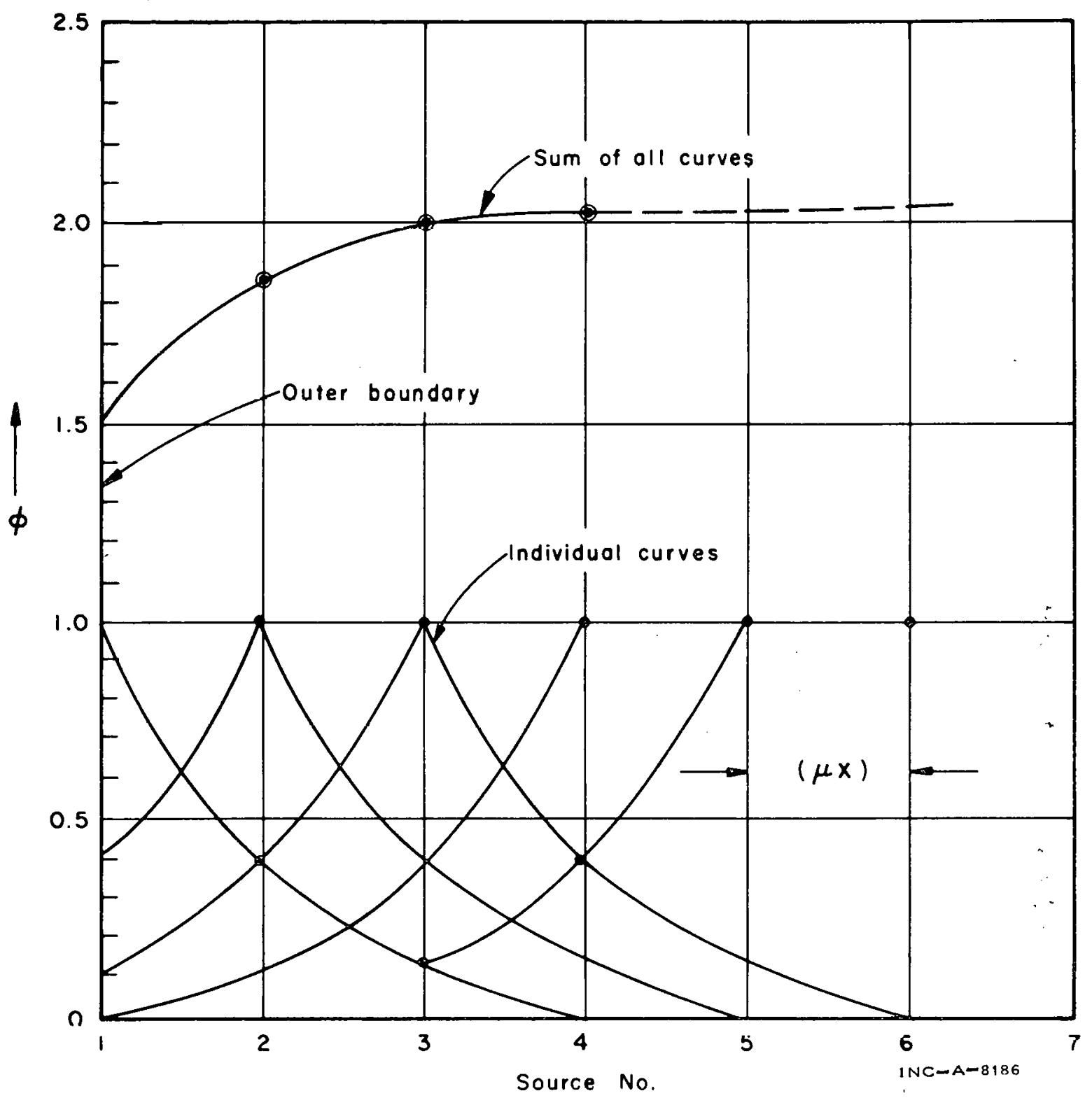

Fig. A-2 Cumulative flux distribution around a line of sources. 
THIS PAGE

\section{WAS INTENTIONALLY LEFT BLANK}


APPENDIX B

DERIVATION OF THE NUMERICAL SOLUTION FOR THE TRANSIENT TEMPERATURE DISTRIBUTION SURROUNDING SMALL- AND LARGE-DIAMETER HEAT SOURCES 
THIS PAGE

\section{WAS INTENTIONALLY LEFT BLANK}




\section{APPENDIX B -- \\ DERIVATION OF THE NUMERICAL SOLUTION \\ FOR THE TRANSIENT TEMPERATURE DISTRIBUTION \\ SURROUNDING SMALL- AND LARGE-DIAMETER HEAT SOURCES}

The boundary value problem for the transient temperature distribution in the medium surrounding a buried fuel element is given by

$$
\begin{aligned}
\frac{\partial^{2} T}{\partial r^{2}}+\frac{1}{r} \frac{\partial T}{\partial r}+\frac{\partial^{2} T}{\partial z^{2}} & =\frac{1}{\alpha} \frac{\partial T}{\partial t} \text { for } r \geq a \\
T\left(r, z, 0^{+}\right) & =T_{s} \\
-k_{S} \frac{\partial T}{\partial r}(a, z, t) & =q(a, z, t), d<z<D \\
& =0 \text { el el ewhere } \\
\operatorname{Lim}_{r \rightarrow \infty} T(r, z, t) & =T_{s} \\
\operatorname{Lim} T(r, z, t) & =T_{s} \\
z \rightarrow \infty & =T_{s}
\end{aligned}
$$

where

$$
\mathrm{T}_{\mathbf{S}}=\text { initial average temperature of the soil }
$$

$q(a, z, t)=a$ specified heat flux.

As indicated in the main text, use of the Fourier sine transform normally requires the evaluation of a complicated inversion integral. A finite sine transform may be used instead if a finite distance, $\mathrm{L}$, much greater than the burial depth, is specifled as the lower boundary below the heat source in the " $\mathrm{z}$ " direction. Inversion of the finite sine transformation is much simpler than the corresponding operation for the infinite Fourier sine transform. This technique is valid if it can be demonstrated that a unique solution for the temperature can be found.

It is convenient at this point to make a change of dependent and independent variables before application of the sine transformation. Let $u=T-T_{S}$ and $\xi=(\pi \mathrm{z} / \mathrm{L})$. Finite sine transformation of Equations $(B-1)$ through $(B-1 e)$ yields the following transformed boundary value problem:

$$
\begin{aligned}
\left(\frac{\partial^{2} \bar{u}}{\partial r^{2}}\right)+\frac{1}{r} \frac{\partial \bar{u}}{\partial r}-\left(\frac{n \pi}{L}\right)^{2} \bar{u} & =\frac{1}{\alpha} \frac{\partial \bar{u}}{\partial t} \\
\bar{u}\left(r, n, 0^{+}\right) & =0 \\
\operatorname{Lim}_{\bar{u}} \bar{u}(r, n, t) & =0 \\
r \rightarrow \infty & \\
-k_{\varepsilon} \frac{\partial \bar{u}}{\partial r}(a, n, t) & =\bar{q}(a, n, t) \\
& =0 \text { elsewhere. }
\end{aligned}
$$


The problem has now been reduced to a partial differential equation in terms of the parameter, $n$, and the independent variables, $r$ and $t$ (the boundary conditions at the values, $\xi=0$ and $\xi=\pi$, have been used in the sine transformation). If the heat flux is time dependent, the sine transformation,

$$
\int_{0}^{\pi} q(a, \xi, t) \sin n \xi d \xi
$$

will require numerical evaluation.

Normally, solution of the boundary value problem given by Equation (B-2) through $(\mathrm{B}-2 \mathrm{C})$ can be obtained formally by the application of the Hankel transformation. Inversion of the Hankel transforms, however, requires numerical evaluation of complicated integrals and is not applicable in this case since the thermal properties of the system are temperature dependent. Thus, the problem must be solved by finite difference methods.

For simplicity, consider the flux as independent of time (simulating a long-term cooled waste) and a function of $z$ only. Since the temperature gradients near a small-diameter, buried, nuclear heat source can be quite large, the approximation of the boundary value problem, Equations (B-2) through $(\mathrm{B}-2 \mathrm{C})$, by finite differences requires small radial increments at points relatively close to the heat source. Increased accuracy is thus obtained at the expense of increased computation time. Since the size of these increments can increase as the distance from the source increases without affecting the accuracy of the calculated temperature, a suitable approximation will result if an algorithm is employed which uses a variable distance increment in the radial direction. The fintte difference representation of Equation (B-2) having equal truncation errors in the spatial derivatives is

$$
\begin{aligned}
& \frac{\bar{u}_{m+1, t}+\Delta t,-(c+1) \bar{u}_{m, t+\Delta t}+c \bar{u}_{m-1, t+\Delta t}}{\left(\frac{c^{2 m-2}+c^{2 m-3}}{2}\right) s_{1}^{2}} \\
& +\frac{1}{\left[a+\Delta r_{1} \sum_{j=0}^{m-2} c^{j}\right]} \frac{\left[2 \bar{u}_{m+1, t+\Delta t}-2\left(1-c^{2}\right) \bar{u}_{m, t+\Delta t}-2 c^{2} \bar{u}_{m-1, t+\Delta t}\right]}{2 c^{m-1},(c+1) \Delta r_{1}} \\
& -\left(\frac{n \pi}{L}\right)^{2} \bar{u}_{m, t+\Delta t}=\frac{1}{\alpha} \frac{\left[\bar{u}_{m, t+\Delta t}-\bar{u}_{m, t}\right]}{\Delta t}
\end{aligned}
$$

for

$$
m=2,3 \ldots M M-1
$$


where $c$ is $\Delta r_{m+1} / \Delta r_{m}$ and is derived in Appendix $D$ and where $m$ denotes a nodal point in the radial direction. The finite difference approximation of the boundary condition $(\mathrm{B}-2 \mathrm{C})$ is given by

$$
\frac{-k_{s}\left[\bar{u}_{1, t+\Delta t}-\bar{u}_{-1, t+\Delta t}\right]}{2 \Delta r_{1}}=\bar{q}(a, n)
$$

where $\bar{q}(a, n)$ is the finite sine transform of the function $q(a, \xi)$ and $\bar{u}-1, t+\Delta t$ is an imaginary nodal point in the region $r<$ a. Derivation of the finite difference expressions for the spatial derivatives using a variable distance increment is given in Appendix D.

Rearrangement of Equation (B-4) and the definition of new quantities result in the following equation at a nodal point:

$$
\theta_{m} \bar{u}_{m-1, t+\Delta t}-\phi_{m} \bar{u}_{m, t+\Delta t}+\sigma_{m} \bar{u}_{m+1, t+\Delta t}=-\beta_{m} \bar{u}_{m, t}
$$

for

$$
m=2,3 \ldots M-2
$$

where

$$
\begin{aligned}
& \theta_{m}=\left\{\frac{4 c^{m}(c+1)\left[a+\Delta r_{1} \sum_{j=0}^{m-2} c^{j}\right]-2\left(c^{2 m}+c^{2 m-1}\right) \Delta r}{1}\right\} \\
& \phi_{m}=\left\{\frac{4(c+1)^{2} c^{m-1}\left[a+\Delta r_{1} \sum_{j=0}^{m-2} c^{j}\right]+2\left(1-c^{2}\right)\left(c^{2 m-2}+c^{2 m-3}\right) \Delta r_{1}}{4 c^{m-1}(c+1)\left[a+\Delta r_{1} \sum_{j=0}^{m-2} c^{j}\right]}\right\} \\
& +\left\{\left(\frac{n \pi}{L}\right)^{2}\left(\frac{c^{2 m-2}+c^{2 m-3}}{2}\right)\left(\Delta r_{1}\right)^{2}+\beta_{m}\right\} \\
& \sigma_{m}=\left\{\frac{4 c^{m-1}(c+1)\left[a+\Delta r_{1} \sum_{j=0}^{m-2} c^{j}\right]+2\left(c^{2 m-2}+c^{2 m-3}\right) \Delta r_{1}}{4 c^{m-1}(c+1)\left[a+\Delta r_{1} \sum_{j=0}^{m-2} c^{j}\right]}\right\}
\end{aligned}
$$


and

$$
\beta_{m}=\left[\frac{c^{2 m-2}+c^{2 m-3}}{2 \Delta t}\right]\left(\Delta r_{1}\right)^{2}
$$

For the case of a constant flux at the boundary, $r=a$, Equation (B-5) reduces to

$$
-k_{s} \cdot \frac{\left[\bar{u}_{1, t+\Delta t}-\bar{u}_{-1, t+\Delta t}\right]}{2 \Delta r_{1}}=\frac{q}{n} \cdot[\cos n \pi d / L-\cos n \pi D / L] \cdot(B-7)
$$

Rearrangement and simplification of Equation (B-7) in terms: of previously defined quantities yield

$$
-\phi_{1} \bar{u}_{1, t+\Delta t}+2 \vec{u}_{2, t+\Delta t}=-\varepsilon_{1} \bar{u}_{1, t}-Q(n)
$$

where

$$
\begin{aligned}
\beta_{1} & =\left(\Delta r_{1}\right)^{2} / \alpha \Delta t \\
Q(n) & =-\left(\frac{q \Delta r_{1}[\cos n \pi d / L-\cos n \pi D / L]\left[2 a-\Delta r_{I}\right]}{n a k_{s}}\right) .
\end{aligned}
$$

Coupling of Equations (B-6) and (B-8) results in the following system of equations which must be solved at each time step for each " $n$ ":

$$
\begin{aligned}
-\phi_{1} \bar{u}_{1}+2 \bar{u}_{2} & =-\beta_{1} \bar{u}_{1, t}-Q(n) \\
\dot{\theta}_{m} \bar{u}_{m-1, t+\Delta t}-\phi_{m} \bar{u}_{m, t+\Delta t}+\sigma_{m} \bar{u}_{i n+1, t+\Delta t} & =-\beta_{I I 1} \bar{u}_{m, t} \\
\theta_{M-1} \bar{u}_{M-2, t+\Delta t}-\phi_{M-1} \bar{u}_{M-1, t+\Delta t} & =-\beta_{M-1 .} \bar{u}_{M-1, t .} .
\end{aligned}
$$

Expression of the system of Equations (B-9) in matrix notation yields

$$
A \bar{U}=\bar{D}
$$

where

$$
A=\left[\begin{array}{cccccc}
-\phi_{1} & 2 & 0 & 0 & \cdot & \cdot \\
\theta_{2} & -\phi_{2} & \sigma_{2} & 0 & \cdot & \cdot \\
\cdot & \cdot & \cdot & \cdot & \cdot & \cdot \\
0 & 0 & \theta_{M-2} & \phi_{M-2} & \cdot & \sigma_{M-2} \\
\cdot & \cdot & \cdot & \theta_{M-1} & \cdot & \phi_{M-1}
\end{array}\right]
$$




$$
\bar{u}=\left[\begin{array}{c}
\bar{u}_{1, t+\Delta t} \\
\bar{u}_{2, t+\Delta t} \\
\cdot \\
\cdot \\
\bar{u}_{M-1, t \Delta t}
\end{array}\right] \quad \bar{D}=\left[\begin{array}{cc}
-\beta_{1} \bar{u}_{1, t}-Q(n) \\
-\beta_{2} \bar{u}_{2, t} \\
\cdot \\
\cdot \\
-\beta_{M-1, t} & \bar{u}_{M-1, t}
\end{array}\right] \cdot
$$

A Gaussian elimination procedure described by Thomas [18] can be used to solve this system of equations. Beginning with Equation (B-9),

$$
\begin{aligned}
& \mathrm{w}_{1}=-\phi_{1} \\
& \mathrm{w}_{\mathrm{m}}=-\phi_{\mathrm{m}}-\theta_{\mathrm{m}} \mathrm{q}_{\mathrm{m}-1}
\end{aligned}
$$

where

$$
\begin{aligned}
& q_{1}=2 / w_{1} \quad g_{1}=\frac{\beta_{1} \vec{u}_{1, t}-Q(n)}{w_{1}} \\
& \text { and } \\
& q_{m}=\frac{\sigma_{m}}{w_{m}} \\
& g_{m}=\frac{\beta_{m} \bar{u}_{m, t}-\theta_{m} g_{m-1}}{w_{m}} \\
& m=2,3 \ldots \ldots . M-1 .
\end{aligned}
$$

The unknowns, $\bar{u}_{m}, t+\Delta t$, are then calculated by a feedback through the matrix, yielding equations of the form,

$$
\begin{aligned}
\bar{u}_{M-1} & =g_{M-1} \\
\bar{u}_{m} & =g_{m 1}-q_{m} \bar{u}_{m+1} ; m=2,3 \ldots M-2 .
\end{aligned}
$$

The boundary value problem for the transient temperature distribution in a cylindrical bin of solidified waste and the surrounding soil is given by the following equations:

For the bin,

$$
\begin{aligned}
& \frac{\partial^{2} \mathrm{~T}_{1}}{\partial \mathrm{r}^{2}}+\frac{1}{\mathrm{r}} \frac{\partial \mathrm{T}_{1}}{\partial \mathrm{r}}+\frac{\partial^{2} \mathrm{~T}_{1}}{\partial \mathrm{z}^{2}}+\frac{\mathrm{q}^{\prime \prime}}{\mathrm{k}_{\mathrm{C}}}=\frac{1}{\alpha_{1}} \frac{\partial \mathrm{T}_{1}}{\partial t} \\
& \quad\left(\text { for } \mathrm{r}<\mathrm{R}_{\mathrm{B}} \text { and } \mathrm{d}<\mathrm{z}<\mathrm{D}\right) .
\end{aligned}
$$


For the soil,

$$
\frac{\partial^{2} \mathrm{~T}_{2}}{\partial r^{2}}+\frac{1}{r} \frac{\partial \mathrm{T}_{2}}{\partial r}+\frac{\partial^{2} \mathrm{~T}_{2}}{\partial z^{2}}=\frac{1}{\alpha_{2}} \frac{\partial \mathrm{T}_{2}}{\partial t}
$$

and the boundary conditions

$$
\begin{aligned}
T_{1}\left(r, z, 0^{+}\right) & =T_{2}\left(r, z, 0^{+}\right)=T_{S} \\
T_{1}(o, z, t) & =\text { Finite } \\
k_{c} \frac{\partial T_{I}}{\partial r}\left(R_{B}, z, t\right) & =k_{S} \frac{\partial T_{2}}{\partial r}\left(R_{B}, z, t\right) \\
T_{1}\left(R_{B}, z, t\right) & =T_{2}\left(R_{B}, z, t\right) \\
T_{1}(r, o, t) & =T_{2}(r, 0, t)=T_{S} \\
\operatorname{Lim}_{z \rightarrow \infty} T_{1}(r, z, t) & =T_{2}(r, z, t)=T_{S} \\
\operatorname{Lim}_{r \rightarrow \infty} T_{2}(r, z, t) & =T_{S} .
\end{aligned}
$$

The solution of the boundary value problem stated in Equations (B-13) through (B-13h) can be obtained in a manner analogous to that for a buried fuel element. A finite sine transformation is applicable if a distance, $\mathrm{L}$, much greater than the burial depth is specified as the boundary in the " $Z$ " direction. Use of the finite sine transform has the advantage of a simple inversion formula.

Before the finite sine transformation is applied to the boundary value problem, it is convenient to make a change of dependent and independent variables. Let $u=T-T_{S}$ and $\xi=\frac{\pi Z}{L}$. Finite sine transformation of the problem in terms of the new variables results in the following system of equations:

$$
\begin{aligned}
\frac{\partial^{2} \bar{u}_{1}}{\partial r^{2}}+\frac{1}{r} \frac{\partial \bar{u}_{1}}{\partial r}-\left(\frac{n \pi}{L}\right)^{2} \bar{u}_{1}+Q_{m}(n) & =\frac{1}{\alpha_{1}} \frac{\partial \bar{u}_{1}}{\partial t} \\
\left(\text { for } r<R_{B}\right) & \\
\frac{\partial^{2} \bar{u}_{2}}{\partial r^{2}}+\frac{1}{r} \frac{\partial \bar{u}_{2}}{\partial r}-\left(\frac{n \pi}{L}\right)^{2} \bar{u}_{2} & =\frac{1}{\alpha_{2}} \frac{\partial \bar{u}_{2}}{\partial t} \\
\bar{u}_{1}\left(r, n, 0^{+}\right) & =\bar{u}_{2}\left(r, n, o^{+}\right)=0 \\
\bar{u}_{1}(0, n, t) & =\text { Finite }
\end{aligned}
$$




$$
\begin{aligned}
k_{c} & \frac{\partial \bar{u}_{1}}{\partial r}(r, n, t)=k_{s} \frac{\partial \bar{u}_{2}}{\partial r}(r, n, t) \\
\bar{u}_{1}\left(R_{B}, n, t\right) & =\bar{u}_{2}\left(R_{B}, n, t\right) \\
\operatorname{Lim}_{r \rightarrow \infty} \bar{u}_{2}(r, n, t) & =0 .
\end{aligned}
$$

Finite difference approximation of Equation (B-14) at any general nodal point " $\mathrm{m}$ " yields the following equation:

$$
\begin{aligned}
& \frac{\bar{u}_{m+1, t}-(c+1) \bar{u}_{m, t}+c \bar{u}_{m-1, t}}{\left(\frac{c^{2 m-2}+c^{2 m-3}}{2}\right)\left(\Delta r_{1}\right)^{2}}-\left(\frac{n \pi}{L}\right)^{2} \bar{u}_{m, t}+\frac{1}{\left(\Delta r_{1} \sum_{j=1}^{M-1} c^{j-1}\right)} \\
& \frac{\left[2 \bar{u}_{M+1, t}-2\left(1-c^{2}\right) \bar{u}_{m, t}-2 c^{2} \bar{u}_{M-1, t}\right]}{2 c^{M-1}(c+1) \Delta r_{1}}=\frac{1}{\alpha_{1}} \frac{\left[\bar{u}_{m, t}-\bar{u}_{m, t-\Delta t}\right]}{\Delta t}-Q_{m}(n) \\
& (m=2,3, \ldots M l-2) .
\end{aligned}
$$

At the point $r=0$, the differential equation assumes an indeterminate form which can be removed by application of L'Hopital's rule as follows:

$$
\operatorname{Lim}_{r \rightarrow \infty}\left(\frac{1}{r} \frac{\partial \bar{u}}{\partial r}\right)=\frac{\partial^{2} \bar{u}}{\partial r^{2}}
$$

The transformed partial differential equation at the point $r=0$ then becomes

$$
\frac{2 \partial^{2} \bar{u}_{1}}{\partial r^{2}}-\left(\frac{n \pi}{L}\right)^{2} \bar{u}_{1}+Q_{1}(n)=\frac{1}{\alpha_{1}} \frac{\partial \bar{u}_{1}}{\partial t} \text {. }
$$

Finite differencing this equation yields the following:

$\frac{2\left[\vec{u}_{2, t}-2 \bar{u}_{1, t}+u_{-1, t}\right]}{\left(\Delta r_{1}\right)^{2}}-\left(\frac{n \pi}{L}\right)^{2} \bar{u}_{1, t}+Q_{1}(n)=\frac{1}{\alpha_{1}} \frac{\left[\bar{u}_{1, t}-\bar{u}_{1, t-\Delta t}\right]}{\Delta t}$. 
Continuity of the heat flux and temperature at the boundary between the source and the soil is expressed by the following finite difference equation:

$$
k_{c} \frac{\left[\bar{u}_{M I, t}-\bar{u}_{M I-1, t}\right]}{\Delta r_{1} c^{M I-2}}=k_{s} \frac{\left[\bar{u}_{M I+1, t}-\bar{u}_{M I, t}\right]}{\Delta r_{1} c^{M I-1}} .
$$
$\overline{\mathrm{u}}_{\mathrm{M} 1, \mathrm{t} \text { : }}$

Rearrangement of Equation $(B-19)$ results in the simplified expression for

$$
\bar{u}_{M 1, t}=K_{s} \bar{u}_{M I+1, t}+c K_{c} \bar{u}_{M I-1, t}
$$

where

$$
\begin{aligned}
& \mathrm{K}_{\mathrm{s}} \triangleq \mathrm{k}_{\mathrm{s}} /\left(\mathrm{c \textrm {k } _ { \mathrm { c } }}+\mathrm{k}_{\mathrm{s}}\right) \\
& \mathrm{K}_{\mathrm{c}} \triangleq \mathrm{k}_{\mathrm{c}} /\left(\mathrm{c} \mathrm{k}_{\mathrm{c}}+\mathrm{k}_{\mathrm{s}}\right) .
\end{aligned}
$$

Equations $(B-15)$ and $(B-18)$ can be simplified by rearrangement and the definition of new quantities; thus, at any nodal point " $\mathrm{m}$ ",

$$
\theta_{m} \bar{u}_{m-1, t}-\phi_{m} \bar{u}_{m, t}+\sigma_{m} \bar{u}_{m+l, t}=-Q_{m}(n)-\beta_{m} \bar{u}_{m, t-\Delta t}
$$

And for the point $m=1$,

$$
-\phi_{1} \bar{u}_{1, t}+4 \bar{u}_{z, t}==R_{1} \bar{n}_{\perp, l-\Delta L}-Q_{1}(n)
$$

where

$$
\begin{aligned}
Q_{m}(n) & =\frac{q^{n}}{k_{e}^{n}}\left[\cos \left(\frac{n \pi d}{L}\right)-\cos \left(\frac{n \pi D}{L}\right)\right]\left(\frac{c^{2 m-2}+c^{2 m-3}}{2}\right)\left(\Delta r_{1}\right)^{2} ;(m<M I) \\
& =0 \text { elsewhere } \\
\phi_{1} & =4+B_{1}+\left(\frac{n \pi \Delta r_{1}}{L}\right)^{2} \\
\phi_{m, n} & =\frac{4(c+1)^{2} c^{m-1} \sum_{j=1}^{M-1} c^{j-1}+2\left(1-c^{2}\right)\left(c^{2 M-2}+c^{2 M-3}\right) .}{4 c^{m-1}(c+1) \sum_{j=1}^{M-1} c^{j-1}}
\end{aligned}
$$




$$
\begin{aligned}
& +\beta_{m}+\left(\frac{n \pi \Delta r_{1}}{L}\right)^{2}\left(\frac{c^{2 m-2}+c^{2 m-3}}{2}\right) \\
& 4 c^{m-1}(c+1) \sum_{j=1}^{M-1} c^{j-1}+2\left(c^{2 m-2}+c^{2 m-3}\right) \\
& \theta_{m}=\frac{j=1}{4 c^{m-1}(c+1) \sum_{j=1}^{M-1} c^{j-1}} \\
& \beta_{m}=\frac{\rho c_{p}\left(\Delta r_{I}\right)^{2}}{k \Delta t}\left(\frac{c^{2 m-2}+c^{2 m-3}}{2}\right) \\
& B_{1}=\frac{\rho c_{p}\left(\Delta r_{I}\right)^{2}}{k \Delta t} \\
& \text { (for } m=2,3, \ldots M l-2 \text {, and } m=M l+2, M l=3, \ldots M-2 \text { ) . }
\end{aligned}
$$

Substitution of Equation (B-20) into Equation (B-15) evaluated at the point M1-1 yields the following equation:

$$
\theta_{\mathrm{Ml}-1} \bar{u}_{\mathrm{Ml}-2, t}-\bar{\phi}_{\mathrm{MI}-1} \overline{\mathrm{u}}_{\mathrm{Ml}-1, t}+\bar{\sigma}_{\mathrm{Ml}-1} \overline{\mathrm{u}}_{\mathrm{MI}+1, t}=-\beta_{\mathrm{Ml}-1} \overline{\mathrm{u}}_{\mathrm{Ml}-1, t}-\mathrm{Q}_{\mathrm{Ml}-1}(\mathrm{n})
$$

where

$$
\begin{aligned}
\bar{\phi}_{\mathrm{Ml}-1} & =\phi_{\mathrm{Ml}-1}-\sigma_{\mathrm{Ml}-1} \mathrm{cK}_{\mathrm{c}} \\
\sigma_{\mathrm{Ml}-1} & =\sigma_{\mathrm{Ml}-1} \mathrm{~K}_{\mathrm{S}} .
\end{aligned}
$$

Use of Equations $(B-15)$ and $(B-20)$ at the point $M 1+1$ results in the following finite difference equation:

$$
\bar{\theta}_{\mathrm{Ml}+1} \bar{u}_{\mathrm{Ml}-1, t}-\bar{\phi}_{\mathrm{Ml}+1} \bar{u}_{\mathrm{Ml}+1, t}+\sigma_{\mathrm{Ml}+1} \bar{u}_{\mathrm{Ml}+2, \mathrm{t}}=-\beta_{\mathrm{Ml}+1} \bar{u}_{\mathrm{Ml}+1, t-\Delta \mathrm{t}}
$$

where

$$
\begin{aligned}
& \bar{\theta}_{\mathrm{Ml}+1}=\theta_{\mathrm{Ml}+1} \mathrm{cK}_{\mathrm{c}} \\
& \phi_{\mathrm{Ml}+1}=\phi_{\mathrm{Ml}+1}-\theta_{\mathrm{Ml}+1} \mathrm{~K}_{\varepsilon} .
\end{aligned}
$$

Combining Equations (B-21), (B-21a), (B-22), and (B-23) gives a system of finite difference equations which can be solved for the unknown transformed temperature at each time step.

$$
-\phi_{1} \bar{u}_{1, t}+4 \bar{u}_{2, t}=-Q_{1}(n)-\beta_{1} \bar{u}_{1, t-\Delta t}
$$




$$
\begin{aligned}
& \theta_{m} \bar{u}_{m-1, t}-\phi_{m} \bar{u}_{m, t}+\sigma_{m} \bar{u}_{m+1, t}=-Q_{m}(n)-\beta_{m} \bar{u}_{m, t-\Delta t} \\
& \text { (for } m=2,3, \ldots M l-2 \text { ) } \\
& \theta_{M I-1} \bar{u}_{M 1-2, t}-\bar{\phi}_{M I-1} \bar{u}_{M I-1, t}+\bar{\sigma}_{M 1-1} \bar{u}_{M I+1, t}=-Q_{M I-1}(n)-\beta_{M 1-1} \bar{u}_{M I-1, t-\Delta t} \\
& \theta_{\mathrm{Ml}+1} \overline{\mathrm{u}}_{\mathrm{Ml}-1, \mathrm{t}}-\bar{\phi}_{\mathrm{Ml}+1} \overline{\mathrm{u}}_{\mathrm{Ml}+1, \mathrm{t}}+-_{\mathrm{Ml}+2} \overline{\mathrm{u}}_{\mathrm{Ml}+2, \mathrm{t}}=-\mathrm{q}_{\mathrm{Ml}+1} \bar{u}_{\mathrm{Ml}+1, \mathrm{t}-\Delta \mathrm{t}} \\
& \theta_{m} \bar{u}_{m-1, t}-\phi_{m} \bar{u}_{m, t}+\sigma_{m} \bar{u}_{m+1, t}=-\beta_{m} \bar{u}_{m, t-\Delta t} \\
& \text { ( for } m=M I+2, M l+3, \ldots M-1) \\
& \theta_{M-1} \bar{u}_{M-2, t}-\phi_{M-1} \bar{u}_{M-1, t}=-\beta_{M-1} \bar{u}_{M-1, t-\Delta t} \quad \cdot(B-24)
\end{aligned}
$$

A Gaussian elimination procedure described by Thomas [18] is the most convenient method of solving the above system of equations on a digital computer. 


\section{APPENDIX C}

PROPERTIES OF THE FINITE SINE TRANSFORM 
THIS PAGE

\section{WAS INTENTIONALLY LEFT BLANK}




\section{APPENDIX C-- \\ PROPERTIES OF THE FINITE SINE TRANSFORM}

The finite Fourier sine transform of a variable in the range $0<x<L$ is defined as follows:

$$
f(n)=\int_{0}^{L} f(x) \sin \left(\frac{n \pi x}{L}\right) d x
$$

where $\mathrm{n}$ is an integer. This transform can be used to eliminate a variable for which

(1) The range of the variable is closed

(2) Only derivatives of even orders need be transformed

(3) The value of the function is spectfied at each end of the range.

Application of the finite sine transform to the term, $\partial^{2} \mathrm{f} / \partial \mathrm{x}^{2}$, in a partial differential equation results in the following expression:

$$
\int_{0}^{L} \frac{\partial^{2} f}{\partial x^{2}}(x) \sin \left(\frac{n \pi x}{L}\right)=\frac{n \pi}{L}\left[f(0)-(-I)^{n} f(L)\right]-\left(\frac{n \pi}{L}\right)^{2} \cdot f(n) \cdot(C-2)
$$

It can be seen from Equation (C-2) that the value of the function at the limits of the varfable being transformed must be known if the finite sine transform is to be employed.

It is also assumed in the use of the sine transform that the order of differentiation and integration is interchangeable [16]; thus,

$$
\frac{\partial^{2}}{\partial y^{2}} \int_{0}^{L} f(x, y) \sin \left(\frac{n \pi x}{L}\right) d x=\int_{0}^{L} \frac{\partial^{2} f}{\partial y^{2}}(x, y) \sin \left(\frac{n \pi x}{L}\right) d x \cdot(C-3)
$$

The ordinary theory of Fourier series can be employed to derive the following inversion formula:

$$
r(x)=\frac{?}{L} \sum_{n=1}^{\infty} f(n) \sin \left(\frac{n \pi x}{L}\right)
$$


THIS PAGE

\section{WAS INTENTIONALLY LEFT BLANK}




\section{APPENDIX D}

DERIVATION OF SPACE-DEPENDENT DISTANCE INCREMENT 
THIS PAGE

\section{WAS INTENTIONALLY LEFT BLANK}




\section{APPENDIX D - \\ DERIVATION OF SPACE-DEPENDENT DISTANCE INCREMENT}

It was found convenient in this study to approximate the partial derivatives of the heat transfer equations in the radial direction using a space-dependent distance increment. If the first increment in the radial direction is denoted by $\Delta r_{1}$, the distance between points $m$ and $m+1$ is given by

$$
\Delta \mathrm{r}_{\mathrm{m}}=\mathrm{c}^{\mathrm{m}-1} \Delta \mathrm{r}_{1}
$$

where $c$ is a constant and $m=2,3 \ldots M-2$.

Using a Taylor's series expansion, the values of a function at the points $(\mathrm{r}+\Delta \mathrm{r})$ and $(\mathrm{r}-\Delta \mathrm{r})$ are

$$
f(r+\Delta r)=f(r)+c^{m-1}\left(\Delta r_{1}\right) f^{\prime}(r)+c^{2 m-2}\left(\Delta r_{1}\right)^{2} \frac{f^{\prime \prime}(r)}{2}+\cdots
$$

and

$$
f(r-\Delta r)=f(r)-c^{m-2}\left(\Delta r_{1}\right) f^{\prime}(r)+c^{2 m-4}\left(\Delta r_{1}\right)^{2} \frac{f^{\prime \prime}(r)}{2}+\ldots
$$

Rearrangement of Equations (D-2) and (D-3) yields the following expression for the first derivative:

$$
f^{\prime}(r)=\frac{2 f(r+\Delta r)-2 f(r)-c^{2 m-2}\left(\Delta r_{1}\right)^{2} f^{\prime \prime}(r)}{2 c^{m-1} \Delta r_{1}} .
$$

Substitution of Equation (D-4) into Equations (D-2) and (D-3) yields the following approximation for the second derivative:

$$
f^{\prime \prime}(r)=\frac{f(r+\Delta r)-(c+1) f(r)+c f(r-\Delta r)}{\left[\frac{c^{2 m-2}+c^{2 m-3}}{2}\right]\left(\Delta r_{1}\right)^{2}} .
$$

Use of Equations (D-4) and (D-5) results in the following expression for the first derivative in terms of the values of the function at $\dot{r},(r+\Delta r)$ and $(r-\Delta r)$ :

$$
f^{\prime}(r)=\frac{2 f(r+\Delta r)-\left[2\left(1-c^{2}\right)\right] f^{\prime}(r)-2 c^{2} f(r-\Delta r)}{2 c^{m-1}(c+1) \Delta r_{1}} .
$$

In the special case where $c=1$, Equations $(D-5)$ and $(D-6)$ reduce to the form for a constant, $\Delta \mathrm{r}$. 
The quantity, c, hereafter referred to as the "mesh size multiplier", may be specified arbitrarily or computed from the following information:

(1) Specification of the initial size increment in the radial direction

(2) The total number of radial increments specified

(3) The distance to the outer boundary in the radial direction.

The distance, $r$, in terms of the initial increment, $\Delta r_{1}$, and the "mesh size multiplier" is given by

$$
r=a+\Delta r_{1}+c \Delta r_{1}+c^{2} \Delta r_{1}+\ldots c^{m-2} \Delta r_{1}
$$

where

$$
\begin{aligned}
& a=\text { radius of the source } \\
& m=2,3, \ldots M \\
& M=\text { outermost nodal point }
\end{aligned}
$$

Let « $N$ " represent the total number of radial distance increments specified and $\mathrm{R}_{\mathrm{B}}$ represent the distance to the outer boundary in the radial direction. The condition given by the following equation must be satisfied independently of the value of $c$ :

$$
\sum_{m=1}^{N} \Delta r_{m}=\left(R_{B}-a\right)
$$

Expression of $\Delta \mathrm{r}_{\mathrm{m}}$ in terms of $\Delta \mathrm{r}_{1}$ and $\mathrm{c}$ from Equation (D-1) results in the following expression for $c$ as a function of the specified quantities:

$$
\sum_{m=1}^{N} c^{m-1}=\left[\frac{R_{B}-a}{\Delta r_{I}}\right] \text {. }
$$

The value of c satisfying Equation (D-9) can be calculated by Newton's method as follows:

If a new function, $\phi(c)$, is defined as

$$
\phi(c)=\left(\frac{R_{B}-a}{\Delta r_{1}}\right)-\sum_{m=1}^{N} c^{m-1}
$$


the first derivative is

$$
\phi^{\prime}(c)=-\sum_{m=1}^{N}(m-1) c^{m-2}
$$

then

$$
c_{r+1}=c_{r}-\frac{\phi\left(c_{r}\right)}{\phi^{\prime}\left(c_{r}\right)}
$$

where $c_{r}$ is an assumed or previously calculated value of the root of Equation (D-10). Since from physical considerations $c \geq 1.0$, the initial value of the root can be taken as 1.0 . 
THIS PAGE

\section{WAS INTENTIONALLY LEFT BLANK}




\author{
APPENDIX E \\ STEADY-STATE TEMPERATURE DISTRIBUTION IN \\ BURIED HEAT SOURCE AND THE SURROUNDING MEDIUM
}


THIS PAGE

\section{WAS INTENTIONALLY LEFT BLANK}




\section{APPENDIX E -- \\ STEADY-STATE TEMPERATURE DISTRIBUTION IN BURIED HEAT SOURCE AND THE SURROUNDING MEDIUM}

The steady-state solution of the boundary value problem given by Equation (1) with a specified constant heat flux can be derived using the following assumptions: (a) the thermal conductivity of the soil is constant, (b) radius "a" of the heat source is small compared to the source length, and (c) the effective thermal conductivity of the heat source is much greater than the thermal conductivity of the surrounding environment. The boundary value problem is thus stated by the following equations:

$$
\begin{aligned}
\frac{\partial^{2} T}{\partial r^{2}}+\frac{1}{r} \frac{\partial T}{\partial r}+\frac{\partial^{2} T}{\partial z^{2}} & =0 \\
T(r, 0) & =0 \\
\operatorname{Lim} T(r, z) & =0 \\
r \rightarrow \infty & T(r, L)=0
\end{aligned}
$$

where $L$ is the depth in the " $\mathrm{Z}$ " direction at which the soil temperature is not affected by the source and is much greater than the burial depth,

$$
\begin{aligned}
-k_{s} \frac{\partial T}{\partial r}(a, z) & =q(z) ; a<z<D \\
& =0 \text { elsewhere } .
\end{aligned}
$$

A change of variable is appropriate at this point to reduce the problem to a form convenient for application of the finite sine transformation. If $\xi=\pi \mathrm{z} / \mathrm{L}$, the problem becomes

$$
\begin{aligned}
\frac{\partial^{2} T}{\partial r^{2}}+\frac{1}{r} \frac{\partial T}{\partial r}+\left(\frac{\pi}{L}\right)^{2} \frac{\partial^{2} T}{\partial \xi^{2}} & =0 \\
T(r, 0) & =0 \\
\operatorname{Lim}_{r \rightarrow \omega} T(r, \xi) & =0 \\
T(r, \pi) & =0 \\
-k_{s} \frac{\partial T}{\partial r}(a, \xi) & =q(\xi) ; \frac{\pi d}{L}<\xi<\pi D / L \\
& =0 \text { elsewhere. }
\end{aligned}
$$

Finite sine transformation of Equation (E-2) and the associated boundary conditions yields

$$
\frac{d^{2} \theta}{d r^{2}}+\frac{l}{r} \frac{d \theta}{d r}-\theta\left(\frac{n \pi}{L}\right)^{2}=0
$$




$$
\begin{aligned}
\operatorname{Lim}_{r \rightarrow \infty} \theta(r, n) & =0 \\
-k_{s} \frac{d \theta}{d r}(a, n) & =\frac{q}{n}\left[\cos \frac{n \pi d}{L}-\cos \frac{n \pi D}{L}\right] \\
& =0 \text { elsewhere. }
\end{aligned}
$$

Equation (E-3) can be changed to the standard form of a modified Bessel's equation by the following definition and change of independent variable:

$$
\text { Let } M_{n} \triangleq n \pi / L \text { and } \dot{X}=r M_{n} \text {. }
$$

After rearrangement, the following system of equations is obtained:

$$
\begin{aligned}
& x^{2} \frac{a^{2} \theta}{d x^{2}}+x \frac{d \theta}{d x}-x^{n} \theta=0 \\
& \operatorname{Limim}_{x \rightarrow \infty} \theta(x, n)=0 \\
& -k_{s} M_{n} \frac{d \theta}{d x}(a, n)=\frac{q}{n}\left[\cos \frac{n \pi d}{L}-\cos \frac{n \pi D}{L}\right] \\
& =0 \text { elsewhere. }
\end{aligned}
$$

The solution of Equation $(E-4)$ is

$$
\theta(X)=A I_{0}(X)+B K_{0}(X)
$$

Since the transformed temparature must rcmulin finlle as $\mathrm{X} \rightarrow \infty$, the modified Bessel function of the first kind (which appritiuhes os as $X$ approaches $\infty$ must be omitted, and the solution then asgumes the form

$$
\theta(X)=B K_{0}(X)
$$

Differentiating Fruation $(\mathrm{E}-6)$ and applying the boundary condition stated in Equation $(E-4 b)$ yields the solution for the transformed temperature:

$$
\theta(X)=\frac{q}{k_{n} M_{n} K_{1}\left(a M_{n}\right)}\left[\cos M_{n} \alpha-\cos M_{n} D\right] K_{0}(x) .
$$

The steady-state temperature is found by application of the inversion formula for the finite sine transform given by Equation $(C-4)$ :

$$
T(r, z)=\frac{2 q L}{\pi^{2} k_{s}} \sum_{n=1}^{\infty} \frac{K_{0}(n n \pi / L)[\cos n \pi d / L-\cos n \pi D / L]}{n^{2} K_{I}(a n \pi / L)} \sin \frac{(n \pi z)}{L} .
$$


An analogous procedure can be used to derive an expression for the steadystate temperature distribution within a buried heat source of low thermal conductivity and the surrounding soil. The boundary value problem for this case is stated by

$$
\begin{aligned}
& \frac{\partial^{2} \mathrm{~T}_{1}}{\partial r^{2}}+\frac{1}{r} \frac{\partial \mathrm{T}_{1}}{\partial \mathrm{r}}+\left(\frac{\pi}{\mathrm{L}}\right)^{2} \frac{\partial^{2} \mathrm{~T}_{1}}{\partial \xi^{2}}+\frac{\mathrm{q}^{\prime \prime}(r, \xi)}{\mathrm{k}_{\mathrm{c}}}=0 \\
& \quad \text { For } 0<r<\mathrm{R}_{\mathrm{B}}, \frac{\pi \mathrm{d}}{\mathrm{L}}<\xi<\frac{\pi \mathrm{D}}{\mathrm{L}}
\end{aligned}
$$

where $\mathrm{q}^{\prime \prime}=0$ for $\xi<\frac{\pi d}{\mathrm{~L}}$ and $\xi>\frac{\pi \mathrm{D}}{\mathrm{L}}$

$$
\begin{aligned}
\frac{\partial^{2} \mathrm{~T}_{2}}{\partial r^{2}}+\frac{1}{r} \frac{\partial \mathrm{T}_{2}}{\partial r} & +\left(\frac{\pi}{\mathrm{L}}\right)^{2} \frac{\partial^{2} \mathrm{~T}_{2}}{\partial \xi^{2}}=0 \\
\left(\text { For } \mathrm{r}>\mathrm{R}_{\mathrm{B}}\right) & \\
\mathrm{T},(0, \xi) & =\text { Finite } \\
-\mathrm{k}_{\mathrm{C}} \frac{\partial \mathrm{T}_{1}}{\partial r}\left(\mathrm{R}_{\mathrm{B}}, \xi\right) & =-\mathrm{k}_{\mathrm{s}} \frac{\partial \mathrm{T}_{2}}{\partial r} \quad\left(\mathrm{R}_{\mathrm{B}}, \xi\right) \\
\mathrm{T}_{1}\left(\mathrm{R}_{\mathrm{B}}, \xi\right) & =\mathrm{T}_{2}\left(\mathrm{R}_{\mathrm{B}}, \xi\right) \\
\mathrm{T}_{1}(r, 0) & =\mathrm{T}_{2}(r, 0)=0 \\
\mathrm{~T}_{1}(r, \pi) & =\mathrm{T}_{2}(r, \pi)=0 \\
\operatorname{Lim}_{r \rightarrow \infty} \mathrm{T}_{2}(r, \xi) & =0 \quad .
\end{aligned}
$$

For the region, $0 \leq r \leq R_{B}$, the finite sine transformation of Equation (E-9) and the applicable boundary conditions result in the following problem:

$$
\begin{gathered}
\frac{d \bar{u}_{1}}{d r^{2}}+\frac{1}{r} \frac{d \bar{u}_{1}}{d r}-\left(\frac{n \pi}{L}\right)^{2} \bar{u}_{l}+\frac{q^{\prime \prime}}{k_{c}^{n}}\left[\cos \frac{n \pi d}{L}-\cos \frac{n \pi D}{L}\right]=0 \\
\bar{u}_{l}(o, n)=\text { Finite } \\
k_{c} \frac{d \bar{u}_{1}}{d r}\left(R_{B}, n\right)=k_{s} \frac{d \bar{u}_{2}}{d r}\left(R_{B}, n\right) \\
\bar{u}_{1}\left(R_{B}, n\right)=\bar{u}_{2}\left(R_{B}, n\right) .
\end{gathered}
$$


For the region $\mathbf{r} \geq \mathbf{R}_{\mathrm{B}}$ in which no heat is generated, application of the finite sine transformation yields

$$
\begin{aligned}
\frac{d \bar{u}_{2}}{d r}+\frac{1}{r} \frac{d \bar{u}_{2}}{d r}-\left(\frac{n \pi}{L}\right)^{2} \bar{u}_{2} & =0 \\
\operatorname{Lim}_{r \rightarrow \infty} \bar{u}_{2}(r, n) & =0 \\
k_{c} \frac{d \bar{u}_{1}}{d r}\left(R_{B}, n\right) & =k_{s} \frac{d \bar{u}_{2}}{d r}\left(R_{B}, n\right) \\
\bar{u}_{1}\left(R_{B}, n\right) & =\bar{u}_{2}\left(R_{B}, n\right) .
\end{aligned}
$$

The boundary value problem may be simplified and the differential equation stated as a modified Bessel's equation if the following definitions are made:

$$
\text { Lct } \begin{aligned}
\frac{\mathrm{q}^{\prime \prime}}{\mathrm{k}_{\mathrm{c}} \mathrm{n}}\left[\cos \frac{\mathrm{n} \pi \mathrm{d}}{\mathrm{L}}-\cos \frac{\mathrm{n} \pi \mathrm{D}}{\mathrm{L}}\right] & \div \mathrm{s}_{\mathrm{n}} \\
M_{n} & =\frac{\mathrm{n} \pi}{\mathrm{L}} \\
\mathrm{X} & =\mathrm{rM}_{\mathrm{n}} .
\end{aligned}
$$

The boundary value problem in terms of the independent variable, $\mathrm{X}$, becomes

$$
\begin{aligned}
x^{2} \frac{d^{2} \bar{u}_{1}}{d x^{2}}+x \frac{d \bar{u}_{1}}{d x}-x^{2} \bar{u}_{1} & =-\left(\frac{S_{n}}{M_{n}}\right) x^{2} \\
\bar{u}_{1}(o, n) & =\text { Finite } \\
k_{c} \frac{d \bar{u}_{1}}{d x}\left(x_{B}, n\right) & =k_{s} \frac{d \bar{u}_{2}}{d x}\left(x_{B}, n\right) \\
\bar{u}_{1}\left(x_{B}, n\right) & =\bar{u}_{2}\left(x_{B}, n\right)
\end{aligned}
$$

and

$$
\begin{aligned}
& x^{2} \frac{d^{2} \bar{u}_{c}}{d x^{2}}+x \frac{d \bar{u}_{\imath}}{d x}-x^{2} \bar{u}_{2}=0 \\
& k_{c} \frac{d \bar{u}_{1}}{d x}\left(x_{B}, n\right)=k_{s} \frac{d \bar{u}_{2}}{d x}\left(x_{B}, n\right) \\
& \bar{u}_{1}\left(x_{B}, n\right)=\bar{u}_{2}\left(x_{B}, n\right) \\
& \operatorname{Lim}_{X \rightarrow \infty} \bar{u}_{2}(x, n)=0 .
\end{aligned}
$$


The complementary and particular solutions to Equations $(E-11)$ and $(E-12)$ are

$$
\bar{u}_{1}(X, n)=A^{\prime} I_{0}(X)+B^{\prime} K_{0}(X)+\left(\frac{S_{n}}{M_{n}}\right)
$$

and

$$
\bar{u}_{2}(X, n)=C I_{0}(X)+E K_{0}(X)
$$

Determination of the arbitrary constants by the use of the boundary conditions ylelds the following expressions for the steady-state temperatures for the source:

$T_{I}(r, z)=\frac{2 L^{2} q^{\prime \prime}}{\pi^{3} k_{c}} \sum_{n=1}^{\infty} \frac{\left[\cos \frac{n \pi d}{L}-\cos \frac{n \pi D}{L}\right] U\left(X, X_{B}, k_{c}, k_{S}\right) \sin \left(\frac{n \pi z}{L}\right)}{n^{3}\left[k_{c} K_{O}\left(X_{B}\right) I_{I}\left(X_{B}\right)+k_{S} K_{I}\left(X_{B}\right) I_{O}\left(X_{B}\right)\right]}$

and for the soil:

$$
T_{2}(r, z)=\frac{2 L^{2} q^{\prime \prime}}{\pi^{3}} \sum_{n=1}^{\infty} \frac{\left[\cos \frac{n \pi d}{L}-\cos \frac{n \pi D}{L}\right]\left[I_{I}\left(X_{B}\right) K_{0}(x)\right] \sin \left(\frac{n \pi z}{L}\right)}{n^{3}\left[k_{C} K_{0}\left(X_{B}\right) I_{I}\left(X_{B}\right)+k_{s} K_{I}\left(X_{B}\right) I_{0}\left(X_{B}\right)\right]}
$$




\section{THIS PAGE \\ WAS INTENTIONALLY \\ LEFT BLANK}




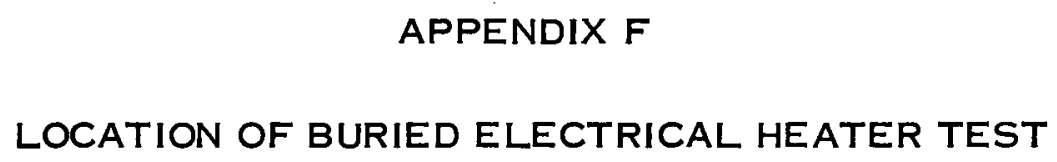


THIS PAGE

WAS INTENTIONALLY

LEFT BLANK 


\section{APPENDIX F -- \\ LOCATION OF BURIED ELECTRICAL HEATER TEST}

The test site for electrically simulating a buried nuclear heat source is located within the confines of the Idaho Chemical Processing Plant (ICPP) at the National Reactor Testing Station (NRTS). The NRTS, shown in Figure F-1, is located in Southeastern Idaho approximately 45 miles west of Idaho Falls. The ICPP is located in the south-central portion of the NRTS. A plot plan of the ICPP area is shown in Figure F-2.

The test site (see Figure F-2) is located approximately 950 feet south of the ICPP stack and 125 feet west of the east "patrol road". This particular site was chosen for the following reasons: (a) the soll at the site had not been disturbed and there was no underground piping in the vicinity; (b) the site was not in a heavily traveled area, but was close to a road, thus making the site accessible to heavy machinery; and (c) electrical power was available. 


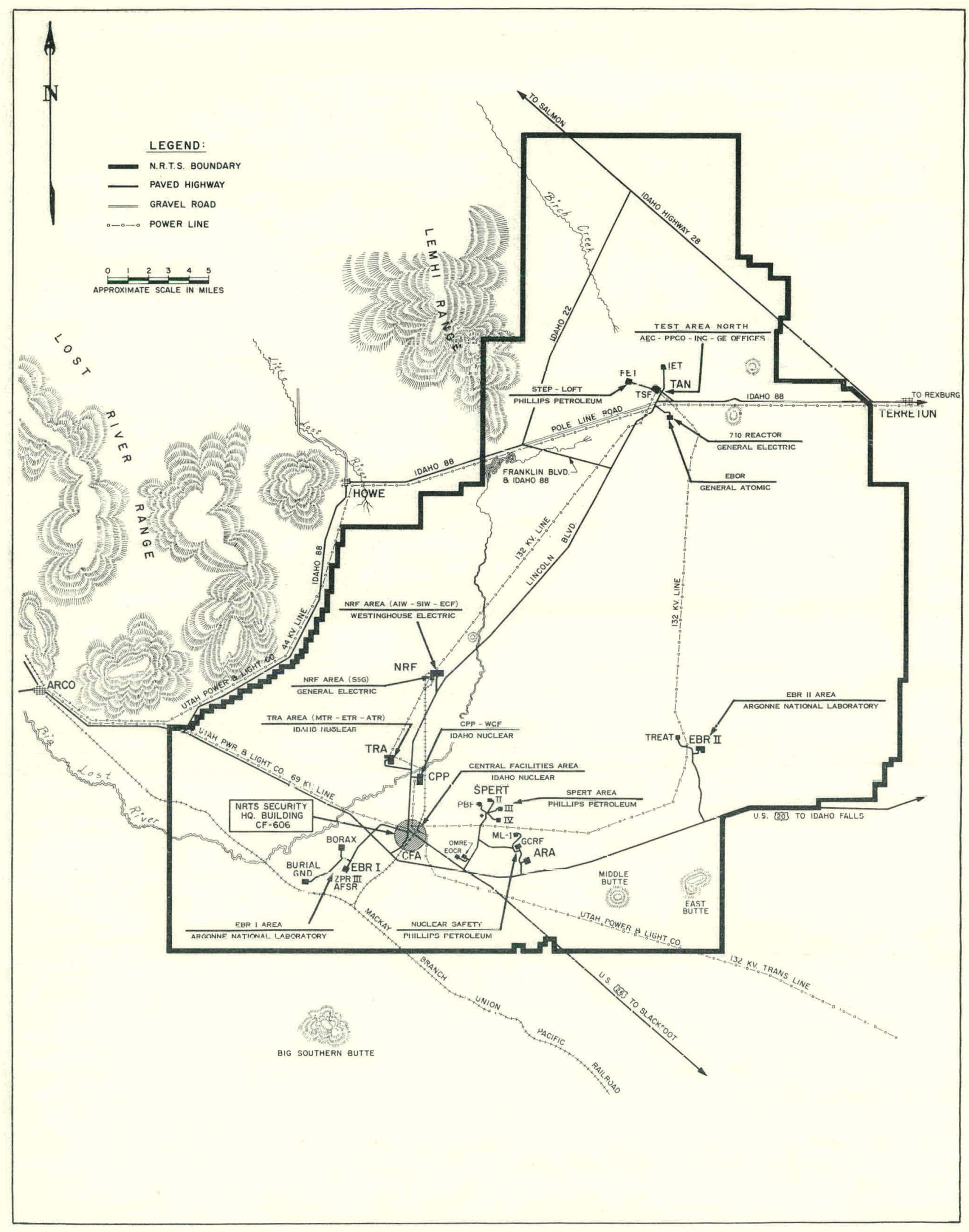

Fig. F-1 Plot plan of NRTS. 


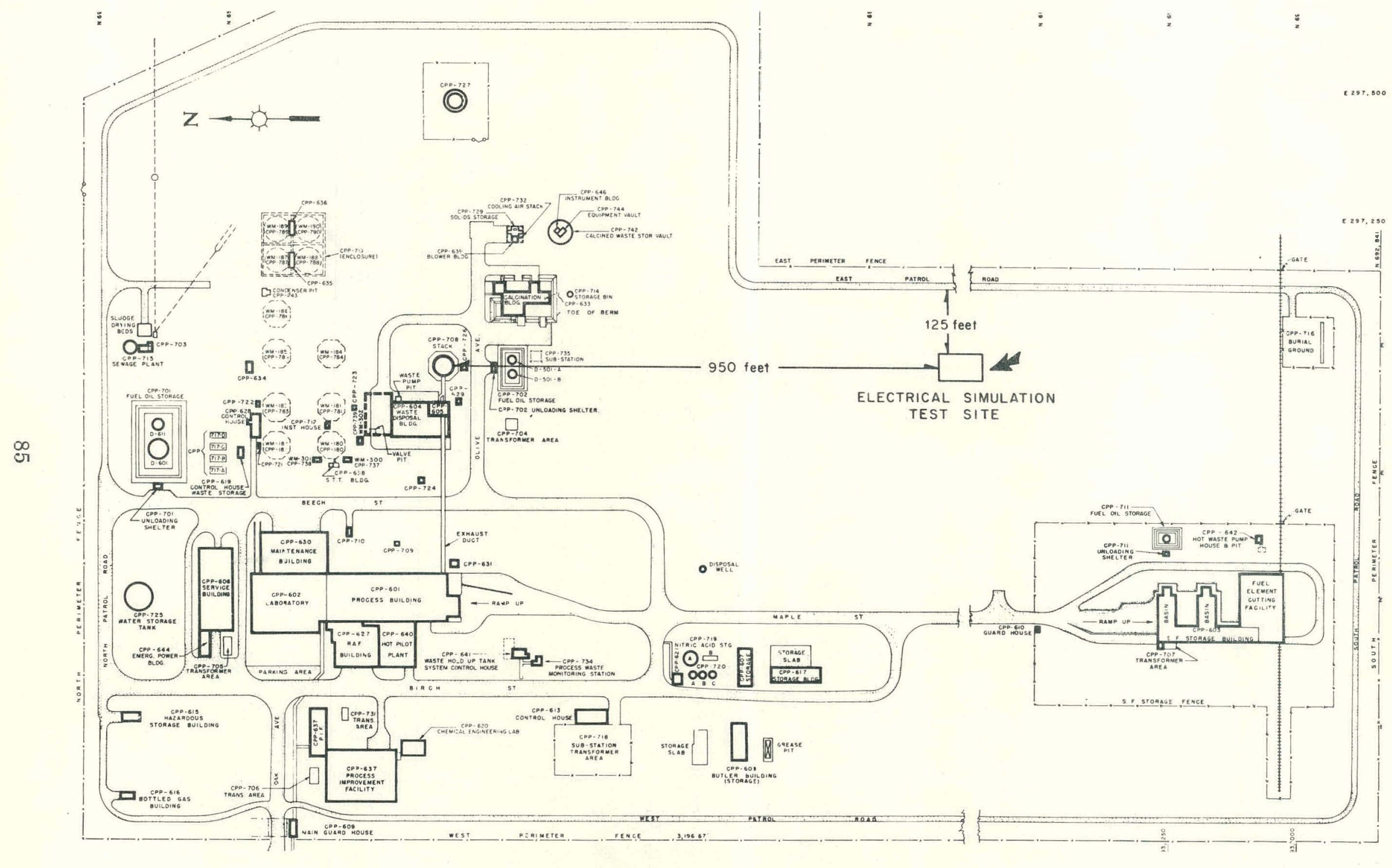

Fig. F-2 Site of buried heater test. 
THIS PAGE

\section{WAS INTENTIONALLY LEFT BLANK}




\begin{abstract}
APPENDIX G
EQUIPMENT USED FOR

DETERMINATION AND MONITORING OF SOIL PROPERTIES
\end{abstract}


THIS PAGE

\section{WAS INTENTIONALLY LEFT BLANK}




\section{APPENDIX G -- \\ EQUIPMENT USED FOR \\ DETERMINATION AND MONITORING OF SOIL PROPERTIES}

The equipment used for determination of the various properties of the soll is discussed in the following sections.

\section{THERMAL CONDUCTIVITY}

A thermal conductivity probe (Model 110BE-2) manufactured by the Rosemount Engineering Company of Minneapolis, Minnesota, was used to determine the thermal conductivity of the soil at the test site. This probe had the following physical parameters:

(1) Radius $=0.01125 \mathrm{ft}$

(2) Mass/unit length $=0.112 \mathrm{lb} / \mathrm{ft}$

(3) Specific heat $=0.12 \mathrm{Btu} / \mathrm{lb}-{ }^{\circ} \mathrm{F}$.

(4) Thermal diffusivity $=0.1441 \mathrm{ft}^{2} / \mathrm{hr}$.

The power supply for the heating element in the probe consisted of a variable-voltage dc power supply capable of providing up to 200 volts dc at 7.5 amperes (only a small fraction of this output was actually used). Figure G-1 shows a schematic diagram of the instrumentation used for each of the three temperature sensors.

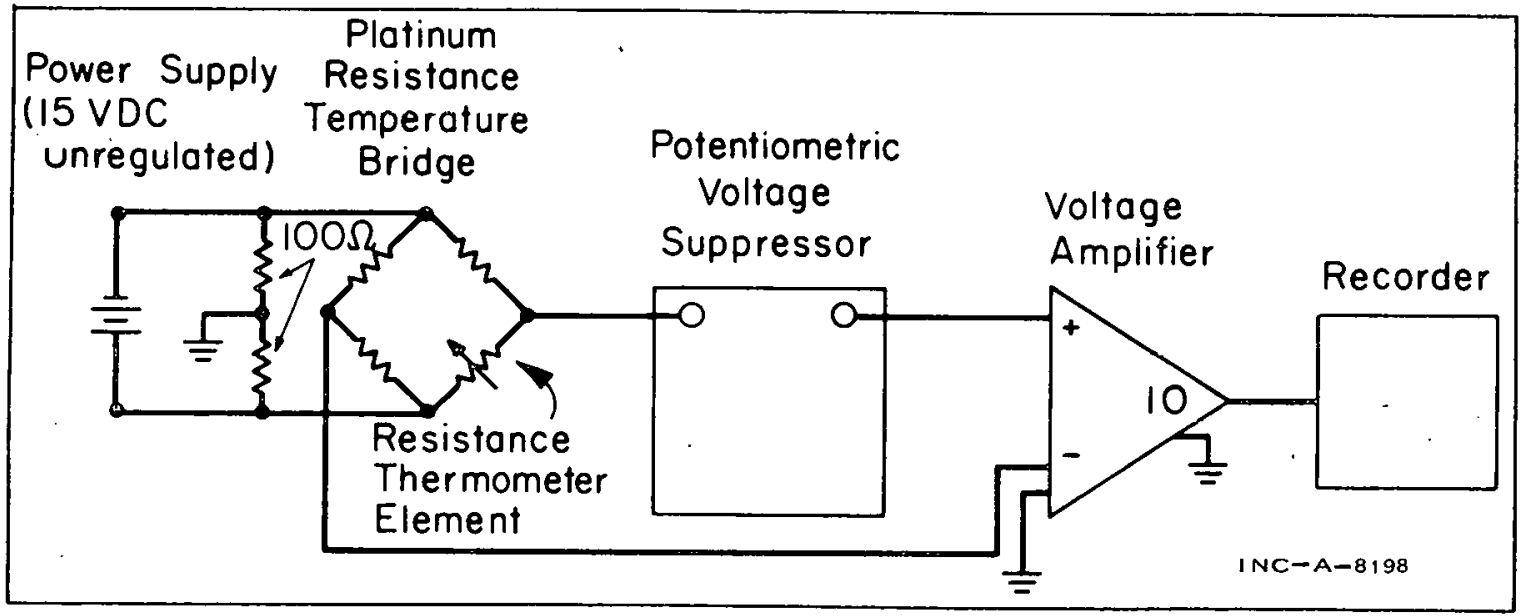

Fig. G-1 Instrumentation for thermal conductivity probe.

The following procedure was used in the thermal conductivity determinations:

(1) Power was supplied to the temperature bridge, the voltage suppressors, and the amplifiers 
(2) Each recorder pin (a total of three) was zeroed at full scale and zero readings

(3) The initial temperature of the soil was determined

(4) The Initial temperature reading was suppressed to zero

(5) The amplifiers were placed "in-line"

(6) An accurately measured rate of power was applied to the heating element of the probe

(7) The temperature rise of the probe was recorded on a 0 to $10^{\circ} \mathrm{F}$ (full-scale) recorder.

While operation of the probe is simple, the accuracy of the results is affected by the probe response and other factors [32]. These factors are summarized in the following paragraphs.

As is the case with most experimental apparatus, the design of a thermal conductivity probe is a compromise between several conflicting factors. For example, the diameter of the probe should be large enough to provide sufficient mechanical strength for the probe to be pushed into the sample without damage to the probe; as the probe diameter increases, however, the axial heat losses increase and the response of the probe diverges from that of an ideal line heat source. This problem may be minimized by maintaining the length-to-diameter ratio of the probe greater than 50 .

The thermal mass, internal and external (at the probe-to-soil interface) contact resistances of the probe, and the location of the temperature sensors within the probe cause an initial transient in its thermal response (refer to Figure 6). By proper design, these factors may be balanced so that the initial transient decays rapidly and the temperature response of the probe quickly approaches that of an "ideal line heat source".

A minimum sample size is required if the contact resistance between the probe and soil is not to affect the test results. The sample length is determined by the length of the probe and should be at least as long as the probe itself. The sample diameter, however, is independent of the probe length and diameter, but is a function of the thermal diffusivity of the sample and the test duration. The radius (R) of the sample may be estimated from the following equation:

$$
e^{-\left(R^{2} / 4 \alpha t\right)} \ll 1
$$

For dry soils, the sample radius should be a minimum of at least two to three Inches.

Even small initial transients in the temperature of the sample other than those imposed by the power input to the probe invalidate the results. In several cases during the determinations made at the test site, the temperature of the soil and the temperature of the probe were not equal (the temperature of the probe was increasing at approximately $1^{\circ} \mathrm{F}$ per five minute-1. Results of the tests gave 
thermal conductivities two to three times higher than those obtained when the soil and probe were in thermal equilibrium at the start of the measurement.

The factors affecting the operation and accuracy of a thermal conductivity probe may be summarized by the following statements:

(1) The length-to-diameter ratio of the probe should exceed 50

(2) The dimensions of the probe should be large enough to permit the probe to be pushed into the sample without damage to the probe

(3) The thermal mass of the probe should be as small as possible to minimize the duration of the initial transient in the temperature response of the probe

(4) The internal and external contact resistances should be minimized

(5) The length of the sample should be at least equal to the length of the probe, and the minimum sample radius should exceed that given by Equation ( $\mathrm{G}-1)$

(6) Temperature of the probe and the surrounding material must be equal before the start of the test.

In addition to these requirements, for satisfactory results, the test duration should not exceed 15 or 20 minutes, and the temperature rise of the probe and the adjacent sample should not exceed 7 or 8 degrees Fahrenheit.

\section{SPECIFIC HEAT}

The apparatus used for the mean specific heat determinations consisted of a Model CS-129 calorimeter, manufactured by Custom Scientific Instruments, Inc., of Kearny, New Jersey. This equipment is shown in Figure G-2.

The procedure given in Test C-351 of the ASTM Standards Manual [39] was used for all mean specific heat determinations.

\section{MOISTURE CONTENT}

$\Lambda$ Model P-19 subsurface suil moisture probe (shown in Figure G-3), manufactured by the Nuclear-Chicago Corporation of Des Plaines, Illinois, was used to determine the moisture content of the soil at varying depths.

The moisture probe consists of a canister containing a 4-to 5-millicurie (radium-beryllium) source of fast neutrons and a detector which is sensitive only to slow neutrons. The count rate of slow neutrons from the detector is accumulated on a Model 2800 (Nuclear-Chicago Corporation) portable scaler 


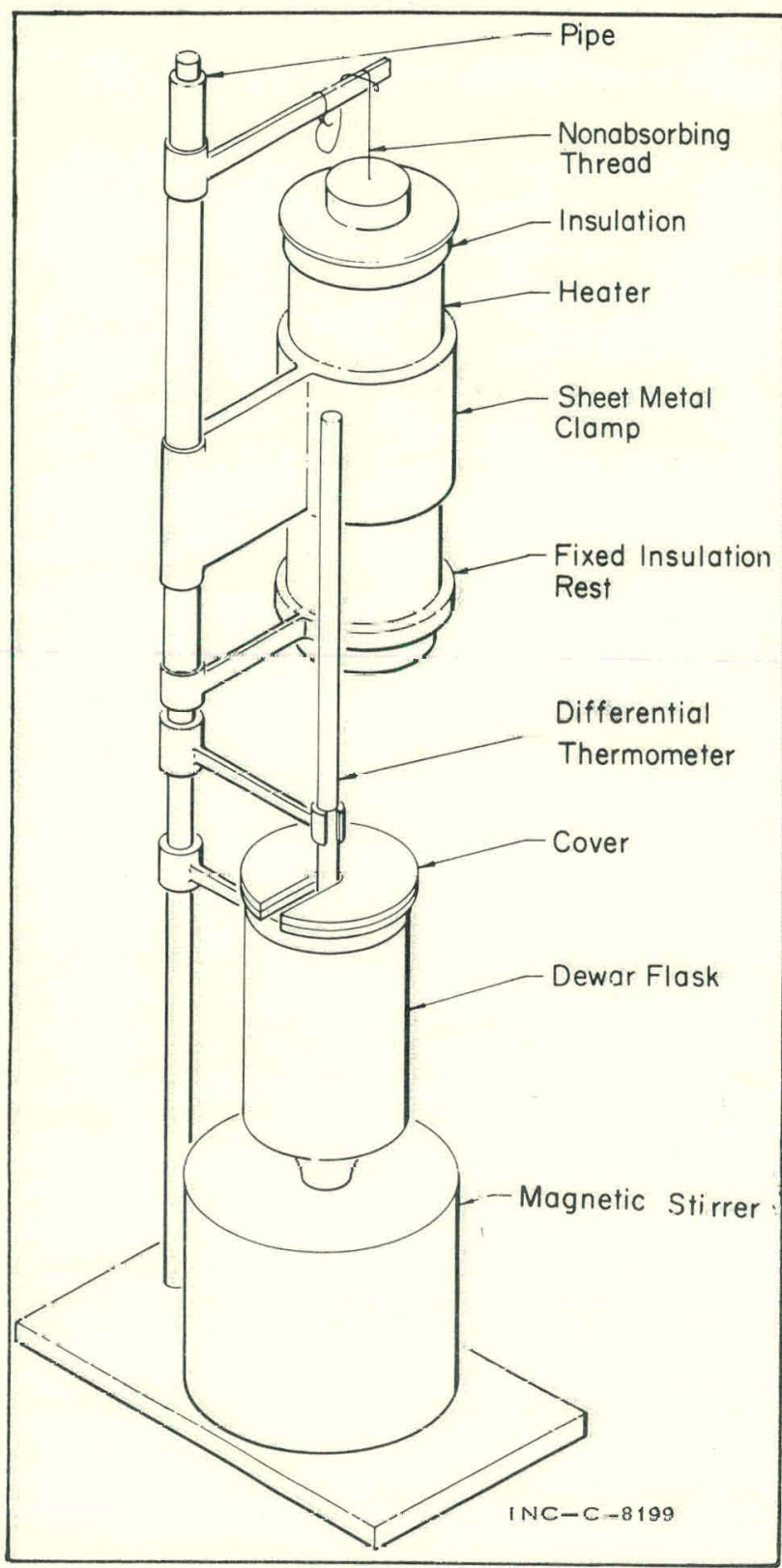

Fig. G-2 Mean specific heat calorimeter.

(shown in Figure G-4). The count rate of slow neutrons is determined above the surface of the soil and again at various depths below the surface of the soil. As the fast neutrons pass into the material surrounding the soil, they are slowed down (moderated) by the presence of hydrogeneous materials. Since the chemical composition of most soils is such that the hydrogen is present primarily as moisture in the soil, the number of slow neutrons can be related to the moisture content of the soil. Moderation of the neutrons is essentially independent of grain structure and aggregation of the soils. The probe can be operated at any

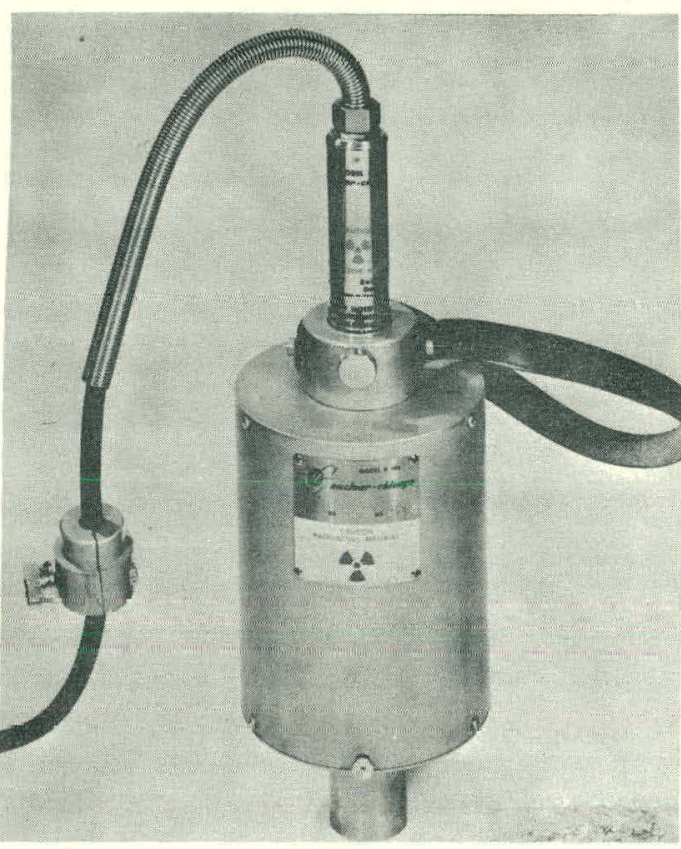

Fig. G-3 Soil moisture probe.

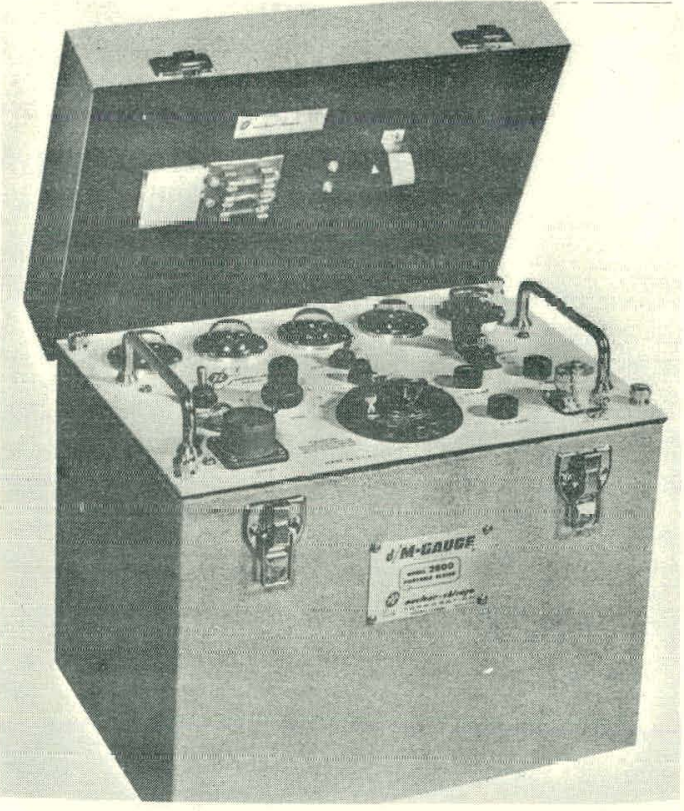

Fig. G-4 Neutron scaler. 
temperature in the range between -20 and $+130^{\circ} \mathrm{F}$ with an accuracy of \pm 2 percent of absolute moisture measurements.

At the test site, the probe was lowered down a hole cased with plastic pipe. Since the plastic contains hydrogeneous materials, a special calibration curve was developed for use of the probe in plastic pipe. 
THIS PAGE

\section{WAS INTENTIONALLY LEFT BLANK}


APPENDIX H

FORTRAN NOMENCLATURE AND SOURCE PROGRAMS 
THIS PAGE

\section{WAS INTENTIONALLY LEFT BLANK}




\section{APPENDIX H -- \\ FORTRAN NOMENCLATURE AND SOURCE PROGRAMS \\ -}

Four separate computer programs were required for calculating the steady-state and transient temperature distributions surrounding a buried cylindrical fuel element or a cylindrical bin filled with solidified radioactive waste. The nomenclature used and the FORTRAN source list are shown for each case.

1. NOMENCLATURE FOR STEADY

TEMPERATURES SURROUNDING A BURIED FUEL ELEMENT

$A=$ radius of the fuel element, $\mathrm{ft}$ $\begin{aligned} \mathrm{AO}(\mathrm{K}, \mathrm{I})= & \text { the value of the modified Bessel function, } \mathrm{K}_{\mathrm{o}}(\mathrm{X}) \text {, computed } \\ & \text { for the argument } \mathrm{X} \text {, dimensionless }\end{aligned}$

AR (I) $=$ the value of the modified Bessel function, $K_{1}(X)$, computed for the argument $\mathrm{X}$. dimensionless

$\mathrm{B}=\mathrm{a}$ dummy variable, dimensionless

BOT $=$ depth below the ground surface of the bottom of the fuel element, $\mathrm{ft}$

$\mathrm{CAY}=$ thermal conductivity of the soil, Btu/hr-ft- ${ }^{\circ} \mathrm{F}$

COG $(I)=$ the trigonometric function $\left[\cos \left(\frac{n \pi d}{L}\right)-\cos \left(\frac{n \pi D}{L}\right)\right]$

CON $=$ the term $\frac{2 q L}{\mathrm{k}_{\mathrm{s}} \pi^{2}},{ }^{\circ} \mathrm{F}$

$\mathrm{DI}=\mathrm{a}$ dummy variable, ${ }^{\circ} \mathrm{F}$

ERR1 = allowable error in the convergence of the temperatures as a function of $\mathrm{L},{ }^{\circ} \mathrm{F}$

$\mathrm{ERR} 2$ = allowable error in the temperature convergence as a function of $\mathrm{n},{ }^{\circ} \mathrm{F}$

FLUX = the specified flux at the surface of the fuel element, Btu/hr-ft ${ }^{2}$

KCOUNT $=$ a counting integer

$\operatorname{KIZERO}(\mathrm{X}, \mathrm{XK}, \mathrm{XI}), \mathrm{KIONE}(\mathrm{X}, \mathrm{XK}, \mathrm{XI})=$ library subroutines used to calculate the modified Bessel functions, $K_{0}(X)$ and $K_{1}(X)$, respectively

$\mathrm{NR}=$ number of points at which the temperature is calculated in the radial direction 
$\mathrm{NZ}=$ number of points below the soil surface at which the temperature is calculated

$\mathrm{PI}=$ the constant $\pi$

$R(I)=a$ radial distance from the center of the fuel element, $\mathrm{ft}$

$T(I)=$ the term,

$$
\frac{K_{0}\left(\frac{n \pi r}{L}\right) \cdot\left[\cos \frac{n \pi d}{L}-\cos \frac{n \pi D}{L}\right] \sin \left(\frac{n \pi Z}{L}\right)}{n^{2} K_{I}\left(\frac{n \pi r}{L}\right)}
$$

TEM (I) = temperature at the surface of the fuel element based on $\mathrm{a}$ : spectified $L,:{ }^{\circ} \mathrm{F}$

TITLE (I) = title of the problem to be solved; appears on first data card TOP $=$ depth below the ground surface of the top of the fuel element,

TSOIL = specified temperature of the soil at the ground surface and at large radial and axial distances away from the heat source, ${ }^{\circ} \mathrm{F}$

$U(K, J)=$ calculated temperature at a specific point in the soil surrounding the fuel element

$\mathrm{UT}=$ a variable name corresponding to the sum,

$$
\sum_{n=1}^{\infty} \frac{K_{0}\left(\frac{n \pi r}{L}\right)\left[\cos \left(\frac{n \pi d}{L}\right)-\cos \left(\frac{n \pi D}{L}\right)\right] \sin \left(\frac{n \pi Z}{L}\right)}{n^{2} K_{L}\left(\frac{a n \pi}{L}\right)}
$$

$\mathrm{V} 1=\mathrm{a}$ variable name denoting maximum temperature as a function of $n,{ }^{\circ} \mathrm{F}$

V2 = variable name denoting minimum temperatures as a function of n, ${ }^{\circ} \mathrm{F}$

$\mathrm{X}=$ the argument of a Bessel function

$\mathrm{XK}=$ value of the Bessel function $\mathrm{K}_{\mathrm{O}}(\mathrm{X})$ or $\mathrm{K}_{1}(\mathrm{X})$

$\mathrm{Z}=$ distance below the ground surface, $\mathrm{ft}$

$\mathrm{ZAX}=$ maximum value of the parameter $\mathrm{L}$ in a given problem, $\mathrm{ft}$

$\mathrm{ZL}=$ the quantity $\mathrm{L}, \mathrm{ft}$ 


$$
\begin{aligned}
& \mathrm{ZLI}=\text { an incremental increase in the quantity } \mathrm{L}, \mathrm{ft} \\
& \mathrm{ZM}=\text { the depth }\left[\mathrm{d}+\left(\frac{\mathrm{D}-\mathrm{d}}{2}\right)\right], \mathrm{ft} .
\end{aligned}
$$

2. NOMENCLATURE FOR

TEMPERATURES IN A BURIED BIN AT STEADY STATE

Some of the nomenclature for this case is identical to that for the buried fuel element and will not be repeated here.

ARI $(I)=$ the value of the modified Bessel function $I_{1}\left(\frac{n \pi R}{L}\right)$

$B R(I)=$ the value of the modified Bessel function $K_{o}\left(\frac{n \pi R_{B}}{L}\right)$

BRI $(I)=$ value of the modified Bessel function $I_{o}\left(\frac{n \pi R_{B}}{L}\right)$

$\mathrm{CAYC}=$ thermal conductivity of the solidified waste, $\mathrm{Btu} / \mathrm{hr}-\mathrm{ft}-{ }^{\circ} \mathrm{F}$

$\mathrm{CAYS}=$ thermal conductivity of the soil, Btu $/ \mathrm{hr}-\mathrm{ft}-{ }^{\circ} \mathrm{F}$

CON $=$ the term $\frac{2 L^{2} q^{\prime \prime}}{\pi^{3} k_{c}},{ }^{\circ} F$

NR1 = number of points in the radial direction within the heat source at which the temperature is calculated

$\mathrm{NR} 2=$ number of points in the radial direction within the soil at which temperatures are calculated

NZ1 = number of depths below the soil surface within the source at which temperatures are calculated

NZ2 = number of depths within the soil at which the temperatures are calculated

$\mathrm{R} 1 \mathrm{I})=$ a radial distance located within the heat source, $\mathrm{ft}$

$\mathrm{Q}=$ heat generation rate within the source, $\mathrm{Btu} / \mathrm{hr}-\mathrm{ft}^{3}$

$\mathrm{R} 2(\mathrm{I})=$ a radial distance located within the soil, $\mathrm{ft}$

$\mathrm{RB}=$ radius of the cylindrical bin, $\mathrm{ft}$

$\mathrm{ZI}(\mathrm{I})=$ distance below the ground surface within the heat source, $\mathrm{ft}$

$\mathrm{Z2}$ (I) = distance below the ground surface within the soil, $\mathrm{ft}$ 
3. FORTRAN SOURCE PROGRAM -- STEADY-STATE FUEL ELEMENT

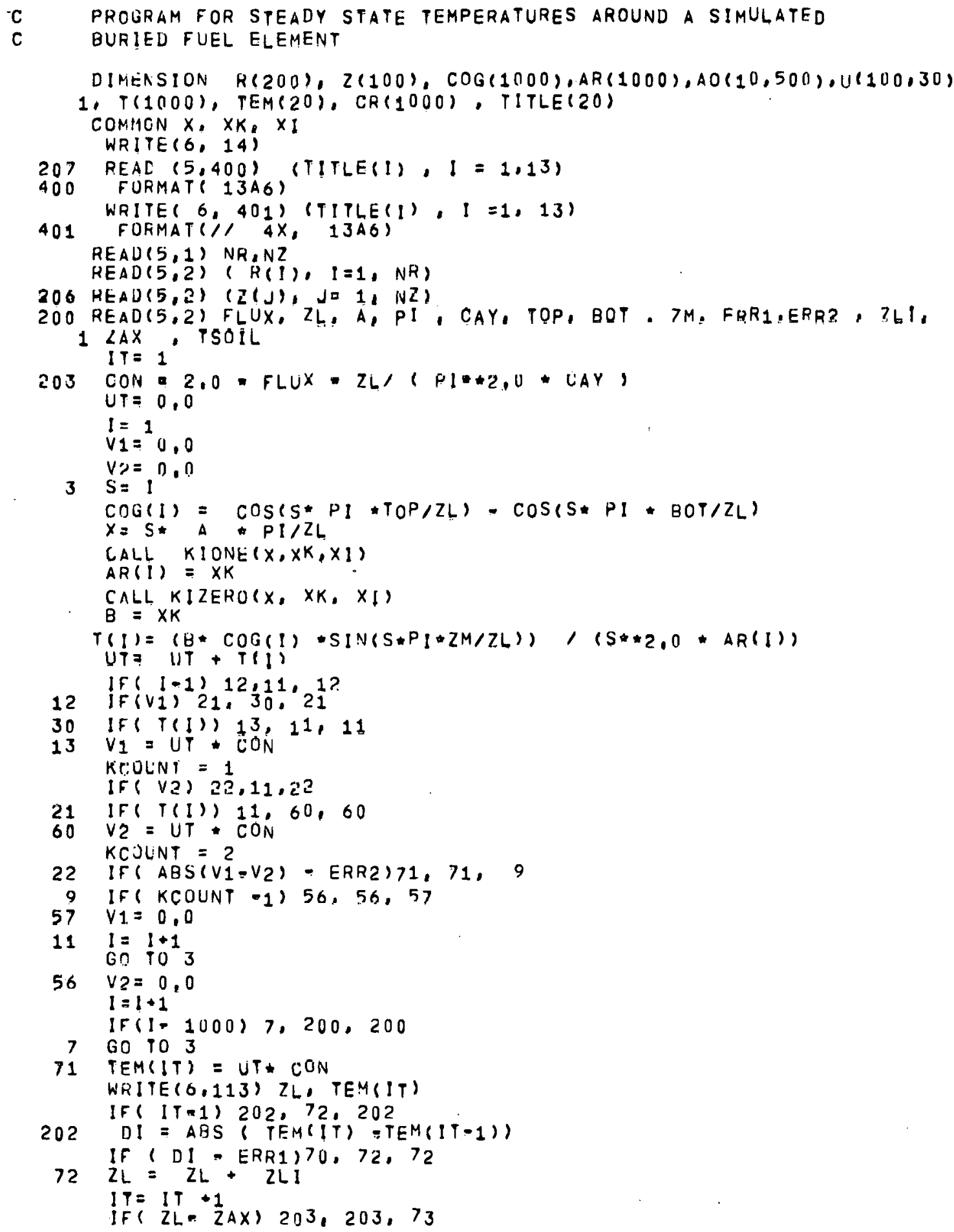


C PROGRAM FOR STEADY STATE TEMPERATURES AROUND A SIMULATED
C BURIED FLEL ELEMENT

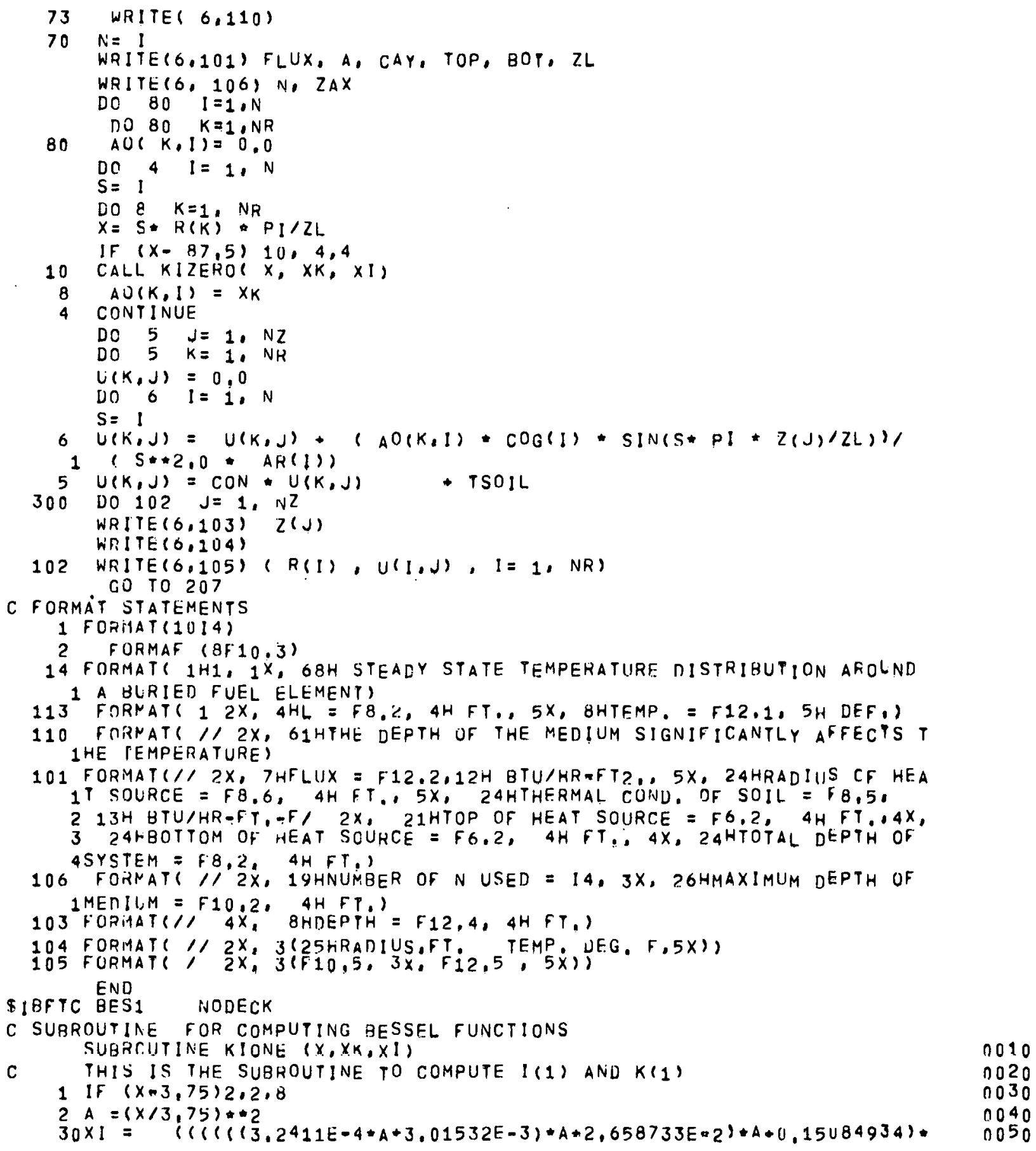


C PROGFAM FOR STEADY STATE TEMPERATURES AROUND A SIMULATED

C BUFIED FUEL ELEMENT

$1 A+0.51498869) * A+0,87890594) * A+0,5) * x \quad 0060$

4 If $(x-2,0) 5,5,10 \quad 0070$

$5 A=(x / 2,0) * 2 \quad 0080$

$60 \times K=((()((-4,686 E-5 * A-1,10404 E-3) * A-1,919402 F-2)+A-0.18156897) * A \quad 0090$

$1-0.67278579) * A+0.15443144) * A+1,0)(X+A \operatorname{LOG}(0.5 * X) * X I \quad 0100$

7 RETUFN

$8 \quad A=3,75 / X$

$90 \times I \doteq((()((1)-4,200587 E-3 * A+1,7876535 E-2) * A-2,8953121 E-2) * A+2,282$

$19673 E-2) * A-1,0315550 E-2) * A+1,638014 E-3) * A-3,620183 E-3)+A-3,9880242$ $2 E-2) * A+.398942280 E+00)((X * 0.5 \star E X P(-X))$

$10 A=2.0 / x$

$110 \times K=((()((-6,8245 E-4 * A+3,25614 E-3) * A=7.80353 E-3) * A+0.01504268) * A *$, $13655620 E=01) * A+0.23496619) * A+1.25331414) * E X P(-X)(X * 0.5$

RETURN END

DIBFTC BESE NODFCK

SUBROUTINE KIZERO $\left(X_{1}, X K, X !\right)$

C

THIS IS THE SUBROUTINE TO COMPUTE $I(0)$ AND $K(0)$

1 If $(x=3,75) 2,2,10$

$2 A=(x / 3,75) * 2$

$30 \times I=((((), 0045813 * A * 0.0360768) * A+0.2659732) * A+1.2067492) * A+3,089$ $194241 * A+3,51562291 * A+1.0$

4 If $(x-2, U) 5,5,40$

$5 A=(x / 2,0) * 2$

$60 \times K=((()((7.40 E-6 * A+1.0750 E-4) * A+0.00262698) * A+0.03488590) * A * 0.8306$

$19756) * A * 0,42278420) * A=0.57721560 * X I * A L 00(0,5 * X)$ 7 RETURN

$10 \quad A=3.75 / x$

$110 \times 1=(((()((.392376) E=02 * A-.16476329 E-01) * A+.26355372 E-01)=A=. a 057$

$17063 E=01) * A+.9162808 E=02) * A=.1575649 E=021 * A+.2253187 E=02) * A+.13285$ $2217 E-01) * A+, 398242200 E \div 00$

$12 B=-0,5$

13 if $(x=87,3) 14,43,43$

$14 X I=X I * X \star B \star E X P(X)$

$40 \quad A=2.0 / x$

$410 \times K=(((\{(<5,3208 F=4 * A-2,51540 E=3) * A+0,00587872) * A-0,01062446) * A+$ $10 . ? 2189568) * A=0,07832358) * A * 1.25331414) * \operatorname{EXP}(-X) / X * 0.5$

42 RETUFN

$43 \times 1=X I * X * \forall / E X P(-X)$

44 GU 1040

50 END

DENTRY TEMP TEMT

0110

0120

0130

0140

0150

0160

0170

0180

.0190

0200

0010

0020

0030

0040

0050

0060

0070

0080

0090

0100

ก.1ก

0120

0130

0140

กI5

0160

0170

0.180

0190

ก200

0210

ก 22ก

0230

0240

0250 


\section{FORTRAN SOURCE PROGRAM -- STEADY-STATE BINS}

C PROGFAM FOR STEADY STATE TEMP, IN AND AROUND A CYLINDFICAL 0506

DIMENSION RI(100), R2(100), Z1(100), 22(100), COG(600), 0506

1 A.R $(600), A 0(10.600), U(50,10), T(600), A R 1(600), B R(600), 0506$

2 BR1 $(600)$, PEM(100), TITLE(20) COMMON $X, X K, X !$

206 READ(5.705)(TITLE(I), I= 1,13$)$

705 FORMAT (13A6)

WRITE( 6.705$)$ (TITLE(1), $1=1.13$ )

205 REAE $(5,1) N R_{1}, N R 2, N 21, N Z 2, K C$

KEAC (5,?) (R1 (1), $\left.1=1, N R_{1}\right)$

$\operatorname{HEAC}(5,2) \quad(21(1), \quad 1=1, N Z 1)$

$\operatorname{REAC}(5,2) \quad(R 2(1), 1=1, N R 2)$

0506

0506

$\operatorname{REAC}(5,2) \quad(22(1), 1=1, N Z 2)$

200 REAC (5,2) D, ZL, RB, PI, CAYC, CAYS, TOP, ROT, ZM, ERRI, EFRE,

1 ZLI, ZAX, TSOIL

WRITE $(6,14)$

203 CON $=2,0 * 0 * Z L * 2,0 /(P I * * 3,0 *$ CAYC $)$

$U T=0,0$

$I=1$

$v_{1}=0,0$

$3 \quad S=1$

$\operatorname{COO}(1)=\operatorname{COS}\left(S * P I * T_{O} P / Z L\right)=\operatorname{COS}(S * P I * B O T / Z L)$

$X=S * R B \pitchfork P_{1} / Z L$

CALL KIONE $(X, X K, X I)$

$A F(1)=X K$

$A F I(I)=X I$

CALL K!ZERO $(X, X K, X !)$

$B R(I)=X K$

$B R I(I)=X I$

$T(I)=\left(\operatorname{COG}(1)+\left(\quad C_{A Y C}+B R(1)+A R I(1)+C_{A Y S}+A R(I)\right.\right.$

$1 *(B R 1(I)-1,0)) * S I N(S * P I+Z M / Z L)) /(S * 3.0 *$

2 (CAYC*BR(I) *ARI (I) + CAYS AR(I) *BRI(I))

$U T=U T$ * $T(1)$

If $\mid-1) 12,11,12$

12 If $\left(V_{1}\right) 21,30,21$

30 If $\mathrm{T}(1)) 13,11,11$

$13 V_{1}=U T \quad \cdot \mathrm{CON}$

KCOLNT $=1$

IF ( V2) $22,11.22$

21 IF $(T(I)) 11,60,60$

$60 \quad V 2=U T \cdot \mathrm{CON}$

KCUUNT $=2$

22 If $\left.\left(A B S\left(V_{1}-V_{2}\right)=E R\right)^{2}\right) 71,71,9$

9 IF ( KCOUNT - 1 ) $56,56,57$

$57 \quad V_{1} \neq 0,0$

GO $10 " 11$

$56 \quad V 2=0,0$

$11 \quad I=I+1$

IF $(1.600) 3,200,200$

71 TEM(IT) = UT CON

WRITE $(0,113)$ ZL: TEM(IT)

IF (IT-1) $202,72,202$

202 DI. $A B S(\operatorname{TEM}(I F)-\operatorname{TEM}(I F=1))$ 
C PRGGFAM FOR STEADY STATE TEMP, IN AND AROUNA A CYLINDFICAL OSO C BIIN BURIED IN THE SOIL

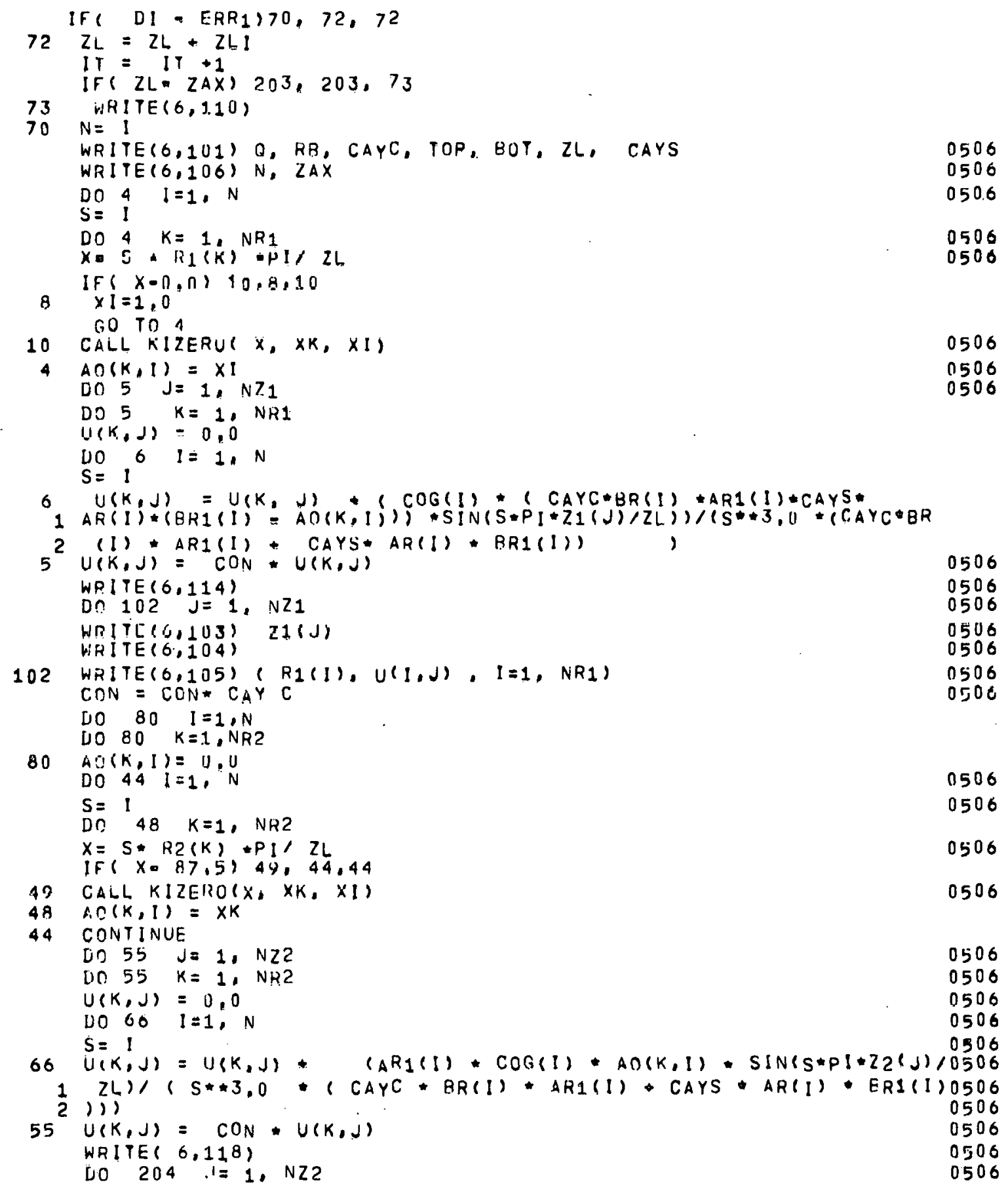


C PROGFAM FOR STEAUY STATE TEMP. IN AND AROUND A CYLINDFICAG OSO C BIN BURIED IN THE SOIL

WRITE $(6,103) \quad Z 2(J) \quad 0506$

0506

$204 W E I T E(0,105)(R 2(1), U(I, j), I=1, N R 2) \quad 0506$

1 FORMAT 1

2 FORMAT $(8 F 10.3)$

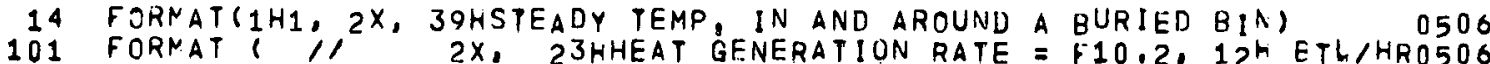
1-FT3, 3X, 16HRADIUS OF BIN = F8.2. 4H FT.I 4X, 27HTHERMAL COAD. 0506 2 UF CALCINE $=F 8,3,12 \mathrm{H}$ GTU/HR-FT-F, 2X, 21HTOP OF HEAT SOLRCF = F0506 $38,2,4 H F T, 3 X_{0}, 24 H B O T T O M$ OF HEAT SOURCE $=$ F8,. 4HFT, 3X, 0506

$424 H T O T A L$ DEPTH OF SYSTEM = F8,2, 4H FT,

$52 X$. 24HTHERMAL COND, OF SOIL = F8,3,12H BTU/HRMFT-F)

106 FORMATL/ 2X, 19 HNUMEER OF N USED $314,3 X$ $1 M E D$ ILM $=F 10,2,4 H F T$, )

114 FORMAT( $/ 1$ 2X, 31HSTEADY TEMP, IN THE STORAGE BIN) 0506

103 FORMAT(/, $4 X, 8 H D E P T H=F 12,4,4 H F T$,

104 FORMAT( $/ / 2 X, 3(25 H R A D I U S, F T !$ TEMP, DEG, F, 5X))

105 FORIATS $, 2 X, 3(F 10,5,3 x, F \pm 2,5,5 X))$

118 FORMAT( 1 HI, 2X, 31HSTEADY TEMP. IN SUIL AROUND BIN) 0506

113 FORMAT( $2 X, 4 H L=F 8,2,4 H F T, 5 X$, BHTEMP. $=F 12.1,5 H$ DEF, )

110 FORMATS $/{ }^{2}, 4$, $4 H T H E$ DEPTH OF THE MEDIUM AFFECTS THE TEMPERATURE 1) END

C BESSEL FLNCTION SUBROUTINE

SIBFTC BESC NODECK

SUGRCUTINE KIZEHO ( $\left.X, X K, X_{1}\right)$

$\mathrm{C}$

THIS IS THE SUBROUTINE TO COM

1 If $(x-3,75) 2,2,10$

$2 A=(x / 3,75) \div 2$

$30 \times 1=((((10,0045813 * A+0.0360768) * A+0.2659732) * A+1,2067492) * A+3,089$

$1942.4) \cdot A+3,5156729)+A+1.0$

4 I $F(x-2,0) 5,5,40$

$5 A=(x / 2,0) *+2$

$60 \times K=((((1), 40 E-6 * A+1.0750 E-4) * A+0.00262698) * A+0.03488590)+A+0.2306$ $19756) * A+0.42278420) * A=0.57721566-X I * A L O G(0.5 * X)$

7 RETIJFN

$10 \quad A=3.75 / X$

$110 \times 1=((()((1.3923767 E=02 * A=.16470329 E=01) * A * .26355372 E=01) * A * .8057$ $17063 E-01) * A+, 9162808 E=02) \star A-.1575649 E-02)+A+.22531 B 7 E-1) 2) \star A+.13285$ $2917 E-01) * A+398942.280 E+00$

$12 B=-0,5$

13 If $(x-87,3) 14,43,43$

$14 X I=X I * X * B * E X P(X)$

$40 A=2,0 / X$

$410 \times K=((()((5,3208 E=4 * A-2.51540 E \cdot 3) * A+0.00587872) * A-0.01062446) * A+$ $10,02189568) * A=0.07832358) * A+1.25331414) * \operatorname{EXP}(-X) / X * * 0.5$

42 RETUFN

$43 \times I=X I * X * B / E X P(=X)$

44 GO TC 40

50 END
0010 0020 0030 0040 0050 $n 060$ 0070 0080 0090 $n 100$ 0110 0120 0130 0140 $n 150$ $\cap 160$ 0170 0180 0190 ก 200 0210 ก 220 0230 ก 240 0250 


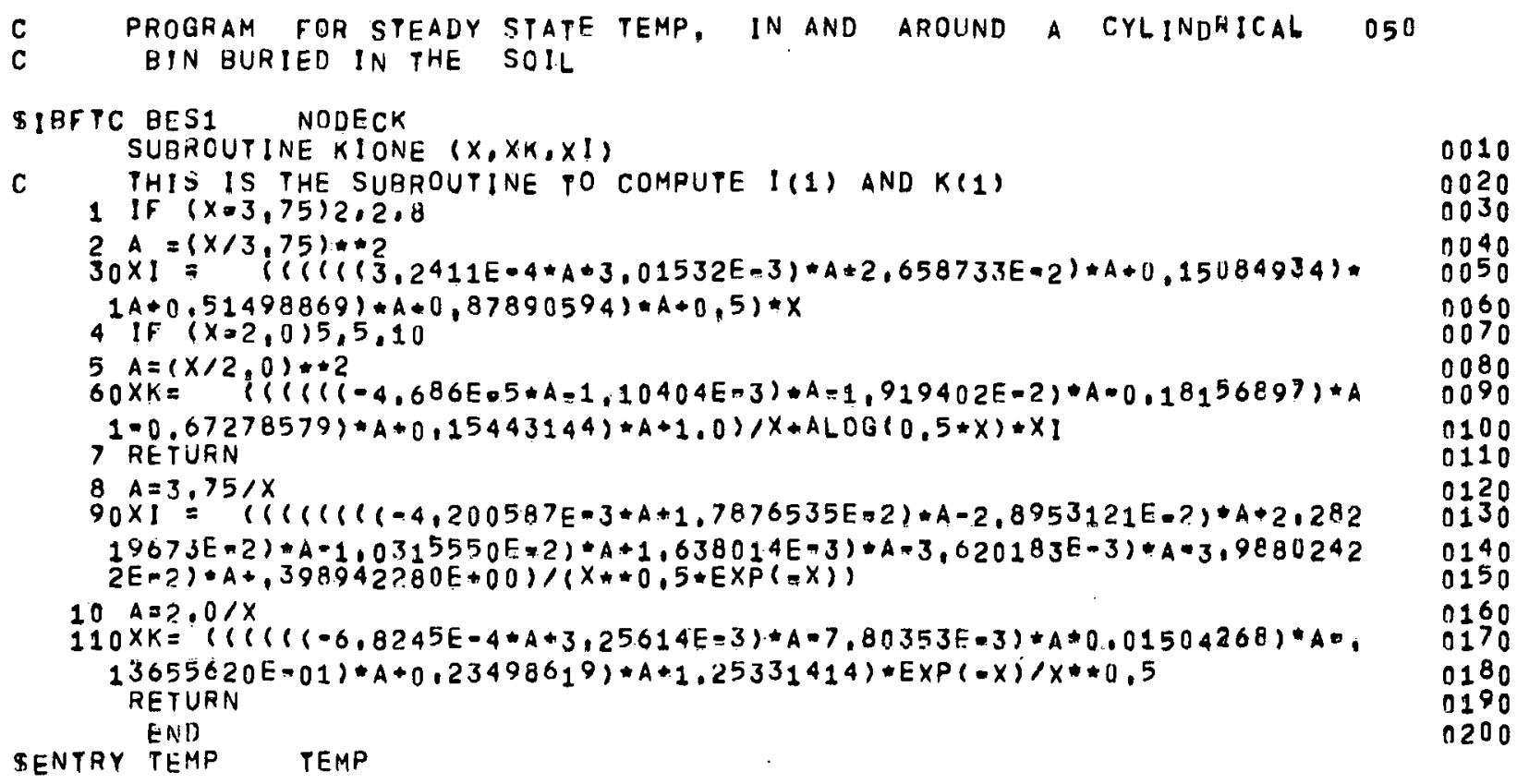

5. NOMENCLATURE FOR TRANSIENT TEMPERATURE DISTRIBUTION SURROUNDING A BURIED FUEL ELEIMENT

$A(I)=$ the first term of the quantity, ${ }_{m}$, defined in Appendix B

A1 $(I)=$ the term $\left(\theta_{m} / w_{m}\right)$ used in Appendix B

$A M=$ the quantity "a" in the equation for an exponentially deoaying heat flux

$\mathrm{B}(\mathrm{I})=$ the quantity defined as $\sigma_{\mathrm{m}}$ in Appendix $\mathrm{B}$

$\operatorname{BETAL}(\mathrm{I})=$ the quantity, $\frac{\left[\rho \mathrm{C}_{\mathrm{p}}\left(\Delta \mathrm{r}_{1}\right)^{2}\right]}{\mathrm{k}_{\mathrm{s}} \Delta t} \frac{\left(c^{2 m-2}+c^{2 m-3}\right)}{2}$

$\mathrm{BOT}=$ distance below the ground surface of the bottom of the fuel element, $\mathrm{ft}$

$C(I)=$ the quantiy, $\theta_{m}$, defined in Appendix B

$\mathrm{CK}=$ thermal conductivity of the soil, $\mathrm{Btu} / \mathrm{hr}-\mathrm{ft}-{ }^{\circ} \mathrm{F}$

CSUBP $=$ heat capacity of the soil, Btu $/ 1 b-{ }^{\circ} \mathrm{F}$

$\mathrm{COEV}=$ subroutine to calculate the coefficients, $\theta_{\mathrm{m}}, \sigma_{\mathrm{m}}$, etc

$D(I)=$ the quantity $\left(\frac{c^{2 m-2}+c^{2 m-3}}{2}\right)$ 
$\mathrm{D} 1 \mathrm{I})=$ the term in Appendix $\mathrm{B}$ defined by $\mathrm{\beta}_{\mathrm{m}} / \mathrm{w}_{\mathrm{m}}$

DELTR = subroutine used to calculate the "mesh size multiplier" $\operatorname{DENOM}(I)=$ the quantity, $4 c^{m-1}(c+1) a+\Delta r_{1} \sum_{j=0}^{m-2} c^{j}$

DIA = diameter of the fuel element, $\mathrm{ft}$.

DUMB = a dummy variable used in calculating time

$\mathrm{E}(\mathrm{I})=$ the function defined by $\mathrm{Q}(\mathrm{n})$ in Appendix $\mathrm{B}$

$\mathrm{E} 1$ (I) = the quantity defined by $\mathrm{q}_{\mathrm{m}}$ in Appendix B

ERR1 = allowable error in computing the "mesh size multiplier"

ERR2 = allowable error in computing the transformed temperatures in the radial direction

ERR3 = error permitted in the convergence of the temperatures as a function of $n$

FLUX $=$ a specified heat flux at the surface of the element or a time-dependent flux calculated on the basis of a specified heat generation rate within the element

$\mathrm{G}(\mathrm{I})=$ the quantity defined as $\mathrm{g}_{\mathrm{m}}$ in Appendix B

IC, IM2 = counting integers used in the main program

INVER = subroutine to invert the transformed temperatures into temperatures which are a function of the original independent variables

$J 1, J 2=$ counting integers used in the main program

$\mathrm{KER}, \mathrm{KP}, \mathrm{KER} 1$ = counting integers used in the main program

$\mathrm{K} 1$ = integer used in the subroutine, INVER

$M=$ outermost nodal point in the radial direction

MM1 = the nodal point, $M-1$

MM2 = the nodal point, $\mathrm{M}-2$

MATINV = subroutine for obtaining the inverse matrix for solution of Equations (B-9)

MAX = number of points at which the temperature is printed out in the radial direction 
$\mathrm{NZ}=$ number of levels points the ground surface at which the tempcrature is calculated

$\mathrm{NI}=$ number of radial increments within the heat source

$\mathrm{ND}=$ number of time intervals for which the $\Delta t$ is specified

$\mathrm{NTPO}=$ number of times for which the temperatures are to be printed out

$\mathrm{NS}=$ an integer denoting a constant or transient heat generation rate

NUMN = maximum number of $\mathrm{n}$ permitted in the calculations

NP $(\mathrm{I})=$ number of print outs within the $i^{\text {th }}$ time zone

NDP (I) $=$ number of time increments between print outs in the $i^{\text {th }}$ lime zone

UU'I'PU'I' = subroutine for printing out the desired information

$P(I, J)=$ the inverse matrix of coefficients required for the solution of Equation (B-9)

PN $(\mathrm{I})=$ dummy variable used in computing the time for each print $\mathrm{Q}=$ a specified heat generation rate, $\mathrm{Btu} / \mathrm{hr}-\mathrm{ft}^{3}$

$R(I)=\underset{f t}{a}$ radial distance from the center of the fuel element, $\mathrm{RAD}$ - radius of the fuel element, ft

RDEL1 = the initial time increment, $\mathrm{ft}$

$\mathrm{RHO}=$ densit.y of the soil, $\mathrm{lb} / \mathrm{ft}^{3}$

$\mathrm{RM}=$ the "mesh size multipler"; denoted by $c$ in the text

$\operatorname{SAN}(J)=$ the trigonometric function, $\sin \left(\frac{n \pi Z}{L}\right)$

$\mathrm{SK}=$ the constant " $\mathrm{b}$ " in the equation for thermal conductivity dependence on temperature, $k_{S}=a+b\left(T-T_{B}\right)$

SUM1, SUM2 = dummy variables used in the main program and subroutines

$\mathrm{T} 1 \mathrm{I})=$ the transformed temperature at a given radial distance

$\mathbf{T}=$ temperature at the surface of the fuel element as a function of $\mathrm{n},{ }^{\circ} \mathrm{F}$ 
$\mathrm{TBA}=$ base temperature for thermal conductivity, ${ }^{\circ} \mathrm{F}$

$\mathrm{T} 2(\mathrm{I}, \mathrm{J}, \mathrm{IC})=$ temperature at a specific point at time $\mathrm{t}$

$\operatorname{TIME}(\mathrm{I})=$ time in hours

TITLE (I) = title of the problem being solved

TSOIL = initial temperature of the soil surrounding the fuel element, ${ }^{\circ} \mathrm{F}$

TOP $=\begin{aligned} & \text { distance below the ground surface of the top of the fuel } \\ & \text { element }\end{aligned}$

$\mathrm{W}(\mathrm{I})=$ the term defined as $\mathrm{w}_{\mathrm{m}}$ in Appendix $\mathrm{B}$

$\mathrm{ZL}=$ the parameter defined as $\mathrm{L}$ in the text, $\mathrm{ft}$

$\mathrm{Z}(\mathrm{I})=$ a specified distance below the ground surface, $\mathrm{ft}$.

6. NOMENCLATURE FOR THE TRANSIENT TEMPERATURE DISTRIBUTION IN A CYLINDRICAL BIN AND THE SURROUNDING SOIL

Nomenclature that is identical to that used in the preceding program will not be repeated here.

$\mathrm{CK}=$ thermal conductivity of the solidified waste, Btu $/ \mathrm{hr}-\mathrm{ft}-{ }^{\circ} \mathrm{F}$

CSUBS $=$ heat capacity of the soil, Btu $/ 1 \mathrm{~b}-{ }^{\circ} \mathrm{F}$

M1 = nodal point at the boundary between the source and the soil

$\mathrm{QT}=$ a dummy variable name for the instantaneous heat generation rate, $\mathrm{Btu} / \mathrm{hr}-\mathrm{ft}^{3}$

$\mathrm{RB}=$ radius of the cylindrical heat source, $\mathrm{ft}$

RHOS $=$ density of the soil, $1 \mathrm{~b} / \mathrm{ft}^{3}$

$\mathrm{S}=\mathrm{a}$ dummy variable name for the transform parameter $\mathrm{n}$. 
7. FORTRAN SOURCE PROGRAM -- TRANSIENT

TEMPERATURES IN AND SURROUNDING A BURIED FUE L E LEMENT

C TRANSIENT TEMP IN FUEL ELEMENT

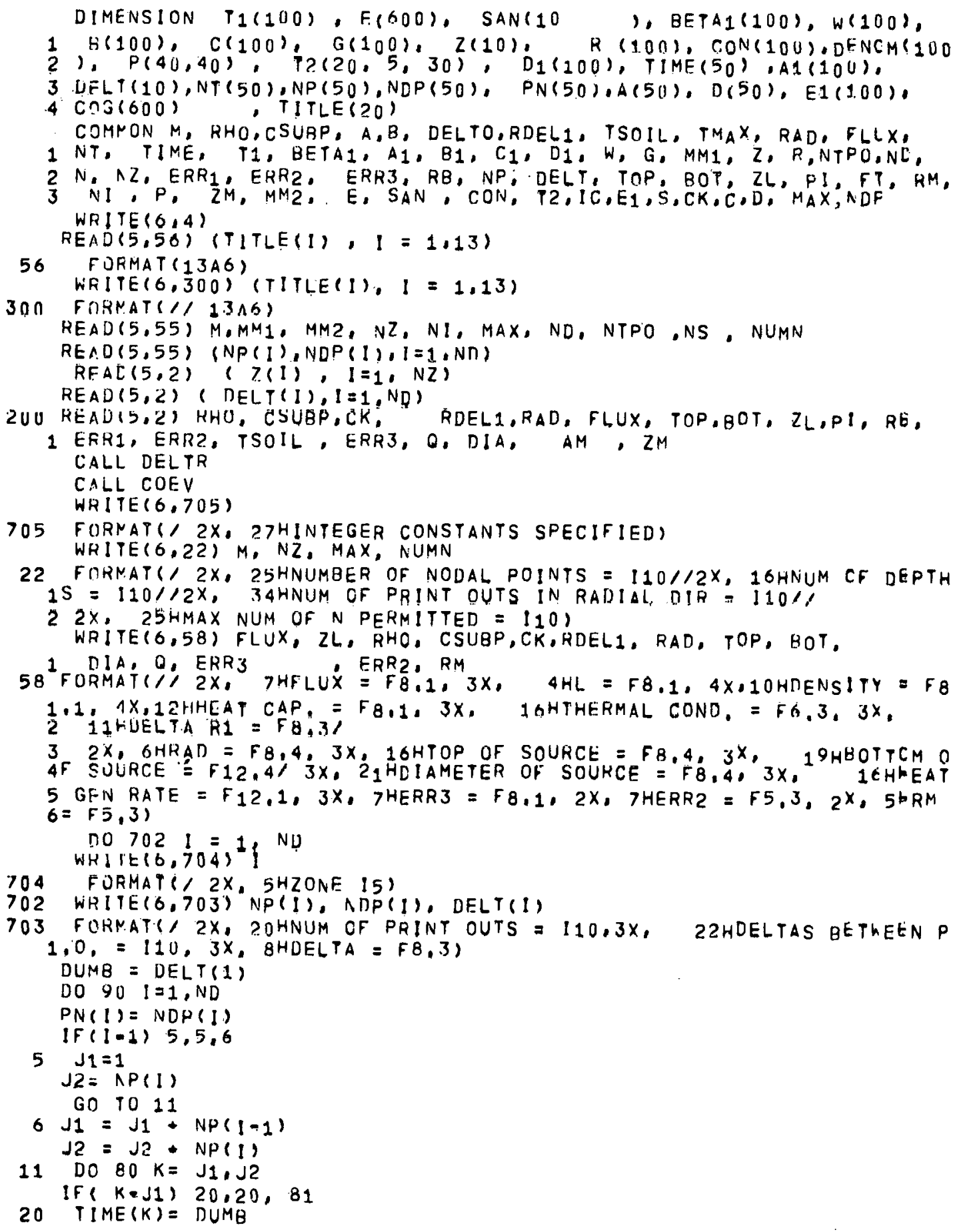


C TRANSIENT TEMP IN FUEL ELEMENT

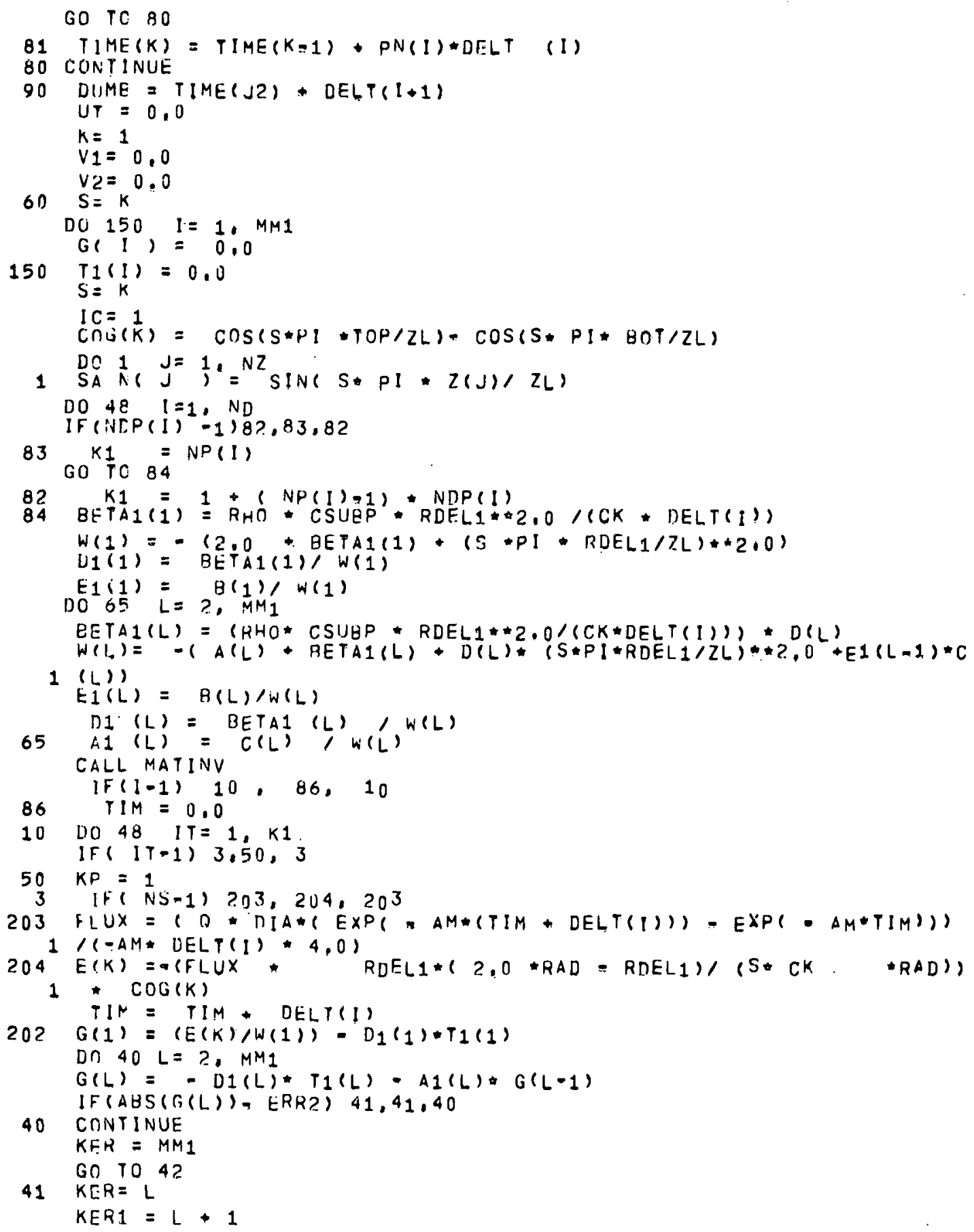


C TRANSIENT TEMP IN FUEL ELEMENT

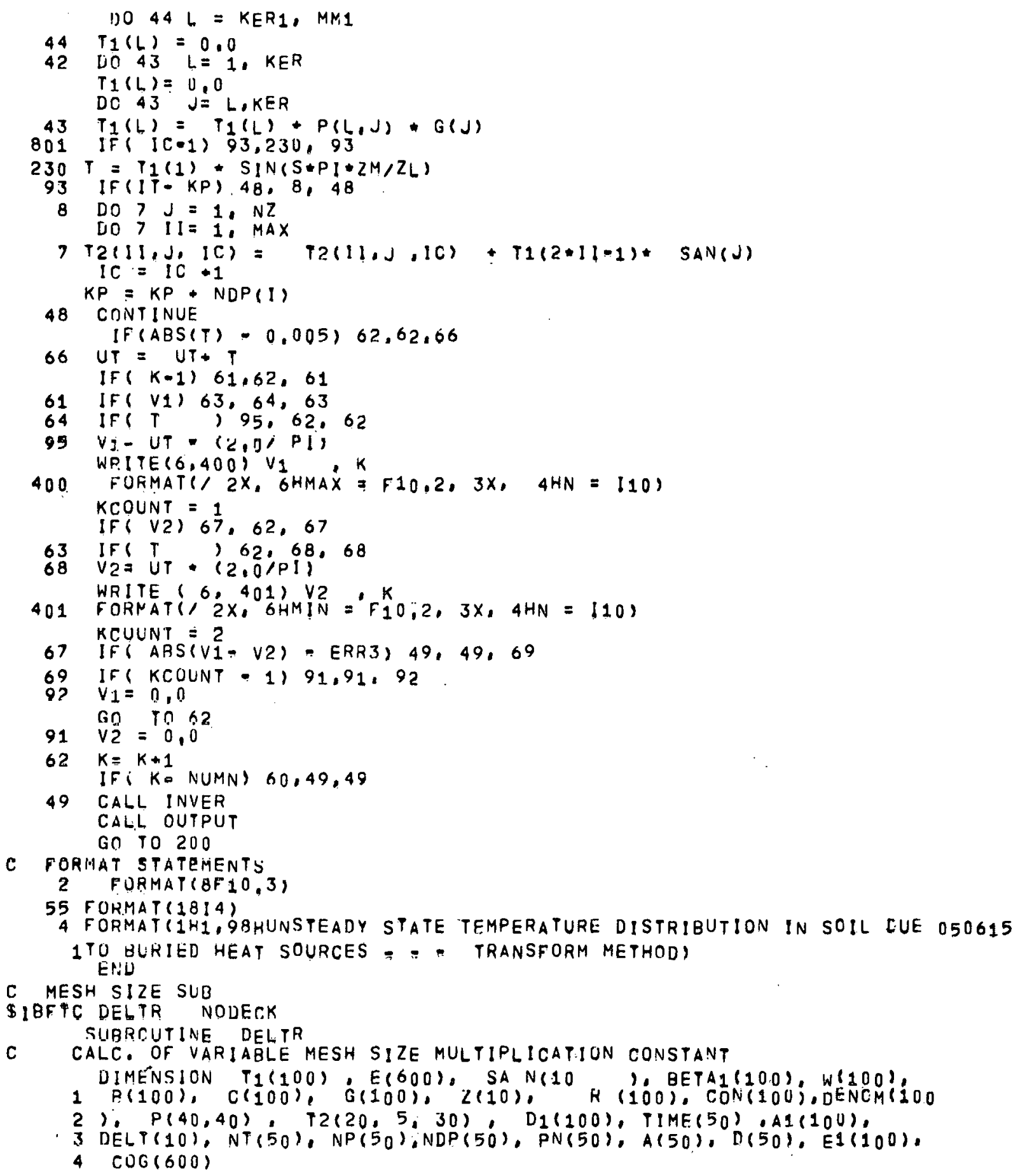




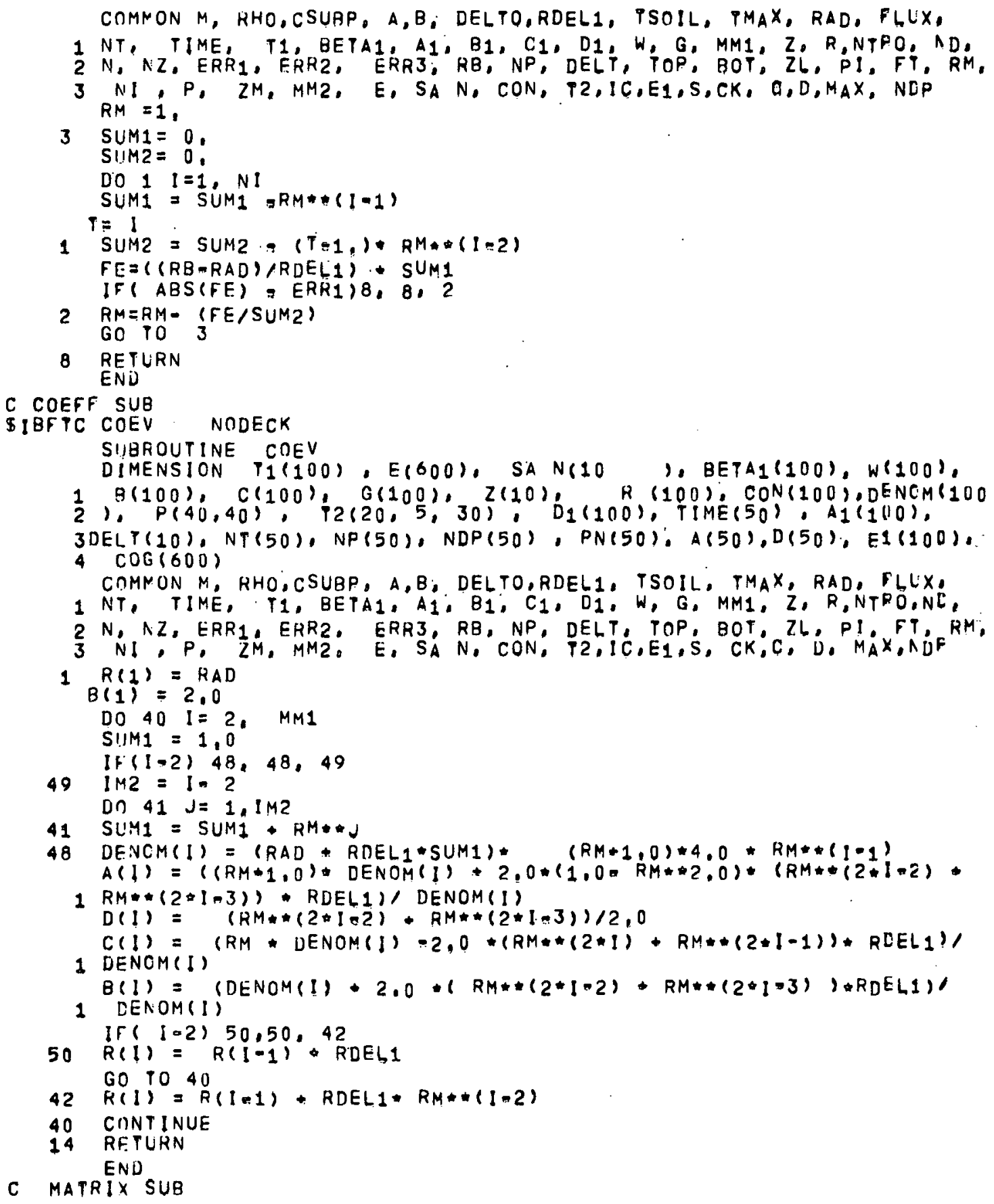


SIBFTC MATINV NODECK

SUBRCUTINE MATINV

DIMENSION TI(100), E(600), SAN (10), BETAI(100), W(100),

$1 B(100), C(100), G(100), \quad Z(10), \quad R(100), C O N(100), D E N C M(100$

$2), P(40,40), P 2(20,5,30): D_{1}(100), T\left(M E(50), A_{1}(100)\right.$.

3 DELT(10), NT $(50), N P(50), N D P(50), P N(50), A(50), D(50), E_{1}(100)$,

4 COG 600$)$

COMMON M, RHO, CSUBP, A,B, DELTO,RDEL1, TSOIL, TMAX, RAD, FLLX,

1 NT, TIME, T1, BETA1, Ai, B1, CI, DI, W, G, MM1, Z, R, NTPO, $C_{D}$,

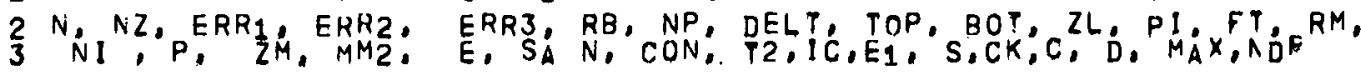

6 DO $3 \quad I=1, M M 2$

$P(1,1+1)=(=1,) \div E 1(1)$

If $(1$. MM2) $4,7,4$

$4 \quad L=1+2$

DO $3 J=L, M M 1$

$3 P(1,1)=(-1)=,(E 1(J, 1)+P(1, J-1))$

7 DO $44 \quad l=1, M M_{1}$ $J=I$

$44 P(I, J)=1$,

DO $43 \quad J=1, M M 2$

$L=J+1$

DO 43 i $\quad$ L, MMI

$43 P(I, J)=0$.

RETURN

END

C INVERSION SUB

\$IBFTC INVER NODECK

SURROUTINE INVER

DIMENSION Fi(100), E(600), SAN IIN), BFTA1(100), H(100),

$1 G(100), C(100), G(100), Z(10), \quad R(100), C O N(1.00), D E N C M(100$

$2), P(40,40), T 2(20,5,30), D_{1}(100)$, TIME(50), $A_{1}(100)$,

3 DELT $(10), N P(50), P N(50), N D P(50), N T(50), A(50), D(50), E_{1}(100)$,

$4 \operatorname{COG}(000)$

COMMON M, RHO,CSUBP, A,B; DELTO,RDEL1; TSOIL, TMAX, RAD, FLLX,

1 NT, TIME, TI; BETA1; $A_{1}, B_{1}, C_{1}, D_{1}, W, E, M M 1, L, K, N T F U, N E$,

$2 \mathrm{~N}, N Z, E R R 1, . E R R 2$, ERR3, RB, NP, DELT, TOP, BOT, ZL, PI, FT, RM,

3 NI, P, ZM, MM2, E, SAN, CON,T2,IC,EI, S, CK, C, D, MAX, ADP WRITE $(6,15)$ TSOIL

15 FORMAT $(2 F 8.2)$

DO $21 I=1, N$.TPO

b0 $4 \quad J=1, N Z$

IF( $12(1, J, I)) 2.2,3$

2 DO $5 \quad K=1$, MAX

5 Ti $(K, J, i)=0,0$

GO TO 4

3 DO $9 \quad K=2$, MÄ

IF( T2(K, J, l)) 7,7,9

$7 K_{1}=K$

GO $P 0 \quad 10$

9 CONTINUE

GO TO 4

10 ก७० $8 K=K 1, \operatorname{MAX}$

8 T2 $(K, J, I)=0,0$

- continue 
C TRANSIENT TEMP IN FUEL ELEMENT

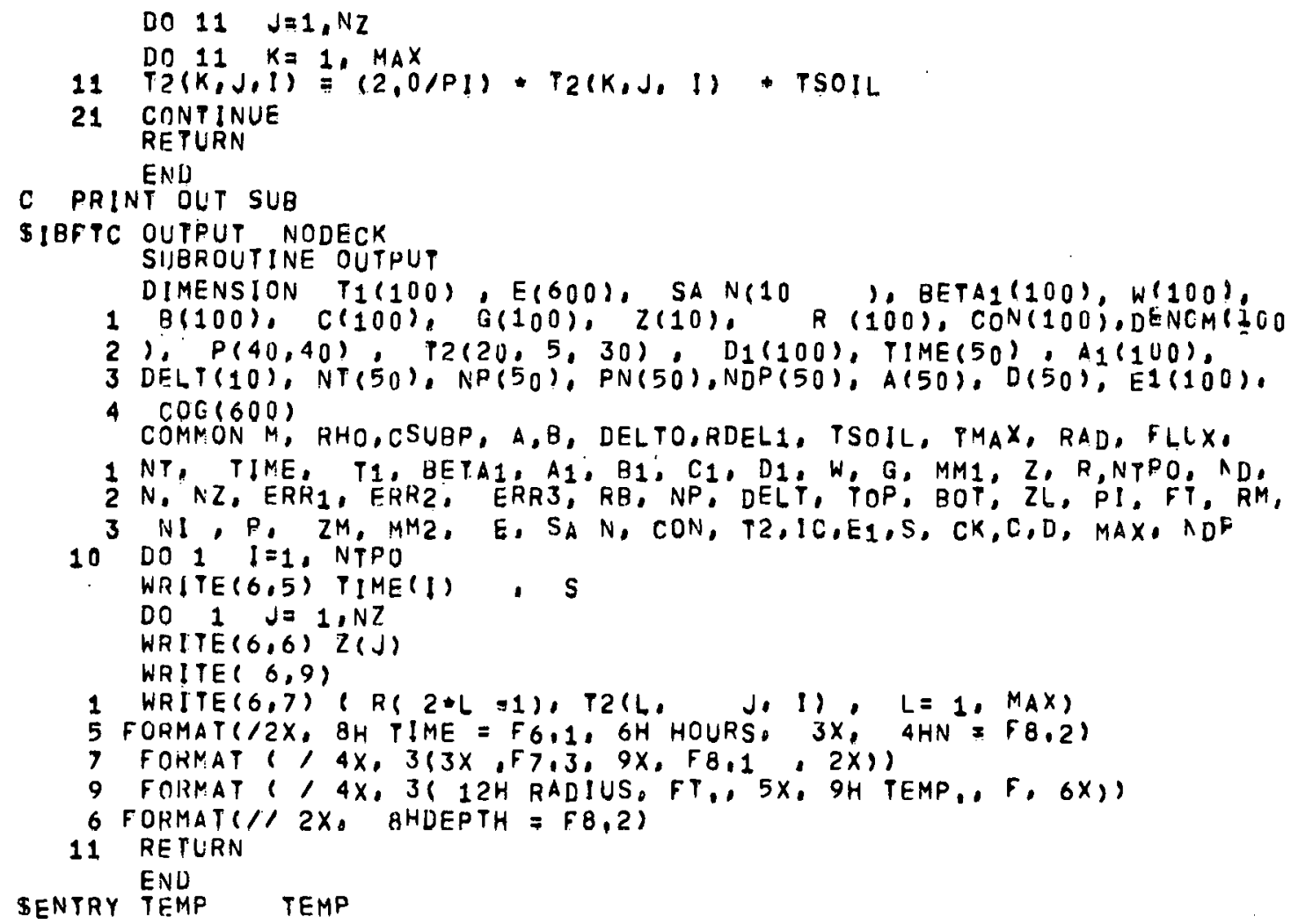


8. FORTRAN SOURCE PROGRAM --

TRANSIENT TEMPERATURES IN AND SURROUNDING

A CYLINDRICAL VESSEL CONTAINING SOLIDIFIED WASTE

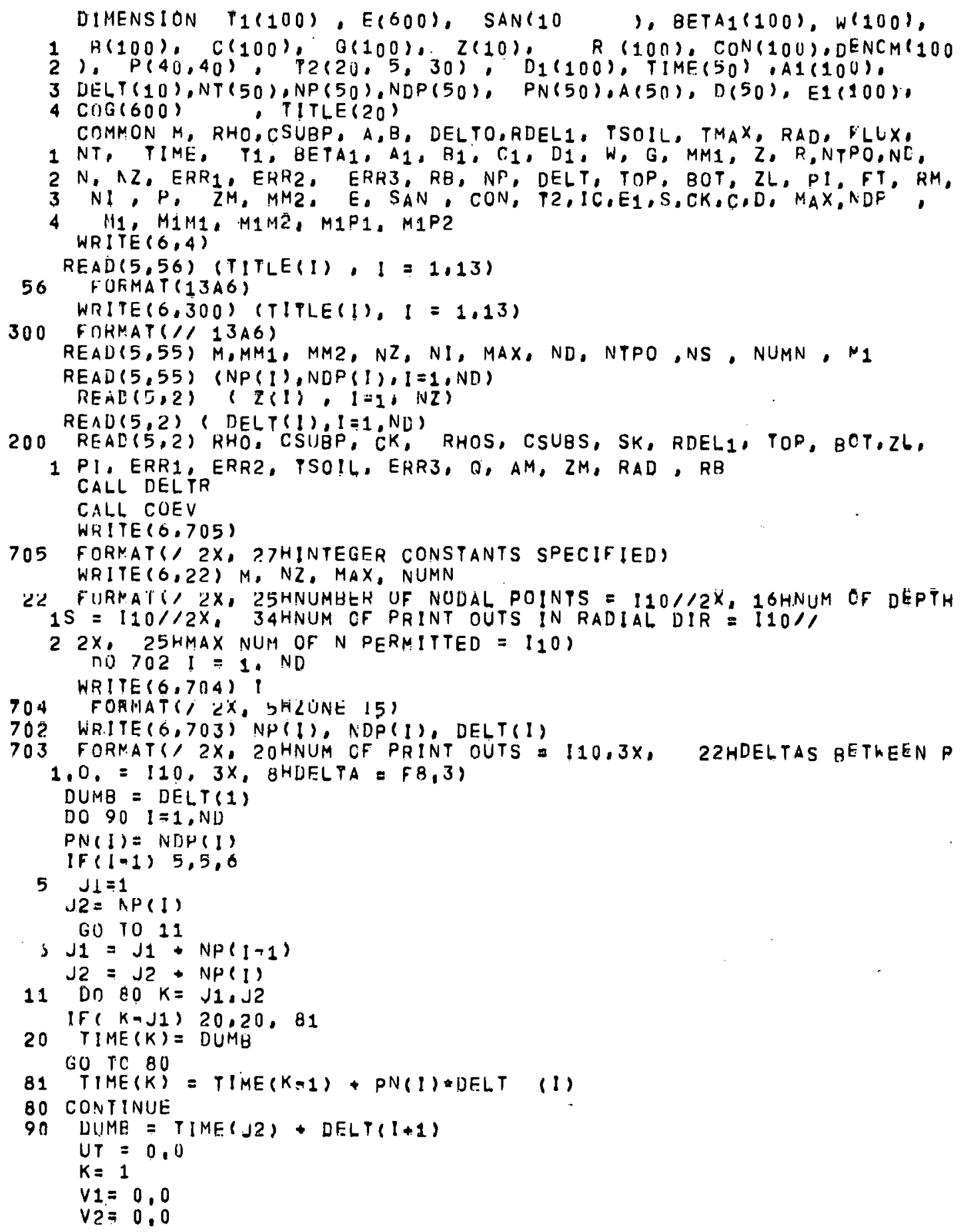


C TRANSIENT TEMP IN BINS

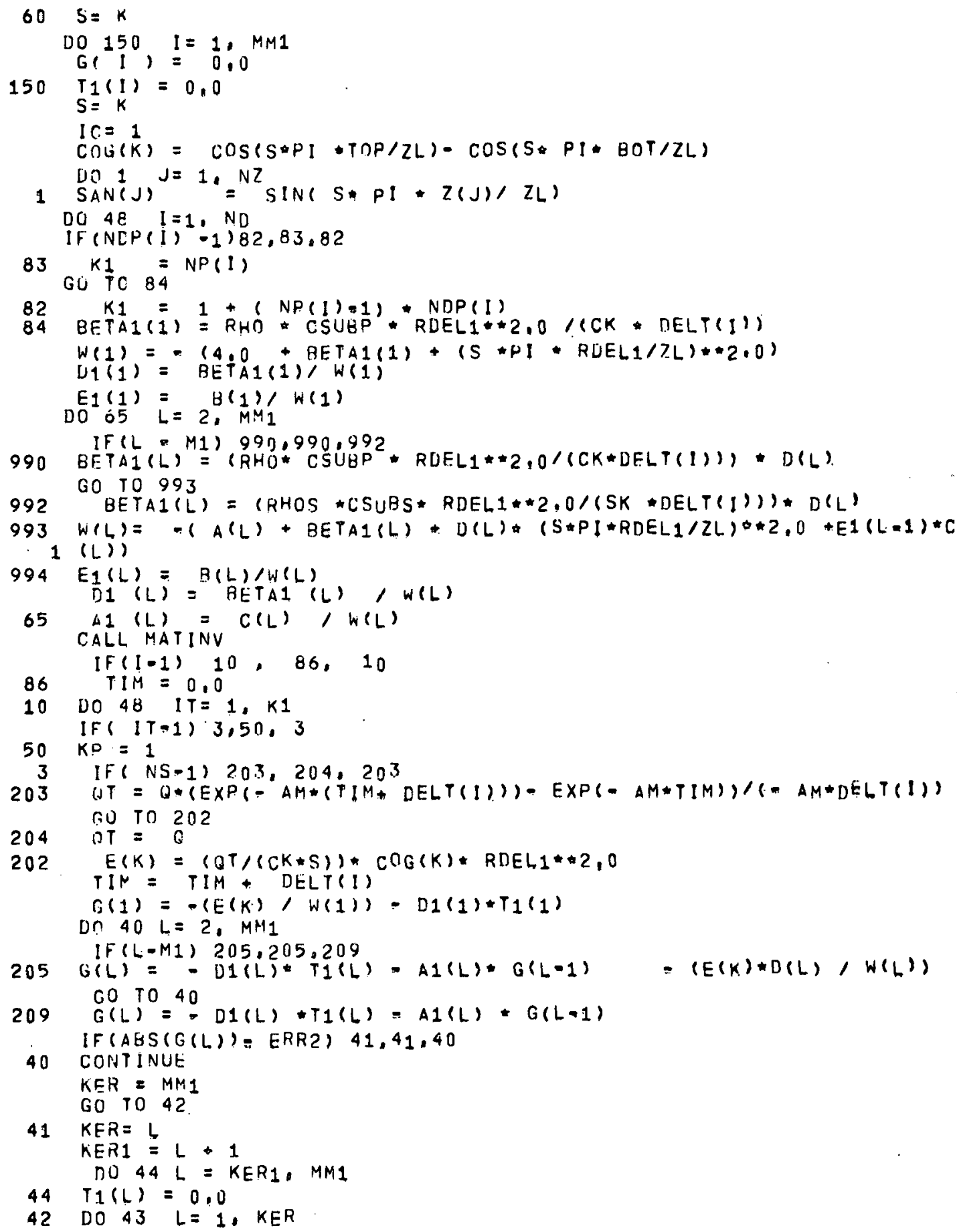




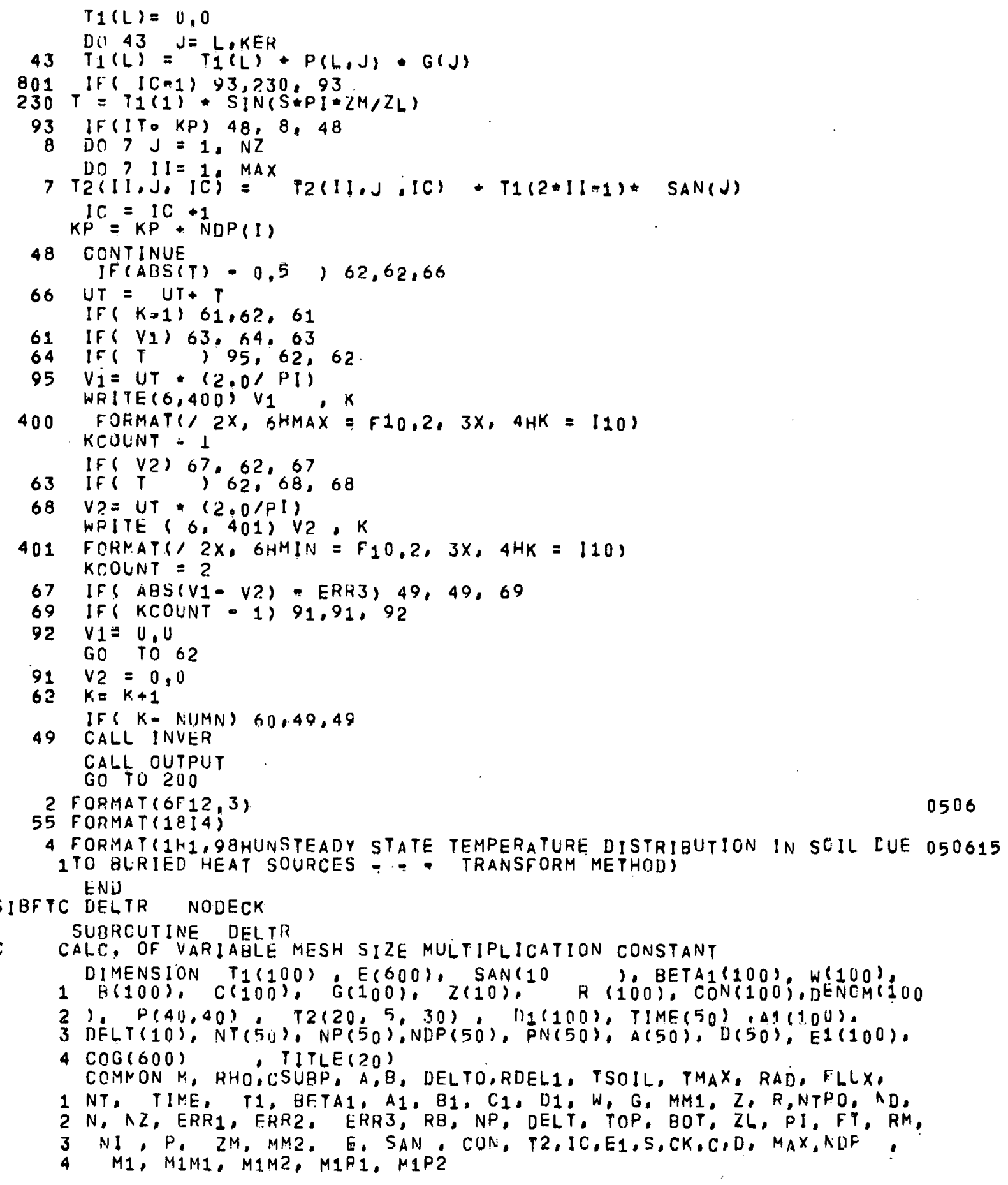


C TRANSIENT TEMP IN BINS

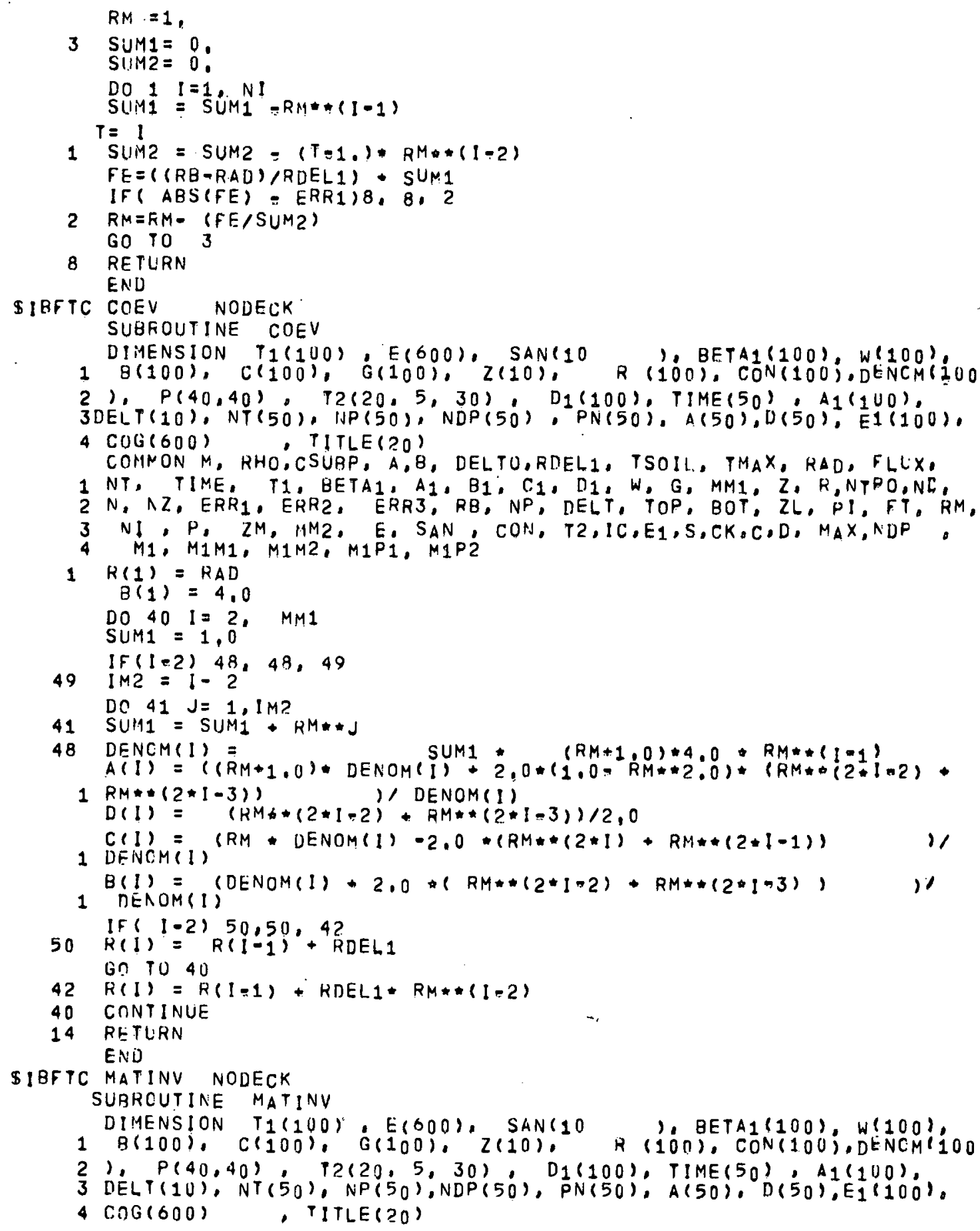


C. TRANSIENT TEMP IN BINS

COMMON.M, RHO, CSUBP, A,B, DELTOFRDEL1, TSOIL, TMAX, RAD, FLLX。

1 NT, TIME, T1, BETA1, $A_{1}, B_{1}, C_{1}, D_{1}, W, G, M M 1, Z, R, N T P O, A D_{1}$

$2 N, N Z, E R H_{1}, E R R_{2}$, EKR3, RE, NP, DELT, TOP, BOT, ZL, PI, FT, RM,

$3 N 1, P, Z M, M M 2, E, S_{A N}, C O N, T 2, I C, E 1, S, C K, C, D, M A X, N D F$,

4. M1, M1M1, MLM2, M1P1, M1P2

6 DO $3 \quad 1=1, M M 2$

$P(1,1+1)=(-1) * E ,1(1)$

If (i. MM. $, 4,7.4$

$4 L=1+2$

$D 0^{3} J J=L$. MMI

$3 \cdot P(I, J)=(=1) *,(E 1(J-1) * P(I, J * 1))$

7 DO $44 \quad l=1, M M_{1}$

$.1=1$

$44 P(1, J)=1$,

DO $4 \dot{J} J=1, M M 2$

$L=J+1$

DO $43 \cdot I=L, M M I$

$43 P(I, J)=0$.

RETURN

CHD

SIBFTC INUER NODECK

SUBRCUTINE INVER

DIMENSION TI(100), E(600), SAN(10) I, BETAI 100$), W(100)$,

$1 \mathrm{~B}(100), C(100), G(100), \quad Z(10), \quad R(100), C O N(100), D E N C M(100$

$2), P(40,40), T 2(20,5,30), D_{1}(100), \operatorname{TIME}(50), A_{1}(100)$,

3 DFLT $(10), N P(50), P N(50), N D P(50), N T(50), A(50), D(50), E_{1}(10)^{\prime}$,

$4 \operatorname{COG}(600)$ TITLE(20)

COMMON M, RHO.CSURP, A,B, DELTO,RDELI, TSOIL, TMAX, RAD, FLLX,

1 NT, TIME, T1, UETA1, $A_{1}, B_{1}, C_{1}, D_{1}, W, G_{1}, M M 1, Z, R, N T F O, N E$,

$2 N, N Z, E R R_{1}, E R R 2, E R R 3, R B, N P, D E L T, T O P, B O T, Z L, P I, F T, R M$,

3 NI, P, ZM, MM2, E, SAN, CON, T2,IC,EI,S,CK,C,D, MAX,NDF, M1, M1M1, M1H2, M1P1. M1P2

WRITE $(6.15)$ TSOIL

15 FORHAT $(, 2 F B .2)$

DO $21 \quad 1=1, N T P O$

D. $4 \quad J=1, \mathrm{NZ}$

If ( T2(1, J, I) $2,2,3$

$2005 \quad K=1$, MAX

$5 \quad T ?(K, J, 1)=0,0$

Go. 101

3 Di, $9 \quad k=2, M A X$

If $(T 2(K, J, I)) 7,7,9$

$7 \quad K_{1}=k$

GO TO 10

9 CONTINUE

Gก 104

$10 \quad 208 k=K 1 . \cdot M A X$

$8 T 2(K, J, 1)=0.0$

4. CONTINUE

DO $11 \mathrm{~J}=1, \mathrm{NZ}$

in 11. $k=1, \operatorname{MaX}$

$11 T 2(K, J, 1)=(2,0 / P I) \cdot T_{2}(K, J, 1)$. TSOOL

21. CONTINUF

RFTLRN

ENU 
C TRANSIENT TEMP IN BINS

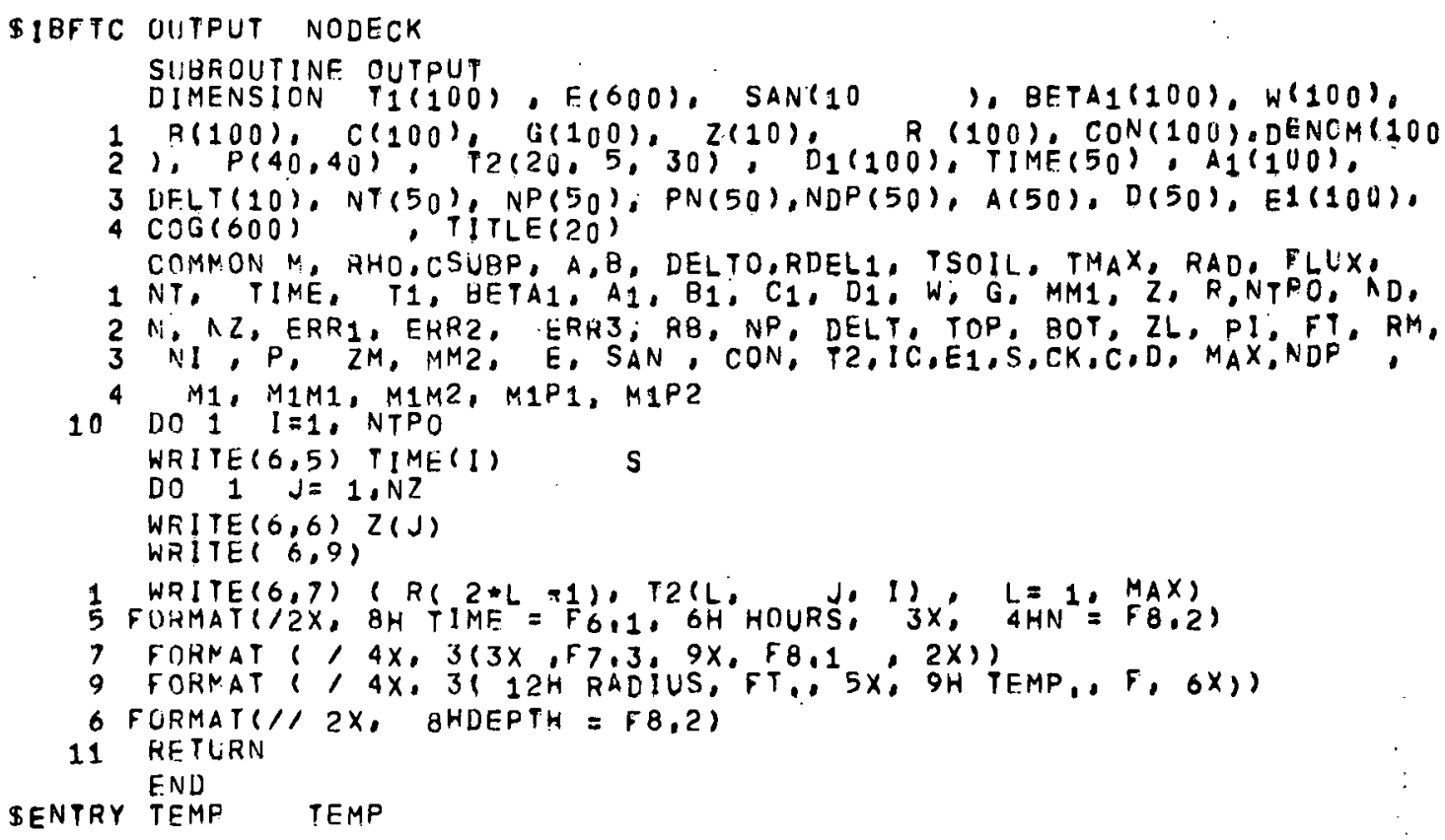




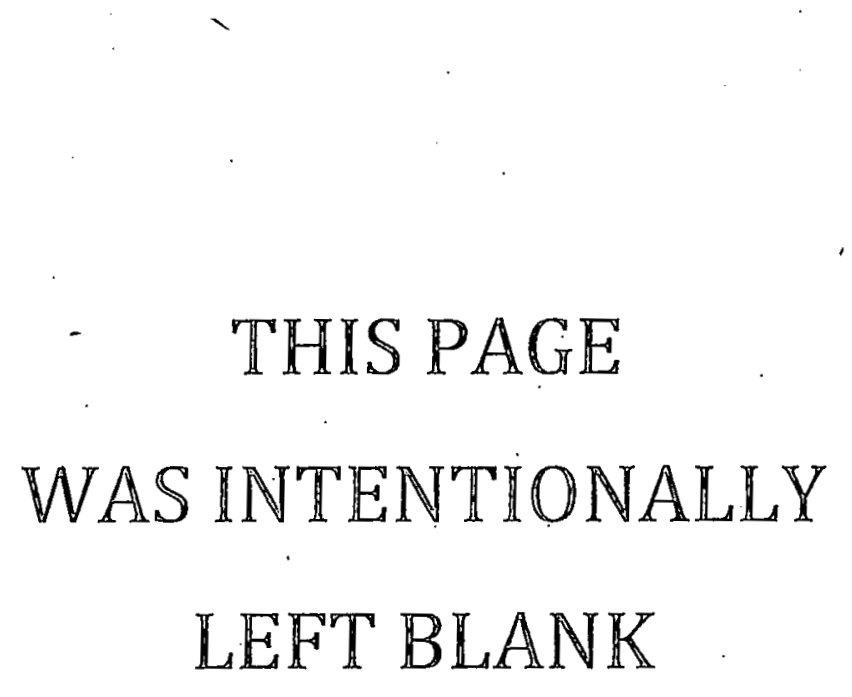


APPENDIX I

DATA INPUT FORMATS 
THIS PAGE

\section{WAS INTENTIONALLY}

LEFT BLANK 


\section{APPENDIX́ I -- \\ DATA INPUT FORMATS}

The arrangement of the input data and the required order of the cards for each program are described in the following section.

1. STE ADY-STATE TEMPERATURE

DISTRIBUT TON AROUND A BURIED FUEL ELEMENT

\subsection{Title Card}

This is the first card in the data deck. Any information is allowed on this card, but it normally contains the program name and identifying information.

\subsection{Data Card 1}

Columns

$$
\begin{aligned}
& 1-4 \\
& 5-8
\end{aligned}
$$

\subsection{Data Card(s) 2}

Columns

$$
1-80
$$

1.4 Data Card(s) 3

Columns

$$
1-80
$$

\section{Input Information}

NR, right-adjusted

$\mathrm{NZ}$, right-adjusted

\section{$\underline{\text { Input Information }}$}

$R(I), I=1, N R$

Read in according to

FORMAT 2. Use as many cards as necessary

Input Information

$\mathrm{Z}(\mathrm{J}), \mathrm{J}=1, \mathrm{NZ}$

\subsection{Data Card 4}

Columns

$$
1-10
$$

11-20

21-30

$31-40$

41-50

$51-60$

$61-70$

71-80
Input Information (FORMAT 2)

FLUX
ZL
A
PI
CAY
TOP
BOT
ZM




\subsection{Datà Car̀d 5}

Columns

$1-10$

$11-20$

$21-30$

$31-40$

$41-50$
Input Information (FORMAT 2)

ERR1

ERR2

ZLI

$\mathrm{ZAX}$

TSOIL

2. STEADY-STATE TEMPERATURE DISTRIBUTION IN A BIN FILLED WITH SOLIDIFIED WASTE

\subsection{Title Card}

First card in the data deck. Program name and other identifying information are normally on this card.

\subsection{Data Card 2}

Columns

$1-4$

$5-8$

$9-12$

$13-16$

1.3 Dala Card(s) 3

Columns

1. -80

1.4 Data Card(s) 4

Columns

$1-80$

1.5 Data Card(s) 5

Columns

$1-80$
Input Information (FUKIVAT i)

NR1, right-adjusted NR2, right-adjusted NZ1, right-adjusted $\mathrm{NZ} 2$, right-adjusted

Input Information (FORMAT 2)

RI(I), I -1 , NRI

Read in according to FORMAT 2. Use cards as required.

Input Information (FORMAT 2)

Z1(I), I=1, NZ1

Cards as required using FORMAT 2.

Input Information (FORMAT 2)

R2(I), I=1, NR2

Cards as required using FORMAT 2. 
1.6 Data Card(s) 6

Columns

$1-80$

1.7 Data Card 7

Columns

$$
\begin{array}{r}
1-10 \\
11-20 \\
21-30 \\
31-40 \\
41-50 \\
51-60 \\
61-70 \\
71-80
\end{array}
$$

\subsection{Data Card 8}

Columns

$$
\begin{array}{r}
1-10 \\
11-20 \\
21-30 \\
31-40 \\
41-50 \\
51-60
\end{array}
$$

Input Information (FORMAT 2)

$\mathrm{Z} 2(\mathrm{I}), \mathrm{I}=1, \mathrm{NZ} 2$

Cards as required using FORMAT 2.
Input Information (FORMAT 2)

$$
\begin{aligned}
& \text { Q } \\
& \text { ZL } \\
& \text { RB } \\
& \text { PI } \\
& \text { CAYC } \\
& \text { CAYS } \\
& \text { TOP } \\
& \text { BOT }
\end{aligned}
$$

Input Information (FORMAT 2)

$$
\begin{gathered}
\text { ZM } \\
\text { ERR1 } \\
\text { ERR2 } \\
\text { ZLI } \\
\text { ZAX } \\
\text { TSOIL }
\end{gathered}
$$

3. TRANSIENT TEMPERATURES IN AND SURROUNDING A BURIED FUEL ELEMENT

1.1 Title Card

A card containing the program name, parameters studied, and other identifying information.

\subsection{Data Card 1}

Columns

$$
1-4
$$$$
5-8
$$$$
\text { 9-12 }
$$$$
\text { 13-16 }
$$$$
\text { 17-20 }
$$$$
\text { 21-24 }
$$$$
\text { 25-28 }
$$$$
\text { 29-32 }
$$

33-36

$37-40$
Input Information (FORMAT 55)

M

MM1

MM2

NZ

NI

MAX

ND

NTPO

NS

NUMN 


\subsection{Data Card(s) 2}

Columns

$$
1-72
$$

1.4 Data Card(s) 3

Columns

$$
1-80
$$

1.5 Data Card(s) 4

Columns

$$
1-80
$$

\subsection{Data Card 5}

\section{Columns}

$$
1-10
$$

$11-20$

21-30

$31-40$

$41-50$

$51-60$

$61-70$

$71-80$
Input Information (FORMAT 55)

(NP(I), NDP(I), I=1, ND) Read in according to FORMAT 55 using cards as required (right-adjusted)

Input Information (FORMAT 2)

(Z (I), I=1, NZ) Read in according to FORMAT 2 using cards as required

Input Information (FORMAT 2)

(DELT(I), l=1, ND) Read in according to FORMAT 2 using cards as requiried

Input Information (FORMAT 2)

RHO
CSUBP
CK
RDELI
RAD
FLUX
TOP
BOT

\section{Columns}

$$
\begin{array}{r}
1-10 \\
11-20 \\
21-30 \\
31-40 \\
41-50 \\
51-60 \\
61-70 \\
71-80
\end{array}
$$

\section{Inpüt Införmation (FURIVATT 2),}

ZL
PI
ERR1
ERR2
TSOIL
ERR3
$Q$
DIA




\subsection{Data Card 7}

Columns

$1-10$

$11-20$

21-30

$31-40$
Input Information (FORMAT 2)
AM
TBA
SK
$\mathrm{ZM}$

4. TRANSIENT TEMPERATURES IN A CYLINDRICAL BIN FILLED WITH RADIOACTIVE SOLIDIFIED WASTE

1.1 Title Card

Card containing the program name and other identifying information.

\subsection{Data Card 1}

Columns

$$
1-4
$$$$
5-8
$$$$
9-12
$$$$
13-16
$$$$
17-20
$$$$
21-24
$$$$
25-28
$$$$
29-32
$$$$
33-36
$$$$
37-40
$$$$
41-44
$$

\subsection{Data Card(s) 2}

Columns

$$
1-72
$$

\subsection{Data Card(s) 3}

Columns

$$
1-80
$$

Input Information

\begin{tabular}{l}
\multicolumn{1}{c}{$M$} \\
MM1 \\
MM2 \\
NZ \\
NI \\
MAX \\
ND \\
NTPO \\
\multicolumn{1}{c}{ NS } \\
NUMN \\
M1
\end{tabular}

\section{Input Information}

(NP(I), NDP(I), I=1, ND) Read in by FORMAT 55 using cards as required.

\footnotetext{
Input Information

(Z(I), I=1, NZ) Read in by FORMAT 2 using cards as required.
} 
1.5 Data Card(s) 4

Columns

$$
1-80
$$

1.6 Data Card 5

Columns

$$
\begin{array}{r}
1-10 \\
11-20 \\
21-30 \\
31-40 \\
41-50 \\
51-80 \\
61-70 \\
71-80
\end{array}
$$

\subsection{Data Card 6}

Columns

$$
\begin{array}{r}
1-10 \\
11-20 \\
21-30 \\
31-40 \\
.41-50 \\
51-80 \\
61-70 \\
71-80
\end{array}
$$

Input Information

(DELT(I), I=1, ND) Read in by FORMAT 2 using required number of cards.

Input Information

RHO
CSUBP
CK
RHOS
CSUBS
SK
RDEL1
TOP

Input Information

BOT

ZI

$P I$

ERRI

ERR2

TSNIL

ERR3

Q

\section{$1.8 \quad$ Data Card 7}

Columns

$$
1-10
$$

$11-20$
$21-30$

$31-40$
Input'Information

$\begin{aligned} & \mathrm{AM} \\ &-\mathrm{ZM} \\ & \mathrm{RAD} \\ & \mathrm{RB}\end{aligned}$

